\title{
PHOSPHORUS PHYSIOLOGY OF THE MARINE CYANOBACTERIUM TRICHODESMIUM
}

By

Elizabeth Duncan Orchard

B.A., Cornell University, 2004

Submitted in partial fulfillment of the requirements of the degree of

Doctor of Philosophy

at the

MASSACHUSETTS INSTITUTE OF TECHNOLOGY

and the

WOODS HOLE OCEANOGRAPHIC INSTITUTION

February 2010

(C) Elizabeth Duncan Orchard

All rights reserved.

The author hereby grants MIT and WHOI permission to reproduce and to distribute publicly paper and electronic copies of this thesis document in whole or in part in any medium now known or hereafter created.

Signature of Author

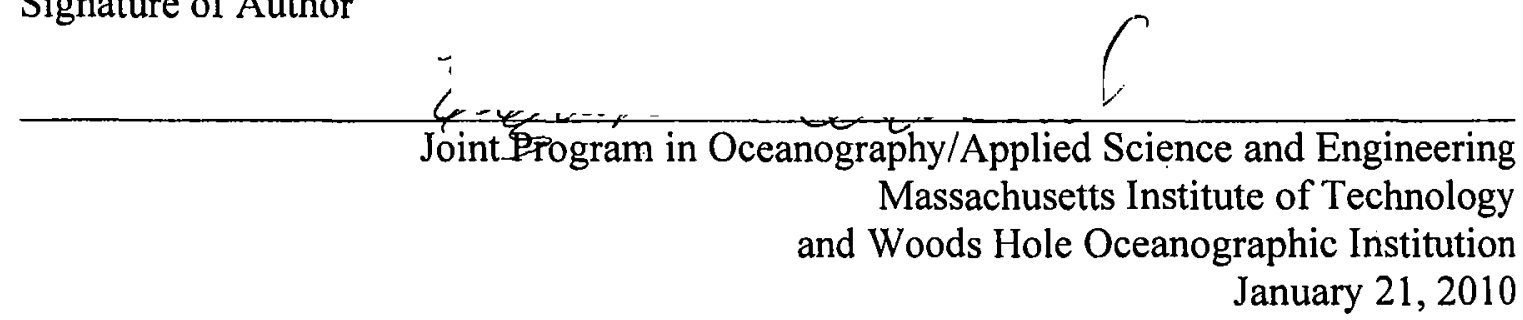

Certified By

r

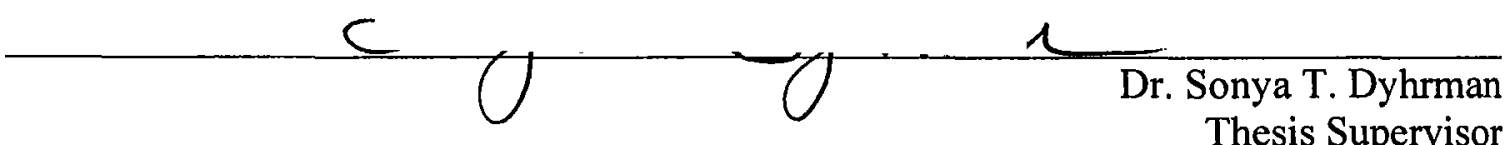

Accepted By
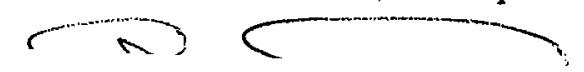

Dr. Simon Thorrold

Chair, Joint Committee for Biological Oceanography

Woods Hole Oceanographic Institution 



\title{
Phosphorus Physiology of the Marine Cyanobacterium Trichodesmium
}

\author{
by \\ Elizabeth Duncan Orchard \\ Submitted in partial fulfillment of the requirement \\ for the degree of Doctor of Philosophy in \\ Biological Oceanography
}

\begin{abstract}
Primary producers play a critical role in the oceanic food chain and the global cycling of carbon. The marine diazotroph Trichodesmium is a major contributor to both primary production and nitrogen fixation in the tropical and subtropical oceans. These regions are often characterized by low phosphorus (P) concentrations, and $\mathrm{P}$ deficiency of Trichodesmium could limit growth, and constrain nitrogen fixation by this genus. Three key components of $\mathrm{P}$ metabolism in cyanobacteria include: inorganic phosphate $(\mathrm{P} i)$ uptake, dissolved organic phosphorus (DOP) hydrolysis, and polyphosphate (polyP) biosynthesis and catabolism. These three pathways lay the foundation for the four chapters that make up the body of this thesis. Chapter two examines the relative importance of $\mathrm{P} i$ and DOP in Trichodesmium in the Sargasso Sea by measuring uptake rates and uptake kinetics of ${ }^{33} \mathrm{P} i$ and DOP (using alpha labeled adenosine-5'-triphosphate ${ }^{33} \mathrm{P}$-ATP as a model $\mathrm{P}$ ester compound). The in situ uptake rates suggest that the contribution of $\mathrm{P}$ ester to total $\mathrm{P}$ uptake can be greater than $25 \%$ for Trichodesmium, and therefore P esters are important for supplementing Trichodesmium's P demand. Chapter three confirms the presence of polyP in the Sargasso Sea populations. This is the first detection of polyP in an oligotrophic system and may indicate micro-scale variability in DIP or DOP supply. Chapter four examines the regulation of several genes involved in P scavenging in cultures of Trichodesmium erythraeum IMS101: two copies of a high affinity phosphate binding protein ( $p s t S$ and $s p h X$ ) and two putative alkaline phosphatases ( $p h o A$ and $p h o X)$. Chapter five calibrates the expression of $p h o X$ to decreases in nitrogen fixation rate in Trichodesmium cultures allowing the use of $p h o X$ expression as a molecular indicator of $\mathrm{P}$ limitation of nitrogen fixation. Detection of phoX expression in the North Atlantic and South Pacific identified the extent and magnitude of $\mathrm{P}$ limitation in these regions. Taken together this thesis provides new insights into how Trichodesmium survives in low P environments, utilizes DOP, stores polyP, and the extent to which $\mathrm{P}$ can limit nitrogen fixation by this genus.
\end{abstract}

Thesis Supervisor:

Dr. Sonya T. Dyhrman

Title: Associate Scientist, Biology Department, Woods Hole Oceanographic Institution 


\section{ACKNOWLEDGMENTS}

Throughout graduate school career I have been supported by the National Science Foundation (grants OCE-0549794 and CCF-424599), the Environmental Protection Agency (R-83041501-0) and the WHOI Academic Programs Office.

This thesis would not have been possible without the guidance, support and assistance of many people. First of all, I would like to thank my advisor, Sonya Dyhrman, for her constant support both personally and professionally since I first entered her lab 6 and a half years ago. From round the clock cruise sampling to experimental design questions you have always been there with an open door to help me. I am very grateful to my thesis committee (John Waterbury, James Ammerman and Edward Delong) for their guidance throughout this process. I would also like to thank my co-authors: Michael Lomas, Eric Webb, James Ammerman and Claudia Benitez-Nelson. Without your assistance much of this work would have been impossible.

The Dyhrman lab has been an amazing place to work over the years, from impromptu singing sessions to help trouble shooting qPCRs. I have received so much help from you all over the years. In particular, I am grateful to Sheean Haley for keeping the lab running, Louie Wurch for being awesome, and Abby Heithoff, Rachel Jakuba and Tony Fagerberg for making the lab such a fun place to work. To my WHOI and non-WHOI friends: Kate Buckman, Katie Silverthorne, Mike Brosnahan, Annette Hynes, Asya Zolotusky, Laurel Senft, Kirstin Peth, Mara Miller, thanks for enriching my life over for the past few years. Thanks especially to Chris Waters for all your support in the last few 
years. Finally, I would like to thank my family for being so encouraging through this process. 


\section{Table of Contents}

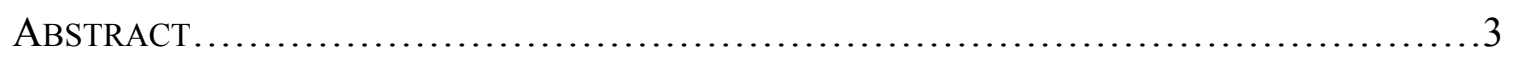

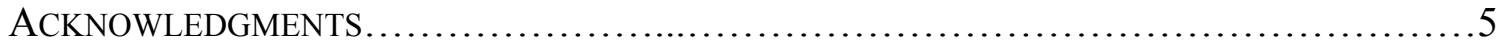

TABLE OF CONTENTS............................................................

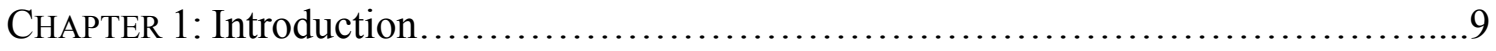

CHAPTER 2: Dissolved inorganic and organic phosphorus uptake in Trichodesmium and the microbial community; the importance of phosphorus ester in the Sargasso Sea.......1

CHAPTER 3: Polyphosphate in Trichodesmium from the low phosphorus Sargasso Sea..5[

CHAPTER 4: Molecular analysis of the phosphorus starvation response in Trichodesmium

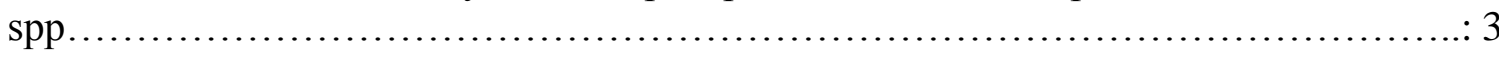

CHAPTER 5: Molecular evidence for phosphorus limitation of Trichodesmium growth and nitrogen fixation in the North Atlantic............................................

CHAPTER 6: Summary and future directions.................................. 


\section{CHAPTER ONE}

\section{Introduction}

Phytoplankton play a key role in the biogeochemistry of the ocean by fixing carbon dioxide $\left(\mathrm{CO}_{2}\right)$ and influencing the flux of carbon to the deep sea. Carbon export in the ocean impacts the atmospheric $\mathrm{CO}_{2}$ concentration, and therefore climate, over geological time scales (Longhurst, 1991). Therefore, a fundamental question in biological oceanography is what controls primary production in the ocean. In many regions, particularly the ocean gyres, the concentration of nutrients such as nitrogen $(\mathrm{N})$, phosphorus (P) and iron (Fe) are very low, and therefore they are thought to be limiting to primary production. Some genera of cyanobacteria, such as Trichodesmium, are capable of converting $\mathrm{N}_{2}$ gas into biologically available nitrogen compounds (termed $\mathrm{N}_{2}$ fixation). Thus, they contribute to carbon cycling directly (as primary producers) and indirectly by fixing atmospheric $\mathrm{N}_{2}$, which can in turn promote the growth of other phytoplankton species (Coles et al., 2004). Trichodesmium populations contribute an estimated $8-47 \%$ of the total primary productivity in the tropical North Atlantic, (Carpenter et al., 2004). The annual input of "new nitrogen" by Trichodesmium has been estimated to be as much as $1.6 \times 10^{12} \mathrm{~mol} \mathrm{~N}$ into the tropical North Atlantic, which can equal or exceed vertical fluxes of nitrate to the surface (Capone et al., 1997). Therefore, this genus has a significant influence on the biogeochemistry of its environment.

Since Trichodesmium can fix atmospheric $\mathrm{N}_{2}$ they are not $\mathrm{N}$-limited, and therefore the productivity of this organism is limited by other physical and chemical properties. 
Because of its biochemical significance there have been a number of studies seeking to identify what limits Trichodesmium and $\mathrm{N}_{2}$ fixation. In particular, $\mathrm{Fe}$ (Berman-Frank et al., 2001; Webb et al., 2001; Kustka et al., 2002; Moore et al., 2009), P (Wu et al., 2000; Sañudo-Wilhelmy et al., 2001; Dyhrman et al., 2002; Mulholland et al., 2002; Moutin et al., 2005; Hynes et al., 2009) or a combination of the two (Mills et al., 2004) have been repeatedly identified as the limiting nutrients for Trichodesmium in various regions of the ocean. In general, these studies suggest that $\mathrm{P}$ is limiting in the North Atlantic while Fe is probably limiting in the South Atlantic and the Pacific (Moore et al., 2004). Mainly due to the fact that during stratified periods in the North Atlantic inorganic P (Pi) concentrations can be two orders of magnitude lower than the North Pacific (CavendarBares et al., 2001). Meanwhile, the North Atlantic receives a large influx of iron-rich dust from the North Africa, and therefore has higher Fe concentrations than the Pacific. The focus of this thesis is to better understand $\mathrm{P}$ metabolism in Trichodesmium, and better evaluate where and when $\mathrm{P}$ limits Trichodesmium growth and $\mathrm{N}_{2}$ fixation in the field.

Three key pathways that mediate $\mathrm{P}$ metabolism in cyanobacteria are (1) inorganic phosphate uptake, (2) dissolved organic phosphorus (DOP) hydrolysis, and (3) polyphosphate (polyP) metabolism. $\mathrm{P} i$ is generally considered the preferred form of $\mathrm{P}$ because it is directly available for growth (Vershinina and Znamenskaia, 2002). In Pi deficient conditions, some microbes can scavenge P from DOP bond classes such as $\mathrm{P}$ esters and phosphonates. In the upper water column of oligotrophic regimes DOP often comprises a significant portion of the total P (Orrett and Karl, 1987; Karl, 1999; 
Ammerman et al., 2003), and several recent studies have suggested that DOP may support from 12-60\% of primary productivity in the North Atlantic (Mather et al., 2008; Lomas et al., 2009). However, it is difficult to chemically characterize the composition of the DOP pool, and therefore, assaying the bio-availability of DOP to a given microbial group remains an ongoing challenge. Chapter two of this thesis examines the relative importance of $\mathrm{P} i$ and DOP to supporting growth in Trichodesmium by measuring ${ }^{33} \mathrm{P} i$ and DOP (using alpha labeled adenosine-5'-triphosphate as a model) uptake and uptake kinetics in the Sargasso Sea.

If $\mathrm{P}$ uptake is in excess of cellular needs, $\mathrm{P} i$ can be stored as polyP granules. PolyP is a linear chain of phosphate residues, and could represent an important reservoir for $\mathrm{P}$ when this nutrient is not readily available in the environment. Additionally, polyP has recently been identified as an important component of the $\mathrm{P}$ cycle in coastal systems (Diaz et al., 2008). PolyP has previously been observed in Trichodesmium populations from the Caribbean Sea (Romans et al., 1994), but it has never been examined in a low P environment such as the Western North Atlantic. Determining how Trichodesmium allocates $\mathrm{P}$ under $\mathrm{P}$ limiting conditions and if polyP formation occurs will provide new insights into how Trichodesmium is adapted to low P environments. Chapter three examines polyP formation and degradation in Trichodesmium from culture and from the Sargasso Sea.

When microbes are P-limited they induce a set genes whose products are involved in P scavenging including genes involved in $\mathrm{P} i$ uptake and DOP hydrolysis. Identifying which genes are responsive to $\mathrm{P}$ limitation in Trichodesmium will allow for a better 
understanding of how Trichodesmium senses and responds changes in $\mathrm{P}$ physiology. $\mathrm{P} i$ uptake in many microbes occurs via the P specific transport (Pst), which includes the high affinity phosphate binding protein, encoded by $\operatorname{sphX}$ or pstS (Vershinina and Znamenskaia, 2002; Suzuki et al., 2004). DOP hydrolysis can be mediated by many different enzymes, including alkaline phosphatases encoded by the $p h o X$ and $p h o A$ genes (Roy et al., 1982; Moore et al., 2005; Wu et al., 2007). Chapter four examines the presence and regulation of $p s t S, \operatorname{sphX}$, phoA and phoX in cultures of Trichodesmium erythraeum IMS101 under different $\mathrm{P}$ physiologies to determine which gene transcripts are responsive to changes in P supply and the time scales of these responses.

Finally, chapter five measures the extent of P limitation of Trichodesmium in the North Atlantic and South Pacific. Various techniques have been utilized to assess algal physiology in situ. The results of these experiments can vary greatly depending on the time scale considered and the process being measured. Nutrient bioassays are probably the most common technique employed in the field to assess nutrient stress; in this method a nutrient (such as $\mathrm{N}$ or $\mathrm{P}$ ) is added to phytoplankton incubations, and community responses such as chlorophyll or $\mathrm{N}_{2}$ fixation rates are measured. This technique is problematic for Trichodesmium because cell lysis generally occurs quickly after Trichodesmium colonies are placed in incubation bottles (Burns et al., 2006). Additionally, contamination of nutrients and bacteria is a constant problem with bottle incubations. Finally, when marine microbes are sampled and incubated in a bottle there tends to be major shifts in the community structure that makes extrapolating bottle incubation results back to the field difficult. 
The cellular ratio of $\mathrm{C}: \mathrm{N}: \mathrm{P}$ may be used to assess nutrient physiology. Phytoplankton tend to adhere to a preferred ratio of 106C: 16N: P (Redfield ratio) for growth (Redfield, 1934). If the ratio of C:P falls above the Redfield ratio, then the cells are considered to be P deficient (Redfield, 1958; Bertilsson et al., 2003; Heldal et al., 2003). Measures of cellular stoichiometry can be extended to include trace metals, and to infer trace metal limitation (Morel et al., 1991; Berman-Frank et al., 2001). However, cellular stoichiometry has been found to be variable in Trichodesmium spp. (Krauk et al., 2006; White et al., 2006), indicating that cellular stoichiometry is not fixed and nonRedfield ratios may not be diagnostic of nutrient limitation. Another commonly used assay of nutrient physiology is measuring the activity of enzymes that are diagnostic of particular physiological states. For example, bulk alkaline phosphatase activity (APA) is often used as a proxy for P limitation (Ammerman and Glover, 2000; Dyhrman and Ruttenberg, 2006). Although valuable, none of these techniques are cell-specific. Different organisms within the same community, or even different species within the same genus, are experiencing and are adapted to different microenvironments; they will, therefore, have different physiologies (Lomas et al., 2004). Thus, key details may be lost by averaging cellular responses over the community as a whole. Alkaline phosphatase activity measured using enzyme-labeled fluorescence (ELF) is cell-specific, but is qualitative, and therefore it can be difficult to assess relative degrees of $\mathrm{P}$ limitation (Dyhrman et al., 2002). Molecular techniques promise to be a useful and innovative approach to probing cellular physiology in a species-specific manner: allowing researchers to distinguish between species-specific and community responses. Chapter 
five uses the expression of, phoX, which was shown to be regulated by P physiology in chapter four, as a marker of $\mathrm{P}$ limitation. Further, the regulation of this gene is calibrated to decreases in $\mathrm{N}_{2}$ fixation rate to identify regions in the ocean where $\mathrm{N}_{2}$ fixation is reduced due to $\mathrm{P}$ limitation.

This work represents a detailed study of $\mathrm{P}$ metabolism in Trichodesmium. Our approach included studies of Trichodesmium physiology in the field and culture using gene expression patterns, tracer-radio isotope experiments, and studies of cellular P allocation. Thus, this work provides new insights into how Trichodesmium survives in low $\mathrm{P}$ environments, utilizes DOP versus $\mathrm{P} i$, stores polyP, and the extent to which $\mathrm{P}$ can limit nitrogen fixation by this genus.

\section{References}

Ammerman, Hood, Case, and Cotner (2003) Phosphorous deficiency in the Atlantic: an emerging paradigm in oceanography. EOS 84: 165.

Ammerman, J., and Glover, W.B. (2000) Continuous underway measurement of microbial ectoenzyme activities in aquatic ecosystems. Mar. Ecol. Prog. Ser. 201: 1-12.

Berman-Frank, I., Cullen, J., Shaked, Y., Sherrell, R.M., and Falkowski, P. (2001) Iron availability, cellular iron quotas, and nitrogen fixation in Trichodesmium. Limnol. Oceanogr. 46: 1249-1260.

Bertilsson, S., Berglund, O., Karl, D., and Chisholm, S.W. (2003) Elemental composition of marine Prochlorococcus and Synechococcus: Implications for the ecological stoichiometry of the sea. Limnol. Oceanogr. 48: 1721-1731.

Burns, J., Zehr, J.P., Montoya, J.P., Kustka, A., and Capone, D.G. (2006) Effect of EDTA Additions on Natural Trichodesmium spp. (Cyanophyta) Populations. Journal of Phycology 42: 900-904.

Capone, D.G., Zehr, J.P., Paerl, H.W., Bergman, B., and Carpenter, E. (1997) Trichodesmium, a globally significant marine cyanobacterium. Science 276: 1221-1229. 
Carpenter, E.J., Subramaniam, A., and Capone, D.G. (2004) Biomass and primary productivity of the cyanobacterium Trichodesmium spp. in the tropical North Atlantic ocean. Deep-Sea Res 1: 173-203.

Cavendar-Bares, K.K., Karl, D.M., and Chisholm, S.W. (2001) Nutrient gradients in the western North Atlantic Ocean: relationship to microbial community structure and comparison to patterns in the Pacific Ocean. Deep-Sea Res. 48: 2373-2395.

Coles, V.J., Wilson, C., and Hood, R.R. (2004) Remote sensing of new production fuelled by nitrogen fixation. In Geophy. Res. Lett., p. doi:10.1029/2003GLO19018.

Diaz, J., Ingall, E.D., Benitez-Nelson, C.R., Paterson, D., de Jonge, M.D., McNulty, I., and Brandes, J.A. (2008) Marine Polyphosphate: A key player in geologic phosphorus sequestration. Science 320: 652-655.

Dyhrman, S.T., and Ruttenberg, K.C. (2006) Presence and regulation of alkaline phosphatase activity in eukaryotic phytoplankton from the coastal ocean: Implications for dissolved organic phosphorus reminerilzation. Limnol. Oceanogr. 5: 1381-1390.

Dyhrman, S.T., Webb, E.A., Moffett, J.W., and Waterbury, J.B. (2002) Cell-specific detection of phosphorus stress in Trichodesmium from the western North Atlantic. Limnol. Oceanogr. 47: 1832-1836.

Heldal, M., Scanlan, D.J., Norland, S., Thingstad, and Mann, N.H. (2003) Elemental composition of single cells of various strains of marine Prochlorococcus and Synechococcus using X-ray microanalysis. Limnol Oceanogr 48: 1732-1743.

Hynes, A.M., Chappell, P.D., Dyhrman, S.T., Doney, S.C., and Webb, E.A. (2009) Cross-basin comparisons of phosphorus stress and nitrogen fixation in Trichodesmium. Limnol. Oceanogr. 54: 1438-1448.

Karl, D.M. (1999) A sea of change: Biogeochemical variability in the North Pacific Subtropical gyre. Ecosystems 2: 181-214.

Krauk, J., Villareal, T.A., Sohm, J.A., Montoya, J.P., and Capone, D.G. (2006) Plasticity of N:P ratios in laboratory and field populations of Trichodesmium spp. Aquat. Microb. Ecol. 42: 243-253.

Kustka, A., Carpenter, E.J., and Sañudo-Wilhelmy, S.A. (2002) Iron and marine nitrogen fixation: progress and future directions. Res. Microbiol. 153: 255-262.

Lomas, M., Swain, A., Schelton, R., and Ammerman, J. (2004) Taxonomic variability of phosphorus stress in Sargasso Sea phytoplankton. Limnol. Oceanogr. 49: 2303-2310. 
Lomas, M.W., Burke, A.L., Lomas, D.A., Bell, D.W., Shen, C., Dyhrman, S.T., and Ammerman, J.W. (2009) Sargasso Sea phosphorus biogeochemistry: an important role for dissolved organic phosphorus (DOP). Biogeosciences Discussions 6: 10137-10175.

Longhurst, A. (1991) Role of the marine biosphere in the global carbon cycle. Limnol. Oceanogr. 36: 1507-1526.

Mather, R.L., Reynolds, S.E., Wolff, G.A., Williams, R.G., Torres-Valdes, S., Woodward, E.M.S. et al. (2008) Phosphorus cycling in the North and South Atlantic Ocean subtropical gyres. Nature Geosci. 1: 439-443.

Mills, M., Ridame, C., Davey, M., La Roche, J., and Geider, R.J. (2004) Iron and phosphorus co-limit nitrogen fixation in the eastern tropical North Atlantic. Nature 429: 292-294.

Moore, C.M., Mills, M.M., Achterberg, E.P., Geiber, R.J., LaRoche, J., Lucas, M.I. et al. (2009) Large-scale distribution of Atlantic nitrogen fixation controlled by iron availability. Nature Geosciences 2: 867-871.

Moore, J.K., Doney, S.C., and Lindsay, K. (2004) Upper ocean ecosystem dynamics and iron cycling in a global three dimensional model. Global Biogeochem Cy 18: GB4028.

Moore, L.R., Ostrowski, M., Scanlan, D.J., Feren, K., and Sweetsir, T. (2005) Ecotypic variation in phosphorus-acquisition mechanisms within picocyanobacteria. Aquat. Microb. Ecol. 39: 257-269.

Morel, F., Hudson, R., and Price, N. (1991) Limitation of productivity by trace metals in the sea. Limnol Oceanogr 36: 1742-1755.

Moutin, T., Van Den Broeck, N., Beker, B., Dupouy, C., Rimmelin, P., and Bouteiller, A. (2005) Phosphate availability controls Trichodesmium spp. biomass in the SW Pacific Ocean. Mar. Ecol. Prog. Ser. 297: 15-21.

Mulholland, M.R., Floge, S., Carpenter, E., and Capone, D. (2002) Phosphorus dynamics in cultures and natural populations of Trichodesmium spp. Mar. Ecol. Prog. Ser. 239: 4555.

Orrett, K., and Karl, D.M. (1987) Dissolved organic phosphorus production in surface seawaters. Limnol. Oceanogr. 32: 383-398.

Redfield (1934) On the proportions of organic derivatives in the sea water and their relation to the composition of plankton. In James Johnstone Memorial Volume. J., D.R. (ed): Press of Liverpool, pp. 177-192. 
Redfield (1958) The biological control of chemical factors in the environment. American Scientist 46: 205-222.

Romans, K.M., Carpenter, E.J., and Bergman, B. (1994) Buoyancy Regulation in the Colonial Diazotrophic Cyanobacterium Trichodesmium tenue: Ultrastructure and storage of carbohydrate, polyphosphate, and nitrogen. $J$ Phyc 30: 935-942.

Roy, N.K., Ghosh, R.K., and Das, J. (1982) Monomeric alkaline phosphatase of Vibrio cholerae. J. Bacteriol. 150: 1033-1039.

Sañudo-Wilhelmy, S.A., Kustka, A.B., Gobler, C.J., Hutchins, D.A., Yang, M., Lwiza, K. et al. (2001) Phosphorus limitation of nitrogen fixation by Trichodesmium in the Central Atlantic Ocean. Nature 411: 66-69.

Suzuki, S., Ferjani, A., Suzuki, I., and Murata, N. (2004) The SphS-SphR two component system is the exclusive sensor for the induction of gene expression in response to phosphate limitation in Synechocystis. J. Biol. Chem. 279: 13234-13240.

Vershinina, O.A., and Znamenskaia, L.V. (2002) The Pho regulons of bacteria. Mikrobiologia 71: 581-595.

Webb, E.A., Moffett, J.W., and Waterbury, J.B. (2001) Iron stress in open-ocean cyanobacteria (Synechococcus, Trichodesmium, and Crocosphaera spp.): identification of the IdiA protein. Appl. Environ. Microbiol. 67: 5444-5452.

White, A.E., Spitz, Y., Karl, D.M., and Letelier, R. (2006) Flexible elemental stoichiometry in Trichodesmium spp. and its ecological implications. Limnol Oceanogr 51: $1777-1790$.

Wu, J., Sunda, W., Boyle, E.A., and Karl, D.M. (2000) Phosphate depletion in the western North Atlantic Ocean. Science 289: 759-762.

Wu, J.-R., Shien, J.-H., Shieh, H.K., Hu, C.-C., Gong, S.-R., Chen, L.-Y., and Chang, P.C. (2007) Cloning of the gene and characterization fo the enzymatic properties of the monomeric alkaline phosphatase (PhoX) from Pasteurella multocida strain X-73. FEMS Microbiol. Lett. 267: 113-120. 
CHAPTER TWO

Dissolved Inorganic and Organic Phosphorus Uptake in Trichodesmium and the Microbial Community; the Importance of Phosphorus Ester in the Sargasso Sea

\author{
Elizabeth D. Orchard, ${ }^{\mathrm{a}}$ \\ James W. Ammerman, b,1 \\ Michael W. Lomas, ${ }^{c}$ \\ Sonya T. Dyhrman ${ }^{\mathrm{d}}$ *
}
${ }^{a}$ MIT-WHOI Joint Program in Oceanography/Applied Ocean Science and Engineering, Woods Hole, Massachusetts
${ }^{\mathrm{b}}$ Rutgers University, Institute of Marine and Coastal Sciences, New Brunswick, New Jersey
${ }^{c}$ Bermuda Institute of Ocean Sciences, Ferry Reach, St. Georges, Bermuda
${ }^{\mathrm{d}}$ Biology Department, Woods Hole Oceanographic Institution, Woods Hole, Massachusetts
${ }^{1}$ Present address: School of Marine and Atmospheric Sciences
Stony Brook University, Stony Brook, New York
*Corresponding author: sdyhrman@whoi.edu

In press in Limnology and Oceanography 


\begin{abstract}
The dynamics and relative importance of inorganic phosphate $(\mathrm{P} i)$ and dissolved organic phosphorus (DOP) uptake were examined in Trichodesmium, and the microbial community. Trichodesmium DOP and Pi uptake rates were also compared to literature values from several other taxonomically important groups in the Sargasso Sea. Uptake rates and uptake kinetics of ${ }^{33} \mathrm{P} i$ and DOP (using alpha labeled adenosine-5' -triphosphate ${ }^{33} \mathrm{P}-\mathrm{ATP}$ as a model $\mathrm{P}$ ester compound) were assayed during two cruises. The in situ uptake rates suggest that the contribution of $\mathrm{P}$ ester to total $\mathrm{P}$ uptake can be greater than $25 \%$ for Trichodesmium, the microbial community, and key phytoplankton groups (Prochlorococcus, Synechococcus, picoeukaryotes, and nanoeukaryotes), depending on the location. Based on the kinetics of $\mathrm{P} i$ uptake and $\mathrm{P}$ ester uptake, Trichodesmium is a poor competitor for $\mathrm{P} i$ but a much better competitor for $\mathrm{P}$ esters as compared to the microbial community. Trichodesmium growth rates calculated from the $\mathrm{P} i$ and $\mathrm{P}$ ester uptake parameters suggest that only a small fraction of the P ester pool needs to be bioavailable to allow reasonable growth rates. These data underscore the importance of $\mathrm{P}$ esters in supporting production by Trichodesmium in the Sargasso Sea, and provide the first in situ measurements of $\mathrm{P}$ ester uptake and uptake kinetics in this important $\mathrm{N}_{2}$ fixing genus.
\end{abstract}

\title{
Introduction
}

Oceanic gyres represent the earth's largest ecosystem, and have a significant effect on global biogeochemical cycles and climate (Karl 2002). Phosphorus (P) has 
increasingly been identified as a limiting nutrient in the ocean gyres, particularly in the Sargasso Sea region of the North Atlantic (Wu et al. 2000; Maranon et al. 2003). Furthermore, it is $\mathrm{P}$ rather than nitrogen $(\mathrm{N})$, which is thought to be the limiting nutrient over geological time scales due to inputs of $\mathrm{N}$ from $\mathrm{N}_{2}$ fixation (Longhurst 1991). Dissolved inorganic phosphate ( $\mathrm{P} i$ ) concentrations in gyres, such as the Sargasso Sea, are extremely low, ranging from sub-nanomolar to $10 \mathrm{nmol} \mathrm{L}^{-1}$ (Cavendar-Bares et al. 2001; Lomas et al. 2009), and numerous approaches have identified evidence of $\mathrm{P}$ deficiency in phytoplankton from this region (Wu et al. 2000; Ammerman et al. 2003; Lomas et al. 2004).

The major forms of $\mathrm{P}$ in the upper water column are $\mathrm{P} i$ and dissolved organic phosphorus (DOP). $\mathrm{P} i$ is considered the preferable $\mathrm{P}$ source for microbes because it is directly available for growth (Vershinina and Znamenskaia 2002), but in the upper water column of oligotrophic regimes DOP often comprises a significant portion of the total P (Karl and Björkman 2001). It is difficult to chemically characterize the composition of the DOP pool, and therefore, assaying the bio-availability of DOP to a given microbial group remains an ongoing challenge. Within the high molecular weight DOP pool that is amenable to characterization (approximately $20-40 \%$ of the DOP), roughly $25 \%$ has a phosphonate bond and roughly $75 \%$ has an ester bond (Clark et al. 1998). As such, P esters represent a larger potential P source than phosphonates, and are the focus of this study.

One enzyme known to hydrolyze $\mathrm{P}$ esters, alkaline phosphatase, has received a great deal of attention because of its importance to microbial DOP hydrolysis in the 
ocean gyres, and because there are commercially available substrates to measure its activity (Ammerman and Glover 2000; Dyhrman et al. 2002; Lomas et al. 2004). Using community alkaline phosphatase activity (APA) as a proxy for DOP hydrolysis, a recent study by Mather et al. (2008) suggested that DOP could fuel up to $30 \%$ of the primary productivity in the North Atlantic. However, both phytoplankton and heterotrophic bacteria contribute to community hydrolysis rates and cell-specific assays of APA have shown that there can be a great deal of taxonomic heterogeneity in the activity of this enzyme (Dyhrman et al. 2002; Lomas et al. 2004; Webb et al. 2007). Both of these factors would influence production estimates based on community hydrolysis rates.

While studies measuring APA have provided insight into the importance and scale of P ester hydrolysis in the ocean, APA assays are problematic in that they typically involve adding excess substrate, and therefore measure a maximal rate of hydrolysis, not the in situ rate. Another approach for measuring nutrient utilization involves short-term incubations with tracer levels of radio-labeled compounds to measure the uptake rate of these isotopes into cells (Fu et al. 2005a; Moutin et al. 2005; Zubkov et al. 2007). This method has the added advantage of allowing direct comparisons of both the uptake of $\mathrm{P} i$ and DOP, and has been previously employed in a culture study of Synechococcus (Fu et al. 2006).

There have been several studies that have focused on $\mathrm{P} i$ uptake in cultures (Fu et al. 2005a) and field populations (Moutin et al. 2005; Sohm and Capone 2006; Sohm et al. 2008) of Trichodesmium, a colony forming $\mathrm{N}_{2}$ fixing cyanobacteria, which can dominate the phytoplankton community in oceanic gyres such as the Sargasso Sea (Capone et al. 
1997; Carpenter et al. 2004). This genus has received much attention because as a diazotroph its growth is not limited by $\mathrm{N}$, but may be limited by P. Additionally, Trichodesmium can be an important source of $\mathrm{N}$ to other co-occurring microbes (Orcutt et al. 2001; Mulholland et al. 2006). In previous studies of $\mathrm{P} i$ uptake it has been suggested that Trichodesmium might meet a majority of its P demand from DOP in the form of $\mathrm{P}$ esters, and that Trichodesmium is a poor competitor for $\mathrm{P} i$ relative to the rest of the microbial community (Mulholland et al. 2002; Sohm and Capone 2006). However, in situ rates of DOP uptake have not been measured in Trichodesmium field populations.

In this study, we compare the variability and relative importance of $\mathrm{P} i$ and DOP uptake in Trichodesmium, the community, and several taxonomically important groups. To accomplish this, uptake rates and uptake kinetics of ${ }^{33} \mathrm{P} i$ and DOP (using alpha labeled adenosine-5'-triphosphate ${ }^{33} \mathrm{P}$-ATP as a model $\mathrm{P}$ ester compound) were assayed during two cruises in the Sargasso Sea.

\section{Methods}

Sample collection

Samples were collected on two cruises to the Sargasso Sea in June 2007 (X0705) and May 2008 (X0804) (Fig. 1). Trichodesmium colonies were collected from the near surface (roughly within the top $20 \mathrm{~m}$ ) using a hand held $130 \mu \mathrm{m}$ net. Single colonies were picked into $0.2 \mu \mathrm{m}$-filtered local surface seawater. Colonies were then transferred into fresh $0.2 \mu \mathrm{m}$-filtered water to reduce contamination of closely associated organisms, and were separated by morphotype (either 'puff' with radial trichomes or 'raft' with 
parallel trichomes) for further analyses. Samples of the bulk microbial community, and for flow cytometric sorting, were collected from a Niskin bottle on a rosette from a depth of $5 \mathrm{~m}$ and processed as described below and in Casey et al. (2009).

\section{Uptake measurements}

Uptake measurements for Trichodesmium and the bulk microbial community were modeled after a previous Trichodesmium ${ }^{33} \mathrm{P} i$ uptake study (Sohm and Capone 2006). In brief, ten washed Trichodesmium colonies were transferred into $10 \mathrm{~mL}$ of surface seawater. In each incubation only one colony morphoytype (puff or raft) was used depending on which morphotype was most abundant at that station. To account for the possibility of free Trichodesmium trichomes contributing to the microbial community uptake calculations, $4 \mathrm{~L}$ of surface seawater was filtered onto $5 \mu \mathrm{m}$ filter, and counted. At most there were 6 trichomes $\mathrm{L}^{-1}$, and therefore it is unlikely that free trichomes had a large affect on uptake rates that were assayed in $10 \mathrm{~mL}$. Coincident with the Trichodesmium colony sampling, $10 \mathrm{~mL}$ of surface seawater was sampled, and both Trichodesmium and the surface seawater (referred to as the microbial community) were incubated with either $37-93 \mathrm{kBq}$ of $\mathrm{H}_{3}{ }^{33} \mathrm{PO}_{4}$ or $9.2-37 \mathrm{kBq}$ of alpha labeled ${ }^{33} \mathrm{P}-\mathrm{ATP}$ for 20-40 or 40-70, minutes respectively. Nucleotides like ATP, were the only commercially available radio-labeled $\mathrm{P}$ esters that could be obtained at the time of the cruise and as such ${ }^{33} \mathrm{P}$-ATP was used as the model for P ester uptake. ATP has previously been used to examine P ester uptake in cultures of Synechococcus (Fu et al. 2006), and in field populations of phytoplankton (Casey et al. 2009), also allowing direct comparisons to 
these studies. The $\mathrm{H}_{3}{ }^{33} \mathrm{PO}_{4}$ and ${ }^{33} \mathrm{P}-\mathrm{ATP}$ were sampled in sets, and the differences in incubation time reflect the time needed to sample one set. Data are referred to herein as ${ }^{33} \mathrm{P} i$ or ${ }^{33} \mathrm{P}$ ester uptake for clarity. Replicate samples for both Trichodesmium and the microbial community were killed with $1 \mathrm{~mL}$ of formalin ( $1 \%$ final concentration) to account for abiotic adsorption of P. The activity of the killed control (typically about $10 \%$ of the total) was subtracted from the total measured activity. To further explore the importance of adsorbed $\mathrm{P},{ }^{33} \mathrm{P} i$ uptake was assayed as above on an oxalate washed Trichodesmium sample and a non-washed Trichodesmium sample following the protocol of Sañudo-Wilhelmy et al. (2004), on a subsequent cruise in a similar region of the Sargasso Sea. In all cases, incubations were ended by filtration onto $0.2 \mu \mathrm{m}$ polycarbonate filters, and then $5 \mathrm{~mL}$ of scintillation cocktail (AquaSol, Perkin Elmer) was added to each sample, they were shaken, and counted on a Tri-Carb 2900 liquid scintillation counter (Packard). Assays of uptake for flow-sorted populations were performed by J. Casey and co-authors (Casey et al. 2009).

Trichodesmium uptake rates were obtained by subtracting the microbial community rates from the Trichodesmium and microbial community combined uptake values. Samples were taken in triplicate, but on occasion Trichodesmium biomass was lost to the walls of the incubation bottle or filter tower, and one of the replicates had to be dropped. Reported uptake rates are the average of duplicate or triplicate samples. Uptake rates were calculated using the following formula: Uptake rate $=\left(R_{s}-R_{k}\right) \times P \times(A$ $\times \mathrm{T} \times \mathrm{B})^{-1}$ where $\mathrm{R}_{\mathrm{s}}$ is the radioactivity of the sample, $\mathrm{R}_{\mathrm{k}}$ is the radioactivity of the killed control, $\mathrm{A}$ is the total radioactivity added to incubation, $\mathrm{T}$ is the time of incubation, $\mathrm{B}$ is 
the chlorophyll $a$ concentration of a replicate sample or Trichodesmium colony number (used for growth rate calculations), and $\mathrm{P}$ is the ambient concentration of the compound of interest in the sample. For ${ }^{33} \mathrm{P} i$ uptake rates, $\mathrm{P}$ was the measured soluble reactive phosphorus (SRP) concentration. The ambient ATP concentration was not measured in this study, but previous bioassay measurements of ATP in the North Atlantic found concentrations around $1 \mathrm{nmol} \mathrm{L}^{-1}$ (Zubkov et al. 2007). Therefore, an ambient ATP concentration of $1 \mathrm{nmol} \mathrm{L}^{-1}$ was used to estimate a minimum ${ }^{33} \mathrm{P}$ ester uptake, as has been used in previous work (Casey et al. 2009). However, this might be a slight overestimate of this minimum value, because North Pacific ATP concentrations were found to be 0.3$0.5 \mathrm{nmol} \mathrm{L}^{-1}$ in the top $100 \mathrm{~m}$ of the water column using a chemical precipitation approach (Karl and Björkman 2001). A maximal ${ }^{33} \mathrm{P}$ ester uptake rate was calculated assuming that ATP is a model for all P ester. Since $75 \%$ of high molecular weight DOP has been shown to be $\mathrm{P}$ ester (Clark et al. 1998), the ${ }^{33} \mathrm{P}$ ester uptake rates are reported as a range using both $1 \mathrm{nmol} \mathrm{L}^{-1}$ and $75 \%$ of the DOP concentration for the constant $\mathrm{P}$ in the uptake equation, unless otherwise noted. To compare uptake rates, all values were normalized to chlorophyll $a$ after Sohm and Capone (2006). However, we acknowledge that there was heterotrophic uptake in both the Trichodesmium and microbial community samples, as has been noted in previous studies (Sohm and Capone 2006; Sohm et al. 2008).

Uptake Kinetics 
For each kinetic curve, $0-1.0 \mu \mathrm{mol} \mathrm{L} \mathrm{L}^{-1}$ cold $\mathrm{P} i$ or cold ATP was added in addition to the ${ }^{33} \mathrm{P} i$ or ${ }^{33} \mathrm{P}$-ATP spike to duplicate incubations and assayed as above. Data was fit (Prism, Graphpad) using the Michaelis-Menton equation: $\mathrm{V}=\mathrm{V}_{\max } \times \mathrm{S}\left(\mathrm{K}_{\mathrm{m}}+\mathrm{S}\right)^{-1}$, where $\mathrm{V}_{\max }$ is the maximal uptake velocity, $\mathrm{S}$ is the substrate concentration (either the measured $\mathrm{P} i$ concentration or the estimated value of $1 \mathrm{nmol} \mathrm{L}^{-1}$ for $\mathrm{P}$ ester), and $\mathrm{K}_{\mathrm{m}}$ is the nutrient concentration where the uptake is half of $\mathrm{V}_{\max }$.

\section{Chlorophyll a}

Ten puff or raft colonies were washed and filtered onto GF/F filters for Trichodesmium analyses, or 1-2 L of seawater were filtered onto a GF/F for microbial community analyses, and all samples were frozen at $-20^{\circ} \mathrm{C}$. Filters were extracted overnight in $90 \%$ acetone at $-20^{\circ} \mathrm{C}$. Chlorophyll $a(\mathrm{Chl} a)$ fluorescence was measured on an Aquafluor handheld fluorometer (Turner Designs) or TD-700 fluorometer (Turner Designs) and analyzed according to Arar and Collins (1997). In all cases, colonies were chosen to best mimic the size of colonies used for the other assays of Trichodesmium, and the Chl $a$ colony $^{-1}$ is reported for recalculating the normalized data as necessary.

\section{P Chemistry}

Soluble reactive phosphorus (SRP) was measured according to the magnesiuminduced co-precipitation method (Karl and Tien 1992), with a detection limit of $0.5 \mathrm{nmol}$ $\mathrm{L}^{-1}$. SRP concentrations measured here are referred to as the $\mathrm{P} i$ concentration for consistency with the reporting of the uptake data. The total dissolved P (TDP) was 
processed according to the persulfate oxidation method (Valderrama 1981). DOP concentrations were calculated as the difference between TDP and Pi.

\section{Alkaline Phosphatase Activity (APA)}

For Trichodesmium APA assays, 3-5 colonies were washed and placed on a $5 \mu \mathrm{m}$ polycarbonate filter. For microbial community APA, $300 \mathrm{~mL}$ of seawater was collected from $5 \mathrm{~m}$, filtered onto a $0.2 \mu \mathrm{m}$ filter and in both cases the filters were stored frozen at $20^{\circ} \mathrm{C}$. Samples were processed as described elsewhere (Dyhrman and Ruttenberg 2006). Briefly, $\quad 10 \mu$ mol $\mathrm{L}^{-1}$ 6,8-difluoro-4-methylumbelliferyl phosphate (di-MUF-P) (Invitrogen) was added to each sample in a petri dish with artificial seawater containing no added P, and fluorescence was measured on a Fluostar Optima plate reader (BMG Labtech) every 5-20 minutes for 5 time points, within the linear range of the assay.

Previous kinetics experiments found the $10 \mu \mathrm{mol} \mathrm{L}^{-1}$ substrate concentration to be saturating (data not shown). Standard curves were generated for each assay using 6,8difluoro-7-hydroxy-4-methylcoumarin (di-MUF) as a standard.

\section{Statistics}

Two-tail paired $t$-tests were preformed to compare data sets. Two data sets were determined to be significantly different from each other if they had a $p$-value less than 0.05 . 


\section{Results}

The Pi concentrations were low for both transects, averaging $3.0 \pm 3.1 \mathrm{nmol} \mathrm{L}^{-1}$ (mean \pm standard deviation) (Table 1). The DOP concentration was more than 15 times higher than the Pi concentration with an average of $48.0 \pm 28.1 \mathrm{nmol} \mathrm{L}^{-1}(p<0.001)$ (Table 1). The Chl $a$ content per colony was similar between stations with an average of $28 \pm 13$ ng Chl $a$ colony $^{-1}$ as was the microbial community Chl $a$ concentration, which averaged $31 \pm 7.7 \mathrm{ng}$ Chl $a \mathrm{~L}^{-1}$ (Table 1 ). The microbial community APA averaged $60.7 \pm 33.2$ nmol $\mathrm{P} \mathrm{h}^{-1} \mu \mathrm{g} \mathrm{Chl} a^{-1}$, while Trichodesmium APA had an average of $19.5 \pm 10.5 \mathrm{nmol} \mathrm{P} \mathrm{h}^{-}$ ${ }^{1} \mu \mathrm{g} \mathrm{Chl} a^{-1}$ (Table 1).

The average Trichodesmium ${ }^{33} \mathrm{P} i$ uptake for both cruises was $0.98 \pm 0.80 \mathrm{nmol} \mathrm{h}^{-1}$ $\mu \mathrm{g} \mathrm{Chl} a^{-1}$ (Table 1). Although not statistically different, the average microbial community ${ }^{33} \mathrm{P} i$ uptake was higher than that of the Trichodesmium, and at each station ${ }^{33} \mathrm{P} i$ uptake was higher for the microbial community than for Trichodesmium (Table 1). Furthermore, the average proportion of ${ }^{33} \mathrm{P} i$ uptake by Trichodesmium (8\%) was significantly lower $(\mathrm{p}<0.001)$ than the average proportion of ${ }^{33} \mathrm{P} i$ uptake by the microbial community $(92 \%)$ relative to the total ${ }^{33} \mathrm{P} i$ uptake at each station. Pi can adsorb to Trichodesmium colonies and other constituents of the microbial community (SañudoWilhelmy et al. 2004). To account for this, the activity assayed in killed controls (approximately $10 \%$ of the total), was subtracted from the total activity to calculate the reported uptake rates. Oxalate washing (Sañudo-Wilhelmy et al. 2004) is a more stringent way to remove adsorbed $\mathrm{P}$. A comparison of ${ }^{33} \mathrm{P} i$ uptake on an oxalate washed Trichodesmium sample vs. a non-washed Trichodesmium sample, suggests that this more 
stringent approach results in $26 \%$ of the uptake being the result of $\mathrm{P} i$ adsorbtion. Therefore, the values presented here (calculated with $10 \%$ ) might be a roughly $16 \%$ overestimate of the Trichodesmium ${ }^{33} \mathrm{P} i$ uptake as they include some $\mathrm{P} i$ adsorbtion.

Trichodesmium rates of ${ }^{33} \mathrm{P}$ ester uptake were variable, with an average minimum of $0.11 \pm 0.13$ and an average maximum of $4.5 \pm 7.1 \mathrm{nmol} \mathrm{P} \mathrm{h}^{-1} \mu \mathrm{g}$ Chl $a^{-1}$ using $1 \mathrm{nmol} \mathrm{L}^{-1}$ or $75 \%$ of the DOP concentration as the ambient $\mathrm{P}$ ester concentration respectively (Table 1). The ${ }^{33} \mathrm{P}$ ester uptake rates for the microbial community ranged from a minimum of $1.4 \pm 1.0$ to maximum of $63 \pm 65 \mathrm{nmol} \mathrm{P} \mathrm{h}^{1} \mu \mathrm{g} \mathrm{Chl} a^{-1}$, calculated with ranges as described above (Table 1). Therefore, for both Trichodesmium and the microbial community, the ${ }^{33} \mathrm{P}$ ester uptake ranged from lower than the ${ }^{33} \mathrm{P} i$ uptake rate to higher, depending on what the ambient bio-available $\mathrm{P}$ ester concentration is assumed to be.

To compare the relative importance of $\mathrm{P}$ ester vs. $\mathrm{P} i$ uptake, the \%P ester uptake of the total $\mathrm{P}$ uptake (Pi plus $\mathrm{P}$ ester) for Trichodesmium and the microbial community was calculated (Fig. 2). For Trichodesmium, the contribution of $\mathrm{P}$ ester to total $\mathrm{P}$ uptake was variable, and spanned different ranges for each station depending on the ambient DOP concentration used to estimate the P ester concentration (Fig. 2). At 3 of the 6 stations, $\mathrm{P}$ ester accounted for at least $25 \%$ of the $\mathrm{P}$ uptake in Trichodesmium and the average minimum for all stations was $29 \%$ (Fig. 2). P ester typically contributed a smaller portion to total $\mathrm{P}$ uptake for the microbial community (Fig. 2). In this case, P ester accounted for at least $25 \%$ of the total P uptake at only 1 out of 6 stations for the microbial community, and the average minimum contribution was 10\% (Fig. 2). 
Using the X0705 cruise taxon specific uptake rates measured by Casey et al. (2009) the contribution of P ester to total P uptake was calculated for picocyanobacteria, picoeukaryotes and nanoeukaryotes. The contribution of $\mathrm{P}$ ester to total $\mathrm{P}$ uptake in Prochlorococcus, and Synechococcus was variable depending on the station; for example at several stations, $\mathrm{P}$ ester contributed a minimum of $25 \%$ to the total $\mathrm{P}$ uptake, but not at all stations (Fig. 3). In contrast, $\mathrm{P}$ ester contributed a minimum of $25 \%$ of the total $\mathrm{P}$ uptake for every station assayed for the picoeukaryotes and the nanoeukaryotes. At X0705 Sta. 16, the only station where both Trichodesmium and the flow-sorted data are available, the contribution of $\mathrm{P}$ ester to total $\mathrm{P}$ uptake was $25 \%$ or more for each group (Figs. 2, 3).

Assays for Trichodesmium and the microbial community ${ }^{33} \mathrm{P} i$ uptake kinetics were performed at four stations; one station on $\mathrm{X} 0705$ and three stations on $\mathrm{X} 0804 .{ }^{33} \mathrm{P}$ ester uptake kinetics were assayed at three stations on cruise X0804. For the ${ }^{33} \mathrm{P} i$ uptake kinetics, Trichodesmium had an average $\mathrm{V}_{\max }$ of $210 \pm 120 \mathrm{nmol} \mathrm{P} \mathrm{h}^{-1} \mu \mathrm{g}$ Chl $a^{-1}$ and an average $K_{m}$ of $0.68 \pm 0.33 \mu \mathrm{mol} \mathrm{L}^{-1}$ (Table 2). The average $K_{m}$ value is similar to those obtained in previous studies with non-oxalate washed samples which include some adsorbed $\mathrm{P}$ (Table 3), however the $\mathrm{V}_{\max }$ calculated herein is higher than those previous studies (Table 3). The $\mathrm{V}_{\max }$ for ${ }^{33} \mathrm{P}$ ester uptake had an average of $54 \pm 34 \mathrm{nmol} \mathrm{P} \mathrm{h}^{-1} \mu \mathrm{g}$ Chl $a^{-1}$ and the $\mathrm{K}_{\mathrm{m}}$ averaged $0.29 \pm 0.18 \mu \mathrm{mol} \mathrm{L}^{-1}$ (Table 2). For the microbial community the $\mathrm{K}_{\mathrm{m}}$ and $\mathrm{V}_{\max }$ of ${ }^{33} \mathrm{P} i$ uptake averaged $0.057 \pm 0.081 \mu \mathrm{mol} \mathrm{L}^{-1}$ and $17 \pm 9.1$ nmol $\mathrm{P} \mathrm{h}^{-1} \mu \mathrm{g}$ Chl $a^{-1}$ respectively (Table 2). The $\mathrm{K}_{\mathrm{m}}$ and $\mathrm{V}_{\max }$ of ${ }^{33} \mathrm{P}$ ester uptake for the 
microbial community averaged $0.51 \pm 0.42 \mu \mathrm{mol} \mathrm{L}^{-1}$ and $11 \pm 6.1 \mathrm{nmol} \mathrm{h}^{-1} \mu \mathrm{g}$ Chl $a^{-1}$ respectively, in the microbial community samples (Table 2).

One measure of maximal $\mathrm{P}$ ester hydrolysis and uptake is the $\mathrm{V}_{\max }$ of ${ }^{33} \mathrm{P}$ ester uptake as described above. An alternative measure of maximal $\mathrm{P}$ ester hydrolysis is APA. The ${ }^{33} \mathrm{P}$ ester $\mathrm{V}_{\max }$ for Trichodesmium was similar to (within the same order of magnitude), but always slightly higher than the APA (Table 2). Likewise, ${ }^{33} \mathrm{P}$ ester $\mathrm{V}_{\max }$ for the microbial community was also similar (within the same order of magnitude) to the APA. There were very few stations where both the APA and the $\mathrm{V}_{\max }$ of ${ }^{33} \mathrm{P}$ ester uptake were measured (Table 2), therefore none of the kinetic parameters were statistically significantly different from each other due to the limited dataset.

\section{Discussion}

The Sargasso Sea has previously been identified as a region where $\mathrm{P} i$ is limiting to phytoplankton growth (Wu et al. 2000; Mather et al. 2008). In this region, being able to utilize the DOP pool as a $\mathrm{P}$ source may be an important growth advantage for microbes. However, determining the bio-availability of DOP is a difficult question to address, as the bio-availability of DOP varies among, and sometimes within, a microbial taxa (Lomas et al. 2004; Moore et al. 2005). Therefore, determining the importance of DOP relative to $\mathrm{P} i$ uptake remains a challenge, but is central to understanding how $\mathrm{P}$ controls growth in this region of the ocean. By combining measurements of ${ }^{33} \mathrm{P} i$ and ${ }^{33} \mathrm{P}$ 
ester uptake and uptake kinetics and we can gain new insights into the importance of DOP to Trichodesmium, and the microbial community, in the low P Sargasso Sea.

\section{Uptake Rates}

The Chl $a$ normalized ${ }^{33} \mathrm{P} i$ uptake rate for Trichodesmium and the microbial community were variable across both transects, with no clear trend with ambient $\mathrm{P} i$ or DOP concentration. However, at each individual station the ${ }^{33} \mathrm{P} i$ uptake rate for Trichodesmium was at least an order of magnitude lower than that of the microbial community, and the proportion of total $\mathrm{P} i$ uptake for Trichodesmium was significantly lower than the community. Therefore, Trichodesmium is not taking up as much Pi per unit $\mathrm{Chl} a$ as the microbial community, and this suggests that $\mathrm{P} i$ may not be as important a $\mathrm{P}$ source for Trichodesmium as it is for the microbial community. These data are consistent with previous comparisons of Trichodesmium and the microbial community in this region, which suggest that Trichodesmium is a poor competitor for $\mathrm{P} i$ (Sohm and Capone 2006). It is important to note that heterotrophic bacteria, which do not contain Chl $a$, are present in the microbial community and associated with Trichodesmium, and therefore likely contribute to measured uptake rates. As a result, the assay and normalization approach used here and elsewhere (Sohm and Capone 2006; Sohm et al. 2008) may overestimate the uptake rates of $\mathrm{P} i$ or $\mathrm{P}$ ester in the microbial community, and Trichodesmium. Trichodesmium, in particular, is known to have tightly associated epibionts. It is not clear, however, whether the P taken up or hydrolyzed by epibionts would eventually contribute to meeting the P demand of Trichodesmium. 
Examining the percent of $\mathrm{P}$ ester uptake contribution to the total $\mathrm{P}$ uptake, allows the relative importance of $\mathrm{P}$ esters as a $\mathrm{P}$ source to be assessed for Trichodesmium, the microbial community, and different microbial taxa. This calculation also cancels out the Chl $a$ normalization and thus eliminates this confounding factor in comparing the microbial community to Trichodesmium. Given the uncertainty regarding the bioavailable $\mathrm{P}$ ester concentration, this proportion was calculated to determine the potential minimum and maximum contribution of $\mathrm{P}$ ester to total $\mathrm{P}$ uptake. Although it is known that some of the microbial populations in this region have the genetic machinery to take up phosphonate DOP (Dyhrman et al. 2006; Ilikchyan et al. 2009), phosphonate uptake should be smaller than combined $\mathrm{P} i$ and $\mathrm{P}$ ester uptake as these chemical pools are more abundant and considered more bio-available. At half of the stations, $\mathrm{P}$ ester contributed a minimum of $25 \%$ of the total $\mathrm{P}$ uptake for Trichodesmium. In contrast, there was only one station where the $\mathrm{P}$ ester contribution was greater than $25 \%$ of the total $\mathrm{P}$ uptake for the microbial community. These data underestimate the importance of $\mathrm{P}$ ester to Trichodesmium, because accounting for $\mathrm{P} i$ that is adsorbed to Trichodesmium would reduce $\mathrm{P} i$ uptake rates by roughly $16 \%$ but should not affect $\mathrm{P}$ ester uptake rates (Fu et al. 2005b; Fu et al. 2006). Taken together these results suggest that $\mathrm{P}$ esters are a major $\mathrm{P}$ source for Trichodesmium, but probably less important to the microbial community. Although, for both Trichodesmium and the microbial community, the specific contribution of $\mathrm{P}$ ester to total $\mathrm{P}$ uptake is highly dependent on the actual concentration of $\mathrm{P}$ ester that is bio-available. 
Using flow cytometry coupled with isotope incubations Casey et al. (2009) measured ${ }^{33} \mathrm{P} i$ and ${ }^{33} \mathrm{P}$-ATP (as a proxy for P ester) uptake in several other taxa including Prochlorococcus, Synechococcus, picoeukaryotes and nanoeukaryotes. Strikingly, even at the average lower limit of $\mathrm{P}$ ester contribution, $\mathrm{P}$ ester is the major (greater than an average of $50 \%$ at all stations) P source for all four of these groups. These data suggest, that like Trichodesmium, these critical phytoplankton groups heavily rely on P esters to support P demand in this system. This is consistent with culture work examining ATP uptake in Synechococcus that suggests that, at least for some strains, P ester is important to meeting $\mathrm{P}$ demand (Fu et al. 2006). At Sta. 16 on X0705, there were simultaneous measurements of Trichodesmium, microbial community, and taxon specific ${ }^{33} \mathrm{P} i$ and ${ }^{33} \mathrm{P}$ ester uptake allowing for direct comparisons. For this station, P esters were particularly important for all individual taxa, even at the lower limit of $\mathrm{P}$ ester contribution, although, the microbial community does not reflect this trend. This observation emphasizes the fact that other groups such as heterotrophic bacteria are probably contributing to the microbial community uptake measurements and are good competitors for $\mathrm{P} i$. Interestingly, Sta. 16 is one of the stations with the lowest $P i$ concentrations of $\leq 0.5 \mathrm{nmol}$ $\mathrm{L}^{-1}$. This suggests that, as one might predict, with lower $\mathrm{P} i$ concentrations $\mathrm{P}$ esters become more important to $\mathrm{P}$ uptake.

\section{Kinetics}

The average Trichodesmium $\mathrm{K}_{\mathrm{m}}$ for $\mathrm{P} i$ and $\mathrm{P}$ ester uptake were similar. Although both affinity constants are higher than the ambient $\mathrm{P}$ ester and the $\mathrm{P} i$ concentrations of the 
upper water column in this system, the $\mathrm{P} i \mathrm{~K}_{\mathrm{m}}$ is consistent with the $\mathrm{K}_{\mathrm{m}}$ measured in previous culture and field studies which ranges between $179-710 \mathrm{nmol} \mathrm{L}^{-1}$ for assays that did not remove adsorbed $\mathrm{P}$ (Table 3). These may be overestimates because the $\mathrm{K}_{\mathrm{m}}$ of $\mathrm{P} i$ uptake is reduced when surface adsorbed $\mathrm{P}$ is removed (Fu et al. 2005b). Nevertheless, the $\mathrm{K}_{\mathrm{m}}$ values detected in the field, across a range of $\mathrm{P} i$ concentrations, are consistent with previous work, which found that Trichodesmium does not alter its $\mathrm{K}_{\mathrm{m}}$ in response to P physiology, or ambient P supply (Fu et al. 2005a). Given that the concentration of DOP (and thus likely bio-available $\mathrm{P}$ ester concentration) is higher than that of $\mathrm{P} i$ in the Sargasso Sea, Trichodesmium is potentially better at taking up P ester than Pi.

Unlike the $\mathrm{K}_{\mathrm{m}}$, Trichodesmium increases its ${ }^{33} \mathrm{P} i \mathrm{~V}_{\max }$ in response to increasing $\mathrm{P}$ limitation (Fu et al. 2005a). In this study, the average $\mathrm{V}_{\max }$ of ${ }^{33} \mathrm{P} i$ uptake for Trichodesmium was nearly an order of magnitude higher than those calculated in other studies of Trichodesmium from the North Atlantic (Sohm and Capone 2006; Sohm et al. 2008) which also did not remove adsorbed $\mathrm{P}$. There are two additional studies that measured $\mathrm{V}_{\text {specific }}$ of Trichodesmium ${ }^{33} \mathrm{P} i$ uptake: Fu et al. (2005a) in culture and Moutin et al. (2005) in the South Pacific. Approximating $V_{\max }$ from those studies (Table 3) also results in lower $\mathrm{V}_{\max }$ values for Trichodesmium from the South Pacific (Moutin et al. 2005), and from $\mathrm{P}$ replete cultures ( $\mathrm{Fu}$ et al. 2005a) relative to the $\mathrm{V}_{\max }$ for ${ }^{33} \mathrm{P} i$ uptake calculated here. However, the average Pi concentration from the stations where uptake kinetics were measured in this study was much lower than that of any previous field study (4.6 nmol L $\mathrm{L}^{-1}$ vs. $45 \mathrm{nmol} \mathrm{L}{ }^{-1}$ for the second lowest $\mathrm{P} i$ concentration; Table 3). Therefore, the higher $\mathrm{V}_{\max }$ values found in this study may reflect Trichodesmium 
populations that are more P-limited than those in previous studies. Fu et al. (2005b) found that when surface adsorbed $\mathrm{P}$ was removed this reduced the $\mathrm{V}_{\max }$ for $\mathrm{P} i$ uptake by half for P-limited Trichodesmium cultures, yet a $50 \%$ reduction in the average ${ }^{33} \mathrm{P} i \mathrm{~V}_{\max }$ calculated herein would still be higher than other field studies (Table 3). This emphasizes the fact that the Trichodesmium in this study are in a particularly low $\mathrm{P} i$ system, and may be P-limited.

Comparisons of kinetic parameters between Trichodesmium and the microbial community are difficult because of the potential for differential contributions of individual taxa and heterotrophic groups. While the $\mathrm{K}_{\mathrm{m}}$ of ${ }^{33} \mathrm{P} i$ uptake for the microbial community is highly variable, the average is an order of magnitude lower than that of Trichodesmium. As was discussed previously, this suggests that Trichodesmium is a poor competitor for $\mathrm{P} i$ as compared to the microbial community. The $\mathrm{K}_{\mathrm{m}}$ of $\mathrm{P}$ ester uptake for the microbial community is similarly variable, but the average is higher than the $\mathrm{K}_{\mathrm{m}}$ of $\mathrm{P}$ ester for Trichodesmium. This suggests that Trichodesmium is a better competitor compared the microbial community for $\mathrm{P}$ ester than for $\mathrm{P} i$. This conclusion is consistent with the observations with Trichodesmium made above, and those of others made with assays of ${ }^{33} \mathrm{P} i$ alone (Sohm and Capone 2006; Sohm et al. 2008). These conclusions are also consistent with the fact that $\mathrm{P}$ ester represented $25 \%$ or more of the total $\mathrm{P}$ uptake for Trichodesmium at more stations than the microbial community.

In this study, the maximal rate of $\mathrm{P}$ ester utilization was examined in two ways; through ${ }^{33} \mathrm{P}$ ester uptake kinetics and through APA assays. APA measurements here represent the maximal rate of $\mathrm{P}$ ester hydrolysis using a model $\mathrm{P}$ ester. Whereas, the $\mathrm{V}_{\max }$ 
of ${ }^{33} \mathrm{P}$ ester uptake measures the maximal rate of $\mathrm{P}$ ester hydrolysis plus incorporation into the cell, assuming that the P ester is not directly taken up by the cell. Each of these assays uses very different model P esters. Given the inherent differences between these approaches, the resulting values were strikingly similar for both Trichodesmium and the microbial community. Together, these data are suggestive of a population that can take advantage of fluctuations in the DOP pool. But because maximal hydrolysis rates are always much higher than in situ rates, these data underscore the fact that tracer studies are excellent compliments to uptake and hydrolysis rates calculated based on APA (nontracer) alone.

\section{Growth rate}

Determining growth rates, or doubling times, for phytoplankton provides insights into how an organism is adapted to its environment, and its nutrient scavenging strategies. Previous studies have used $\mathrm{C}$ and $\mathrm{N}$ uptake in the field to estimate a Trichodesmium doubling time (Carpenter and Romans 1991; Orcutt et al. 2001). These doubling times are variable; literature values range from $0.7-2,500$ days (Orcutt et al. 2001; Moutin et al. 2005). An estimate for a rapid doubling time has been made using C uptake of roughly 2 days for Trichodesmium in the Sargasso Sea (Orcutt et al. 2001). This is similar to doubling times for Trichodesmium in culture of 2-4 days (Capone et al. 1997; Krauk et al. 2006). Using the average kinetic parameters from our study, different $\mathrm{P}$-specific doubling times can be determined at a range of $\mathrm{P} i$ and $\mathrm{P}$ ester concentrations 
by following the equation of Moutin et al. (2005) $\left(t_{d}\right)=\ln (2)\left(K_{m}+S\right)\left(24 \times V_{s p} \times S\right)^{-1}$. Where $t_{d}$ is the doubling time, $V_{s p}$ is the $V_{\max }$ divided by the P quota per colony; here the $\mathrm{P}$ quota was assumed to be $2.6 \mathrm{nmol} \mathrm{P}$ colony $^{-1}$ (Sañudo-Wilhelmy et al. 2004), and S is the substrate concentration (Table 4). It is important to note that the P quotas are from colonies without adsorbed P and are therefore a conservative estimate (Sañudo-Wilhelmy et al. 2004). Three different $\mathrm{P} i$ concentrations were used; $6 \mathrm{nmol} \mathrm{L}^{-1}$ (the average $\mathrm{P} i$ concentration for the stations where kinetic parameters were measured), 3.3, and 0.42 nmol L $\mathrm{L}^{-1}$ (based on Zubkov et al. (2007) which suggested that only 7-55\% of the $\mathrm{P} i$ concentration is bio-available). For both the 6 and $3.3 \mathrm{nmol} \mathrm{L}^{-1} \mathrm{P} i$ concentration, the doubling times are reasonable for the Sargasso Sea and roughly equivalent to the Trichodesmium doubling times calculated using C (Orcutt et al. 2001). For the P ester calculations, concentrations of 1,10 , and $36 \mathrm{nmol} \mathrm{L}^{-1}$ were used based on the possible range of bio-available $\mathrm{P}$ ester. If only $10 \mathrm{nmol} \mathrm{L}^{-1} \mathrm{P}$ ester is bio-available, then Trichodesmium can reach the same doubling time as on $6 \mathrm{nmol} \mathrm{L}^{-1}$ of $\mathrm{P} i$. Therefore, only a small portion of the DOP pool needs to be bio-available P ester to fully support Trichodesmium $\mathrm{P}$ uptake, based on these data. This is true even if the $\mathrm{P}$ quota is increased, and using a longer doubling time in this analysis only reinforces the relative importance of $\mathrm{P}$ ester compared to $\mathrm{P} i$ in this system.

Here we address the role of $\mathrm{P} i$ and $\mathrm{P}$ ester in supporting the growth of Trichodesmium, the microbial community, and draw comparisons with different phytoplankton groups. The in situ uptake rates suggest that the contribution of $\mathrm{P}$ ester to total P uptake can be greater than $25 \%$ for Trichodesmium, the microbial community, and 
key phytoplankton groups, depending on the station. The $\mathrm{P}$ ester contribution to Trichodesmium was over $25 \%$ at half of the stations examined, and further work in other systems with variable $\mathrm{P}$ chemistry would confirm if this frequency is similar in higher $\mathrm{P}$ systems, or to what extent the $\mathrm{P}$ ester uptake rate changes with ambient DOP over a larger dataset. Several studies have suggested that Trichodesmium is P-limited in the Sargasso Sea (Sañudo-Wilhelmy et al. 2001; Dyhrman et al. 2002; Mulholland et al. 2002) and the high ${ }^{33} \mathrm{P} i \mathrm{~V}_{\max }$ values found here support that conclusion. A comparison of the $\mathrm{K}_{\mathrm{m}}$ values for both ${ }^{33} \mathrm{P}_{i}$ and ${ }^{33} \mathrm{P}$ ester uptake suggests that Trichodesmium is a better competitor for $\mathrm{P}$ ester than for $\mathrm{P} i$ relative to the microbial community. This is consistent with previous work (Sohm and Capone 2006), which focused solely on $\mathrm{P} i$ uptake kinetics. Future work focused on the uptake kinetics of other individual phytoplankton taxa would help evaluate the consistency of this relationship. Additionally, this work focused on enzyme activity and uptake assays, highlights the importance of pairing tracer level experiments (which measure in situ uptake rates) to experiments where saturating concentrations of substrate are added (which measure $V_{\max }$ of enzymatic hydrolysis). Trichodesmium growth rates calculated from the ${ }^{33} \mathrm{P} i$ and ${ }^{33} \mathrm{P}$ ester uptake parameters indicate that only a small fraction of the $\mathrm{P}$ ester pool needs to be bio-available to meet $\mathrm{P}$ demand, which further supports the importance of P ester to this group in the Sargasso Sea. Taken together, these data underscore the importance of P esters to supporting production by Trichodesmium, picocyanobacteria, and small eukaryotes in the Sargasso Sea. 


\section{Acknowledgements}

We thank the Bermuda Atlantic Time-series Study (BATS) technicians and members of the Atlantic Time-series Phosphorus Process Program (ATP ${ }^{3}$ ) who have assisted in sample collection and processing, as well as the crew of the Atlantic Explorer. We also thank B. Van Mooy, L. Wurch, and E. Bertrand for insights and discussions of this data, and A. Heithoff for assistance with sample processing. This research was supported by the National Science Foundation Biological Oceanography Program through awards OCE-0453023 (M.W.L.), OCE-0451419 (S.T.D.), OCE-0452904 (J.W.A.), and the Center for Microbial Oceanography: Research and Education. 


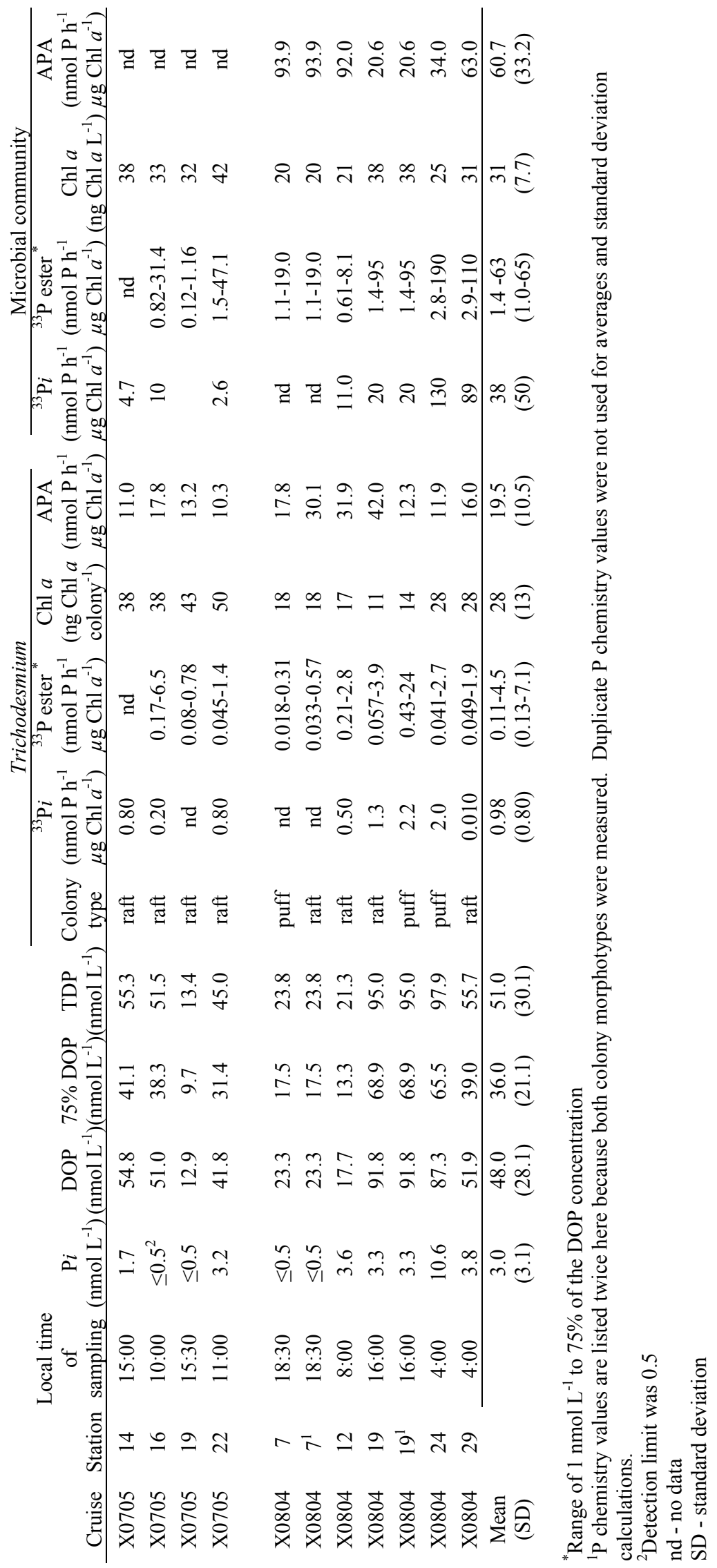




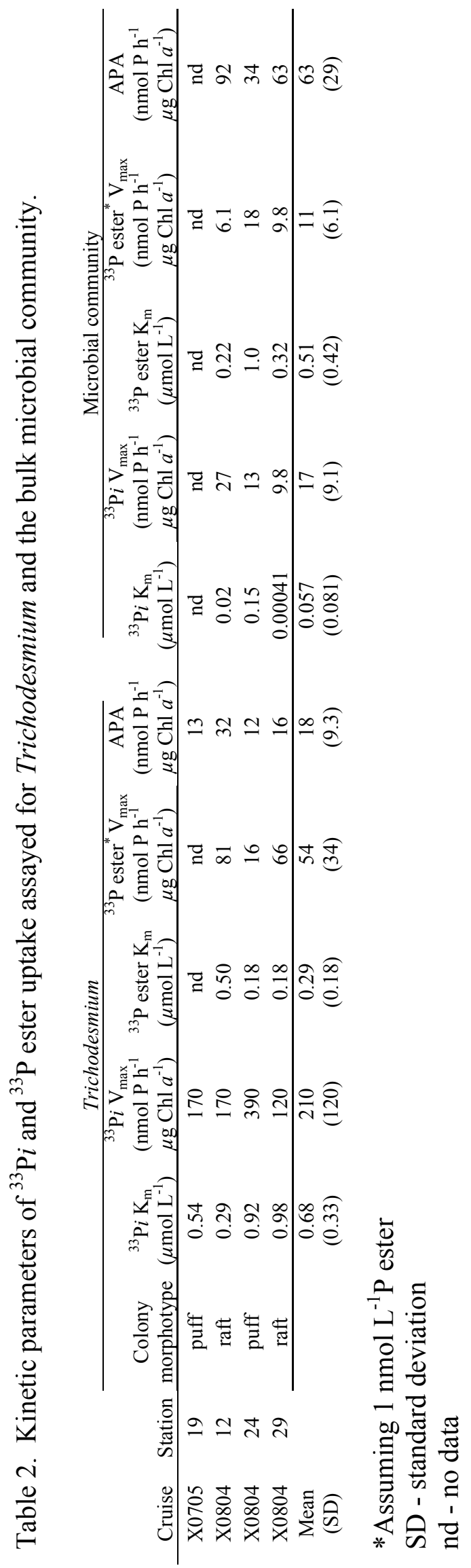


Table 3. A comparison of Trichodesmium Pi uptake kinetics and Pi concentrations in this and other studies of Trichodesmium from cultures and field populations.

\begin{tabular}{|c|c|c|c|c|c|}
\hline Source & Location & $\begin{array}{c}\mathrm{P} i \\
\left(\mathrm{nmol} \mathrm{L}{ }^{-1}\right)\end{array}$ & $\begin{array}{c}\text { Colony } \\
\text { morphotype }\end{array}$ & $\begin{array}{c}{ }^{33} \mathrm{P} i \mathrm{~K}_{\mathrm{m}} \\
\left(\mathrm{nmol} \mathrm{L}{ }^{-1}\right)\end{array}$ & $\begin{array}{c}{ }^{33} \mathrm{P} i \mathrm{~V}_{\max } \\
\left(\mathrm{nmol} \mathrm{h} \mathrm{h}^{-1} \mu \mathrm{g} \mathrm{Chl} a^{-1}\right)\end{array}$ \\
\hline This study & N. Atlantic & 4.6 & $\begin{array}{l}\text { puffs or } \\
\text { rafts }\end{array}$ & 680 & 210 \\
\hline (Sohm and Capone 2006) & N. Atlantic & 65 & mixed & 710 & 10.4 \\
\hline (Sohm et al. 2008) & N. Atlantic & 45 & mixed & 180 & 7.0 \\
\hline (Moutin et al. 2005) & S. Pacific & $\begin{array}{l}20-240 \\
\text { P-replete }\end{array}$ & $\begin{array}{l}\text { mixed } \\
\text { NA }\end{array}$ & $\begin{array}{l}630 \\
340\end{array}$ & $\begin{array}{l}3.1^{1} \\
36^{1}\end{array}$ \\
\hline (Fu et al. 2005a) & Cultures & P-limited & NA & 650 & 80 \\
\hline
\end{tabular}

NA - not applicable

${ }^{1}$ These values are derived assuming a $\mathrm{P}$ quota of 2.6 nmol per colony from SañudoWilhelmy et al. (2004) and an average Chl $a$ content per colony of $27 \mathrm{ng}$ (Table 1). 
Table 4. Trichodesmium doubling times calculated using the average ${ }^{33} \mathrm{P} i$ and ${ }^{33} \mathrm{P}$ ester kinetic parameters from Table 2, and a range of potentially bio-available $\mathrm{P}$ concentrations.

\begin{tabular}{ccc}
$\begin{array}{c}\mathrm{P} i \\
(\mathrm{nmol} \mathrm{L}\end{array}$ & $\begin{array}{c}\text { P ester } \\
\left(\mathrm{nmol} \mathrm{L}^{-1}\right)\end{array}$ & $\begin{array}{c}\text { Doubling time } \\
(\text { days })\end{array}$ \\
\hline 6 & - & 1.4 \\
3.3 & - & 2.5 \\
0.42 & - & 20 \\
- & 36 & 0.36 \\
- & 10 & 1.4 \\
- & 1 & 14
\end{tabular}




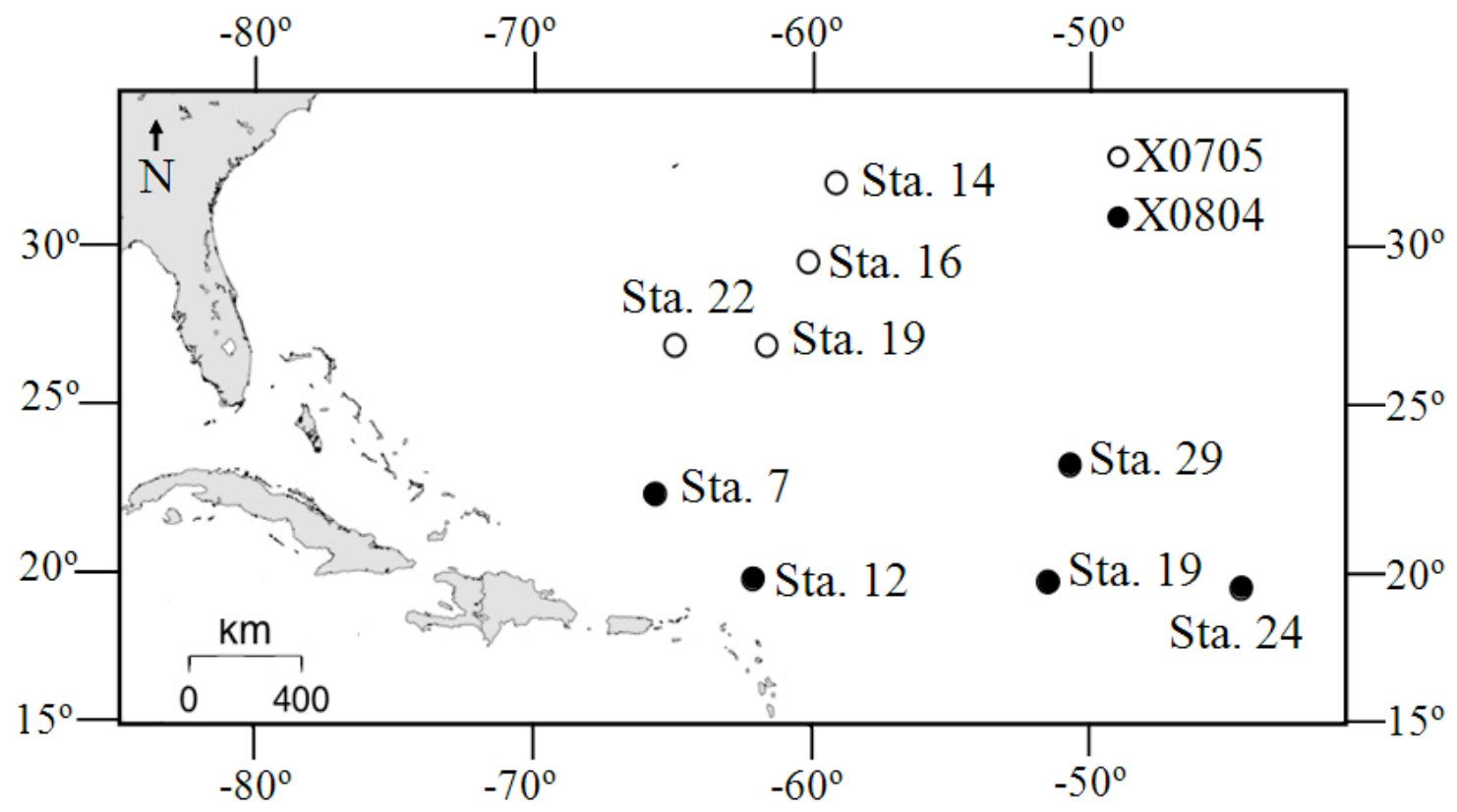

Figure 1. Station locations for two cruises to the Sargasso Sea: X0705 in June 2007 and X0804 in May 2008. 

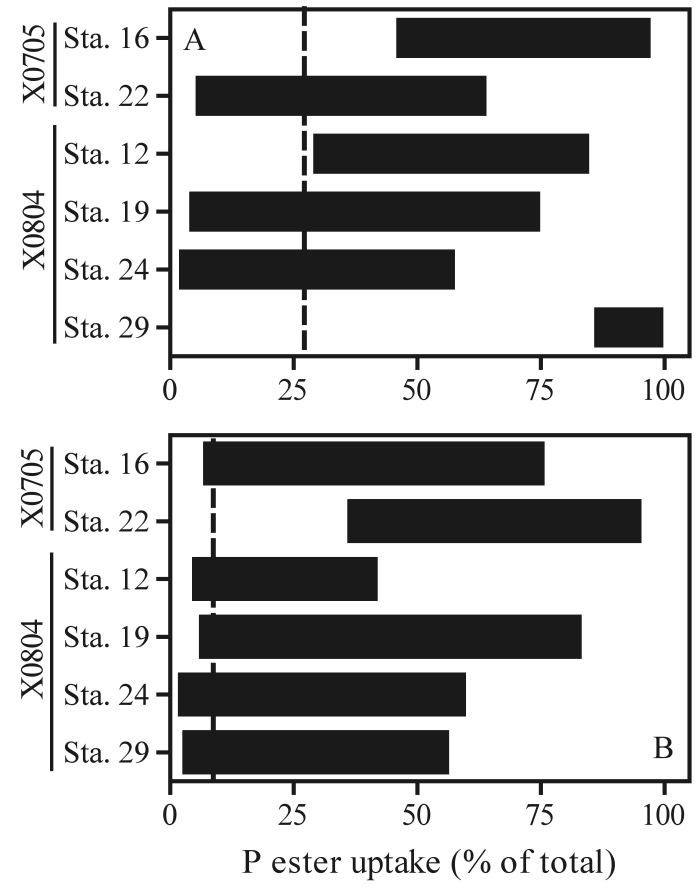

Figure 2. The estimated range of $\mathrm{P}$ ester uptake relative to total $\mathrm{P}$ uptake for (A) Trichodesmium and (B) the microbial community. The black bars span the upper and lower limits of P ester uptake, and were calculated using a lower limit of $1 \mathrm{nmol} \mathrm{L}^{-1}$ (the predicted ATP concentration) and an upper limit of $75 \%$ of the ambient DOP concentration (representing the potential $\mathrm{P}$ ester concentration). The dashed line indicates the average lower limit of $\mathrm{P}$ ester uptake relative to total $\mathrm{P}$ uptake. 
Prochlorococcus

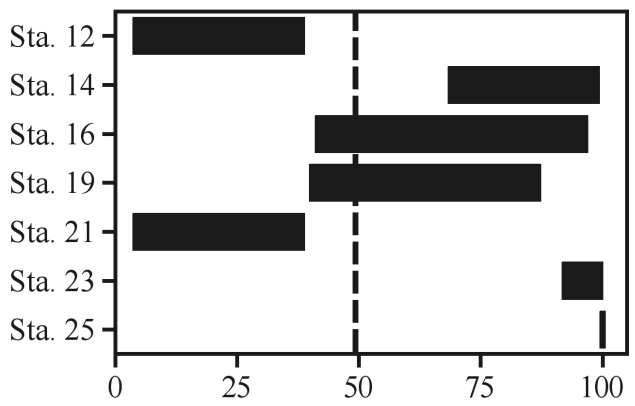

Picoeukaryotes

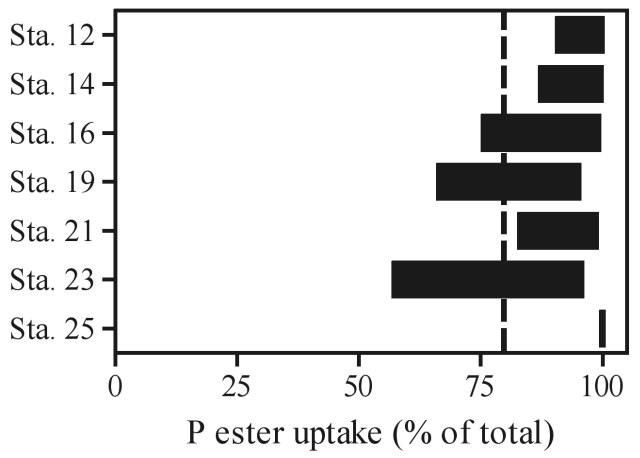

Synechococcus

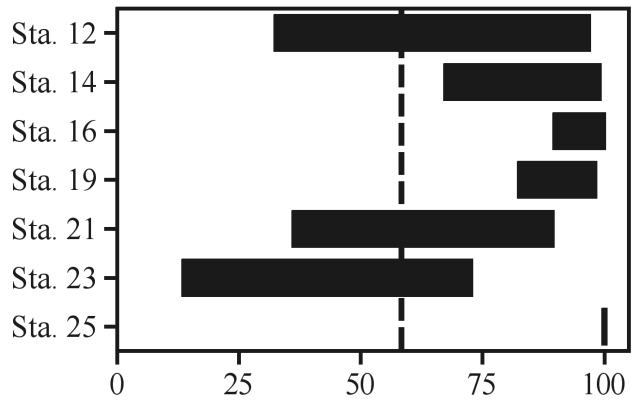

Nanoeukaryotes

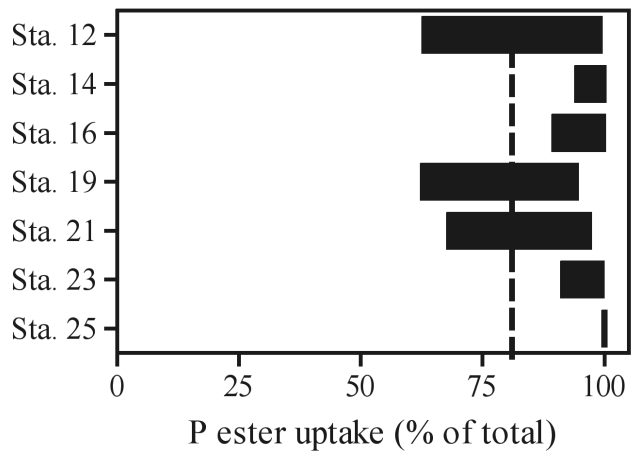

Figure 3. The estimated range of the proportion of $\mathrm{P}$ ester uptake as a function of total $\mathrm{P}$ uptake for Prochlorococcus, Synechococcus, picoeukaryotes, and nanoeukaryotes during X0705 recalculated from Casey et al. (2009). The black bars span the upper and lower limits of $\mathrm{P}$ ester uptake, and were calculated using a lower limit of $1 \mathrm{nmol} \mathrm{L}^{-1}$ (the predicted ATP concentration) and an upper limit of $75 \%$ of the ambient DOP concentration (representing the potential $\mathrm{P}$ ester concentration). The dashed line indicates the average lower limit of $\mathrm{P}$ ester uptake relative to total $\mathrm{P}$ uptake. 


\section{References}

Ammerman, J. W., R. R. Hood, D. A. Case, and J. B. Cotner. 2003. Phosphorus deficiency in the Atlantic: an emerging paradigm in oceanography. EOS 84: 165170 .

Ammerman, J., and W. B. Glover. 2000. Continuous underway measurement of microbial ectoenzyme activities in aquatic ecosystems. Mar. Ecol. Prog. Ser. 201: $1-12$.

ARAR, E. and G. COLLINS. 1997. Method 445.0 in vitro determination of chlorophyll $a$ and pheophytin $a$ in marine and freshwater algae by fluorescence. US Environmental Protection Agency, Office of Research and Development National Exposure Research Lab.

Bertilsson, S., O. Berglund, D. Karl, and S. W. Chisholm. 2003. Elemental composition of marine Prochlorococcus and Synechococcus: implications for the ecological stoichiometry of the sea. Limnol. Oceanogr. 48: 1721-1731.

Capone, D. G., J. P. Zehr, H. W. Paerl, B. Bergman, and E. Carpenter. 1997. Trichodesmium, a globally significant marine cyanobacterium. Science 276: 1221-1229.

CARPENTER, E. J., and K. M. RomAns. 1991. Major role of the cyanobacterium Trichodesmium in nutrient cycling in the North Atlantic Ocean. Science 254: 1356-1358.

Carpenter, E. J., A. Subramaniam, and D. G. Capone. 2004. Biomass and primary productivity of the cyanobacterium Trichodesmium spp. in the tropical North Atlantic Ocean. Deep-Sea Res. I 51: 173-203.

Casey, J. R., M. W. Lomas, V. K. Michelou, S. T. Dyhrman, E. D. Orchard, J. W. Ammerman, J. B. Sylvan. 2009. Phytoplankton taxon-specific orthophosphate $(\mathrm{P} i)$ and ATP utilization in the western subtropical North Atlantic. Aquat. Micro. Ecol. 58:31-44.

CAVEndar-BARES, K. K., D. M. KARL, and S. W. Chisholm. 2001. Nutrient gradients in the western North Atlantic Ocean: relationship to microbial community structure and comparison to patterns in the Pacific Ocean. Deep-Sea Res. I 48: 2373-2395.

Clark, L. L., E. D. IngALL, and R. BENNER. 1998. Marine phosphorus is selectively remineralized. Nature 393: 426. 
DyHRMAN, S., and K. C. RUTTENBERG. 2006. Presence and regulation of alkaline phosphatase activity in eukaryotic phytoplankton from the coastal ocean: Implications for dissolved organic phosphorus remineralization. Limnol. Oceanogr. 51: 1381-1390.

Dyhrman, S. T., P. D. Chappell, S. T. Haley, J. W. Moffett, E. D. Orchard, J. B. WATERBURY, and E. A. WeBB. 2006. Phosphonate utilization by the globally important marine diazotroph Trichodesmium. Nature 439: 68-71.

Dyhrman, S. T., E. A. WebB, J. W. Moffett, and J. B. Waterbury. 2002. Cell-specific detection of phosphorus stress in Trichodesmium from the western North Atlantic. Limnol. Oceanogr. 47: 1832-1836.

Fu, F.-X., Y.ZhANG, P. R. F. BeLL, and D. Hutchins. 2005a. Phosphate uptake and growth kinetics of Trichodesmium (cyanobacteria) isolates from the North Atlantic ocean and the Great Barrier Reef, Australia. J. Phycol. 41: 62-73.

Fu, F.-X., Y. Zhang, K. Lebanc, S. A. SAÑUdo-Wilhelmy, D. A. Hutchins. 2005b. The biological and biogeochemical consequences of phosphate scavenging onto phytoplankton cell surfaces. Limnol. Oceanogr. 50:1459-1472.

Fu, F.-X., Y. Zhang, Y. Feng, D. A. Hutchins, 2006. Phosphate and ATP uptake and growth kinetics in axenic cultures of the cyanobacterium Synechococcus CCMP 1334. Eur. J. Phycol. 41: 15-28.

ILIKCHYAN, I., M. L. McKAY, J. P. ZeHR, S. T. DyHRMAN, and G. S. BuLleRJAhN. 2009. Detection and expression of the phosphonate transporter gene $p h n D$ in marine and freshwater picocyanobacteria. Environ. Microbiol. 11: 1314-1324.

KARL, D., and K. M. BJÖRKMAN. 2001. Phosphorus cycle in seawater: dissolved and particulate pool inventories and selected phosphorus fluxes, p. 249-366. In J. H. Paul [ed.], Marine microbiology. Academic Press.

KARL, D. 2002. Nutrient dynamics in the deep blue sea. Trends Microbiol. 10: 410-418.

KARL, D. M., and G. TIEN. 1992. MAGIC: A sensitive and precise method for measuring dissolved phosphorus in aquatic environments. Limnol. Oceanogr. 37: 105-116.

Krauk, J., T. A. Villareal, J. A. Sohm, J. P. Montoya, and D. G. Capone. 2006. Plasticity of N:P ratios in laboratory and field populations of Trichodesmium spp. Aquat. Microb. Ecol. 42: 243-253. 
Lomas, M. W., A. L. Burke, D. A. Lomas, D. W. Bell, C. Shen, S. T. Dyhrman, J. W. AMMERMAN. 2009. Sargasso Sea phosphorus biogeochemistry: an important role for dissolved organic phosphorus (DOP). Biogeosciences Discussions. 6: 1013710175.

Lomas, M. W., A. Swain, R. Schelton, and J. Ammerman. 2004. Taxonomic variability of phosphorus stress in Sargasso Sea phytoplankton. Limnol. Oceanogr. 49: 2303-2310.

LONGHURST, A. 1991. Role of the marine biosphere in the global carbon cycle. Limnol. Oceanogr. 36: 1507-1526.

Maranon, E., M. J. Behrenfield, N. GonZalez, B. Mourino, and M. ZubKov. 2003. High variability of primary production in oligotrophic waters of the Atlantic Ocean: uncoupling from phytoplankton biomass and size structure. Mar. Ecol. Prog. Ser. 257: 1-11.

Mather, R. L., S. E. Reynolds, G. A. WolfF, R. G. Williams, S. Torres-Valdes, E. M. S. WoOdWARD, A. LANDOlfi, X. PAN, R. SANDERS, and E. ACHTERBERG. 2008. Phosphorus cycling in the North and South Atlantic Ocean subtropical gyres. Nature Geosci. 1: 439-443.

Moore, L. R., M. Ostrowski, D. J. Scanlan, K. Feren, and T. SweEtsiR. 2005. Ecotypic variation in phosphorus-acquisition mechanisms within picocyanobacteria. Aquat. Microb. Ecol. 39: 257-269.

Moutin, T., N. Van Den Broeck, B. Beker, C. Dupouy, P. Rimmelin, and A. BOUTEILLER. 2005. Phosphate availability controls Trichodesmium spp. biomass in the SW Pacific Ocean. Mar. Ecol. Prog. Ser. 297: 15-21.

Mulholland, M. R., P. W. Bernhardt, C. Heil, D. Bronk, and J. O'Neil. 2006. Nitrogen fixation and release of fixed nitrogen by Trichodesmium spp, in the Gulf of Mexico. Limnol. Oceanogr. 51: 1762-1776.

Mulholland, M. R., S. Floge, E. Carpenter, and D. Capone. 2002. Phosphorus dynamics in cultures and natural populations of Trichodesmium spp. Mar. Ecol. Prog. Ser. 239: 45-55.

Orcutt, K. M., F. Lipschultz, K. Gundersen, R. Arimoto, A. Michaels, A. KnaP, and J. R. GALLON. 2001. A seasonal study of the significance of $\mathrm{N}_{2}$ fixation by Trichodesmium spp. at the Bermuda Atlantic Time-series Study (BATS) site. Deep-Sea Res. II 48: 1583-1608. 
Sañudo-Wilhelmy, S. A., A. B. Kustka, C. J. Gobler, D. A. Hutchins, M. Yang, K. LwizA, J. Burns, D. G. CAPone, J. A. RAVEn, and E. J. CARPenter. 2001. Phosphorus limitation of nitrogen fixation by Trichodesmium in the Central Atlantic Ocean. Nature 411: 66-69.

Sañudo-Wilhelmy, S. A., A. Tovar-Sanchez, F. X. Fu, D. G. Capone, E. J. CARPENTER, and D. A. HutCHINS. 2004. The impact of surface-adsorbed phosphorus on phytoplankton Redfield stoichiometry. Nature 432: 897-901.

SoHM, J. A., and D. G. CAPONE. 2006. Phosphorus dynamics of the tropical and subtropical north Atlantic: Trichodesmium spp. versus bulk plankton. Mar. Ecol. Prog. Ser. 317: 21-28.

Sohm, J. A., C. MAhAFFeY, and D. G. CAPONE. 2008. Assessment of relative phosphorus limitation of Trichodesmium spp. in the North Pacific, North Atlantic, and the north coast of Australia. Limnol. Oceanogr. 53: 2495-2502.

VALDERRAMA, J. C. 1981. The simultaneous analysis of total nitrogen and total phosphorus in natural waters. Mar. Chem. 10: 109-122.

Vershinina, O. A., and L. V. ZnAmenskaia. 2002. The Pho regulons of bacteria. Mikrobiologia 71: 581-595.

WebB, E., R. W. Jakuba, J. W. Moffett, and S. Dyhrman. 2007. Molecular assessment of phosphorus and iron physiology in Trichodesmium populations from the Western Central and Western South Atlantic. Limnol. Oceanogr. 52: 2221-2232.

Wu, J., W. Sunda, E. A. Boyle, and D. M. KarL. 2000. Phosphate depletion in the western North Atlantic Ocean. Science 289: 759-762.

Zubkov, M., I. Mary, E. Malcolm, S. Woodward, P. WArwick, B. Fuchs, D. SCANLAN, and P. BURKKILL. 2007. Microbial control of phosphate in the nutrientdepleted North Atlantic subtropical gyre. Environ. Microbiol. 9: 2079-2089. 
CHAPTER THREE

\title{
Polyphosphate in Trichodesmium From the Low Phosphorus Sargasso Sea
}

\author{
Elizabeth D. Orchard ${ }^{1}$ \\ Claudia R. Benitez-Nelson ${ }^{2}$ \\ Perry J. Pellechia ${ }^{3}$ \\ Michael W. Lomas ${ }^{4}$ \\ Sonya T. Dyhrman ${ }^{5}$
}

${ }^{1}$ MIT-WHOI Joint Program in Oceanography/Applied Ocean Science and Engineering

${ }^{2}$ Department of Earth and Ocean Sciences and Marine Sciences Program, University of South Carolina

${ }^{3}$ Department of Chemistry, University of South Carolina

${ }^{4}$ Bermuda Institute of Ocean Sciences

${ }^{5}$ Biology Department, Woods Hole Oceanographic Institution 


\section{Abstract}

Polyphosphate (polyP), linear chains of three or more phosphate residues, is often considered to be the product of luxury uptake in areas of excess phosphorus (P). However, polyP can also accumulate in P-depleted cells in response to pulsed $\mathrm{P}$ resupply. As such, the ability to synthesize and degrade polyP may be a key adaptation to survive in environments, like the oligotrophic oceans, with a variable P supply. To test the hypothesis that polyP is present in phytoplankton from oligotrophic systems, the marine diazotroph, Trichodesmium was collected from the low $\mathrm{P}$ surface waters of the Sargasso Sea and assayed with solid-state ${ }^{31} \mathrm{P}$ nuclear magnetic resonance (NMR) spectroscopy. In this system, up to $25 \%$ of Trichodesmium cellular phosphorus was characterized as polyP, despite physiological data that indicated the colonies were $\mathrm{P}$ deplete. These data are consistent with culture studies, which underscore that all Trichodesmium species have the genetic machinery to produce polyP, and that allocation of $\mathrm{P}$ to polyP increases under $\mathrm{P}$ deplete conditions relative to $\mathrm{P}$ replete conditions. Trends in the amount of Trichodesmium polyP along the cruise transect, show that allocation of $\mathrm{P}$ to polyP is consistently high, and that the ratio of polyP:C varies in response to changes in temperature and mixed layer depth. We hypothesize that Trichodesmium is taking advantage of fluxes in $\mathrm{P}$ supply, and that polyP is a physiological fingerprint of this variability. Additionally, if polyP formation is a common trait in phytoplankton, these data suggest that polyP released from cells is an additional bio-available component of the dissolved organic phosphorus pool. Taken together, this study highlights the importance of polyP to $\mathrm{P}$ cycling and cellular $\mathrm{P}$ allocation even in oligotrophic regions. 


\section{Introduction}

Inorganic polyphosphate (polyP) is a polymer of phosphate ranging in length from 3-1000's of groups. PolyP synthesis and catabolism are typically controlled by a gene $(p p K)$ encoding a polyphosphate kinase that reversibly adds phosphate to the end of the polyP chain (Tzeng and Kornberg 1998), and a gene ( $p p X)$ encoding an exopolyphosphatase that removes the terminal phosphate from a polyP molecule (Akiyama et al. 1993). PolyP has been found in all major groups of life examined to date, but its function is varied, and in many regards remains unclear (Kornberg et al. 1999). Accumulation of cellular polyP has been variously attributed to a stationary phase adaptation, an energy storage compound, an osmotic regulator, a buffer against alkali conditions, a factor in DNA competency (as part of a DNA channel), and in intracellular phosphorus (P) storage (Kornberg 1995; Kornberg et al. 1999). It is the link between polyP and phosphate storage that has driven research on polyP dynamics as a function of microbial P physiology.

There are two basic processes that have been studied involving polyP formation in bacteria in response to $\mathrm{P}$. The first, termed luxury uptake, is the storage of $\mathrm{P}$ as polyP when $\mathrm{P}$ is consistently in excess relative to other macronutrients like nitrogen (e.g., growth is not $\mathrm{P}$ controlled) and uptake exceeds instantaneous growth demands. Luxury uptake has been extensively studied in waste water treatment applications (Crocetti et al. 2000), and in marine and freshwater phytoplankton culture experiments (e.g., Bertilsson et al. 2003; Diaz et al. 2008). Luxury uptake could thus drive the accumulation of polyP in coastal systems or areas where $\mathrm{P}$ is in excess relative to nitrogen. Second, and 
fundamentally distinct from luxury uptake, is the overplus response, where P deplete cells accumulate polyP in response to short term pulses in P supply (Bolier et al. 1992; Jacobson and Halmann 1982). The overplus response is not well studied in marine phytoplankton, or marine systems in general, but it has been hypothesized that overplus could drive the cellular accumulation of polyP in low $\mathrm{P}$ systems where phytoplankton are $\mathrm{P}$ deficient, but experience short term variations in their local P environment (Karl and Björkman 2001).

Several different taxa of marine phytoplankton are known to accumulate polyP, including Skeletonema, Thalassiosira, Synechocystis, Nostoc, Calothrix (Diaz et al. 2008; Mateo et al. 2006) and Trichodesmium, a nitrogen-fixing marine cyanobacteria (Romans et al. 1994). Putative genes involved in polyP synthesis and degradation also appear to be present, and expressed, in a number of both eukaryotic (Dyhrman et al. 2006b) and prokaryotic phytoplankton (Gomez-Garcia et al. 2003; Martiny et al. 2006; Hewson et al. 2009). Taken together, these observations suggest that many phytoplankton produce and degrade polyP, but despite its potential significance to $\mathrm{P}$ physiology, and $\mathrm{P}$ cycling, there are only a few studies that have assayed polyP accumulation in a marine setting (Diaz et al. 2008; Romans et al. 1994). Furthermore, the presence of phytoplankton polyP has never been examined in a chronically low P environment, such as the Sargasso Sea.

In this study, Trichodesmium near-surface populations from the Sargasso Sea were assayed with solid-state ${ }^{31} \mathrm{P}$ nuclear magnetic resonance (NMR) spectroscopy to examine cellular allocation of $\mathrm{P}$ as polyP in an oligotrophic system. Results are 
compared to culture data, and co-varying field parameters, to examine potential drivers of intracellular polyP dynamics.

\section{Methods}

\section{Culture Conditions}

Trichodesmium cultures were grown in RMP medium with Sargasso seawater as previously described (Webb et al. 2001). Species examined include Trichodesmium erythraeum IMS101, T. tenue Z-1, T. thiebautii II-3, and T. spiralis KAT, T. spp. H9-4 obtained from the culture collection of Dr. John Waterbury at the Woods Hole Oceanographic Institution. All cultures were unialgal but not axenic. Cultures were grown at $25^{\circ} \mathrm{C}$ on a shaker table with daily cycles that consisted of $1 \mathrm{hr}$ at $13.5 \mu \mathrm{E} \mathrm{m}^{-2} \mathrm{~s}^{-1}$, $10 \mathrm{~h}$ at $33.7 \mu \mathrm{E} \mathrm{m}^{-2} \mathrm{~s}^{-1}, 1 \mathrm{~h}$ at $13.5 \mu \mathrm{E} \mathrm{m}^{-2} \mathrm{~s}^{-1}$, and $12 \mathrm{~h}$ of dark. Chlorophyll $a$ fluorescence was monitored using an aquaflor fluorometer (Turner Designs). $T$. erythraeum IMS101was grown with (+P) and without (-P) $16 \mu \mathrm{mol} \mathrm{L}^{-1}$ phosphoric acid added to the media and samples were taken for particulate carbon $(\mathrm{C})$, nitrogen $(\mathrm{N})$ and $\mathrm{P}$ as well as for solid-state ${ }^{31}$ P NMR spectroscopy (see below) throughout the experiments.

\section{Field Samples}

Samples were collected during a transect of the Sargasso Sea in May 2006 (Fig. 1). Trichodesmium colonies were collected from the near surface (roughly within the top 20 m) using a hand held $130 \mu \mathrm{m}$ net. Colonies were not sorted by morphology, but the puff 
morphology was typically most abundant. Single colonies were picked into $0.2 \mu \mathrm{m}$ filtered local surface seawater, and then transferred into fresh $0.2 \mu \mathrm{m}$-filtered water to reduce contamination of closely associated organisms. Colonies were then separated for further analyses as indicated below.

\section{${ }^{31}$ P NMR spectroscopy}

Colonies from the field (approximately 100) or Trichodesmium cultures were filtered onto a $47 \mathrm{~mm} 5 \mu \mathrm{m}$ polycarbonate filter. Filters were dried at $65^{\circ} \mathrm{C}$ prior to analysis, according to conditions empirically validated in other work (Benitez-Nelson et al. 2004).

Solid-state ${ }^{31} \mathrm{P}$ NMR spectra were recorded on a Varian Inova 500 spectrometer operating at $202.489 \mathrm{MHz}$ using a Doty Scientific $4 \mathrm{~mm} / \mathrm{XC}$ magic angle spinning (MAS) probe. Bloch decays of $50 \mathrm{~ms}$ were collected with a $200 \mathrm{ppm}$ window after 30 degree excitation pulses. Two pulse phase modulation (Mcgeorge et al. 1999) proton dipolar decoupling with a field strength of $45 \mathrm{kHz}$ was applied during acquisition, and a MAS speed of 10 $\mathrm{kHz}$ was used. Spectra were fit with 5 Lorentzian lines to determine the relative ratio of the species (polyP $=-23 \mathrm{ppm}$ ). The percentage of total $\mathrm{P}$ as polyP was determined from the signal at -23 ppm (Fig. 2). This is likely to be a minimum measurement given the assumption that all polyP has a peak signal at $-23 \mathrm{ppm}$. Results are reported as a \%polyP of total $\mathrm{P}$ or as the polyP:C. The later value was determined as the fraction polyP of total $\mathrm{P}$ multiplied by the ratio of total P:C in the sample to account for changes in the absolute amount of $\mathrm{P}$ in the sample due to variations in colony size or $\mathrm{P}$ quota. The \%polyP values reported have an error of $\pm 5 \%$, similar to solid-state ${ }^{31} \mathrm{P}$ NMR studies in other 
systems (Diaz et al. 2008).

\section{Alkaline Phosphatase Activity (APA)}

For Trichodesmium APA assays, 3-5 colonies were filtered onto a $5 \mu \mathrm{m}$ polycarbonate filter. Samples were processed as described elsewhere (Dyhrman and Ruttenberg 2006). Briefly, $\quad 10 \mu \mathrm{mol} \quad \mathrm{L}^{-1} \quad$ 6,8-difluoro-4-methylumbelliferyl phosphate (di-MUF-P) (Invitrogen) was added to each sample in a petri dish with artificial seawater containing no P, and fluorescence was measured on a Fluostar Optima plate reader (BMG Labtech) every 5-20 minutes for 5 time points, within the linear range of the assay. Previous kinetics experiments found the $10 \mu \mathrm{mol} \mathrm{L}^{-1}$ substrate concentration to be saturating (data not shown). Standard fluorescence curves were generated for each assay using 6,8difluoro-7-hydroxy-4-methylcoumarin (di-MUF).

\section{Chemical analyses}

For $\mathrm{C}, \mathrm{N}$ and total $\mathrm{P}$ measurements 20 Trichodesmium colonies from the field, were collected onto pre-combusted $\mathrm{GF} / \mathrm{F}$ filters and stored dried at $65^{\circ} \mathrm{C}$ in pre-combusted foil. Each filter was split for analysis of C, N, and total particulate P. C and N concentrations were measured using a Perkin Elmer 2400 CHN Element Autoanalyzer with no acid fuming (Karl et al. 1991). Total particulate P was measured as described in BenitezNelson et al. (2004). Soluble reactive phosphorus (SRP) was measured according to the MAGIC-SRP method (Karl and Tien 1992), with a detection limit of $0.5 \mathrm{nmol} \mathrm{L}^{-1}$. SRP concentrations measured here are referred to as the dissolved inorganic phosphorus (DIP) 
concentration. The total dissolved P (TDP) was processed according to the persulfate oxidation method (Valderrama 1981). Dissolved organic P (DOP) concentrations were calculated as the difference between TDP and DIP. With the methods used herein, polyP would be detected within the DOP pool (Monaghan and Ruttenberg 1999).

\section{Statistics}

Pair-wise coefficients of correlation and $p$ values were calculated between all parameters; Trichodesmium polyP:C, Trichodesmium APA, N:P ratio, C:P ratio, surface temperature, mixed layer depth, latitude, DOP and DIP concentration at $20 \mathrm{~m}$ using JMP software (SAS, Cary NC). The mixed layer depth was defined as where the temperature changed by $0.5^{\circ} \mathrm{C}$ relative to the surface. A two-tailed t-test was used to compare \%polyP among growth phases of cultured Trichodesmium and between $+\mathrm{P}$ and $-\mathrm{P}$ culture treatments.

\section{Genome annotation}

The putative $p p X$ and $p p K$ genes were identified using the Integrated Microbial Genomes (IMG) portal at the Joint Genome Institute- US Department of Energy website (http://img.jgi.doe.gov/v1.1/main.cgi) and the National Center for Biotechnology Information Genbank database (http://www.ncbi.nlm.nih.gov/), based on homology.

\section{DNA Amplification and Sequencing}

Cultures of Trichodesmium were collected by filtration onto a $5 \mu \mathrm{m}$ polycarbonate filter and stored at $-20^{\circ} \mathrm{C}$ until extraction. DNA was extracted using the Instagene Matrix (Bio- 
Rad) according to the manufacturer's instructions or as described in Ehrenreich et al. (2005). PCR primers were designed to either amplify fragments of the putative $p p X$ (F 5 , GGAATGTCCGAAAAGCGAGC 3' R 5' GCCCAAAAAGCAACCCCGTTC 3') and ppK (F 5' CGCTTTATCAAACTGATTCGTCGG 3'

R 5' CGCAAACAACAAATACCACGGAC 3') genes. Each PCR reaction consisted of a 5 min denaturation step at $95^{\circ} \mathrm{C}$, followed by 35 cycles of 1 min at $95^{\circ} \mathrm{C}, 1 \mathrm{~min}$ at $60.7^{\circ} \mathrm{C}, 1 \mathrm{~min}$ at $72^{\circ} \mathrm{C}$ and a final extension of $10 \mathrm{~min}$ at $72^{\circ} \mathrm{C}$, in a Bio-Rad iCycler. PCR amplification was done using $0.5 \mu \mathrm{L}$ iTaq DNA polymerase (Bio-Rad, Hercules, CA), $2.5 \mu \mathrm{L}$ of DNA template, $2.5 \mu \mathrm{L}$ of $2 \mathrm{mM}$ dNTP, $2.5 \mu \mathrm{L}$ of $5 \mathrm{x}$ iTaq buffer, $50 \mathrm{pmol}$ of each primer, and sterile water to a final volume of $25 \mu \mathrm{L}$. PCR products were gel extracted using the QIAquick gel extraction kit (Qiagen), and direct sequenced at the MWG Biotech facility or at the University of Maine, according to the facility's protocols. Sequences were edited using Sequencher (Gene Codes Inc.) and verified manually. Alignments were done in MacVector. The sequences have been deposited in Genbank (Accession\# GU299287-GU299292).

\section{Results}

\section{Genes}

T. erythraeum has gene homologs for a $p p K$, and for $p p X$. The genes are not contiguous, and do not appear to be downstream of a Pho box P regulatory sequence (Su et al. 2007), although previous work has highlighted that there may be heterogeneity in the Trichodesmium Pho box sequence (Orchard et al. 2009). All species of Trichodesmium 
tested (T. erythraeum, T. spiralis, T. tenue, and T. thiebautii) had $p p K$ and $p p X$. For these species over the sequenced 156 base pair fragment, $p p K$ was $88-93 \%$ identical at the nucleotide level, and the sequenced 223 base pair fragment of $p p X$ was $93-100 \%$ identical at the nucleotide level.

\section{Culture experiments}

Multiple Trichodesmium species had detectable polyP. The maximum \%polyP that was measured in P replete cultures was $12 \%$ for $T$. tenue, $14 \%$ for $T$. spp. H9-4, 19\% for $T$. thiebauttii and 22\% for T. erythraeum. The \%polyP in P replete T. erythraeum IMS101 cultures was significantly lower in log phase, than in stationary phase (Table 1). The \%polyP in log phase P replete cultures (cultures with a C:P ratio less than 200) was significantly lower than $\log$ phase $\mathrm{P}$ deplete cultures (grown with no added $\mathrm{P}$ and with a C:P ratio greater than 200) (Table 1).

\section{Field data}

The surface temperature increased with decreasing latitude from north to south increasing from $24.6^{\circ} \mathrm{C}$ to $27.7^{\circ} \mathrm{C}$ (Table 2). The mixed layer depth generally shoaled in the more southern latitudes decreasing from a maximum of $32 \mathrm{~m}$ to a minimum of $13 \mathrm{~m}$ (Table 2). DIP and DOP concentrations at $20 \mathrm{~m}$ were relatively constant along the cruise transect, ranging from $0.5 \mathrm{nmol} \mathrm{L}-1-3.0 \mathrm{nmol} \mathrm{L}{ }^{-1}$ and $22.9 \mathrm{nmol} \mathrm{L}-46.8 \mathrm{nmol} \mathrm{L}^{-1}$ respectively, and with no clear trend from north to south (Table 2). The average Trichodesmium C:P ratio and $\mathrm{N}: \mathrm{P}$ ratio were above the Redfield ratio of $106: 1$ and $16: 1$ respectively and 
Trichodesmium APA ranged from $0.23-0.97$ nmol $\mathrm{P} \mathrm{hr}^{-1}$ colony ${ }^{-1}$. None of these potential metrics of $\mathrm{P}$ physiology showed a consistent trend on the north to south transect (Table 2), or a significant correlation to other environmental parameters. However, these metrics of $\mathrm{P}$ physiology were consistently in the range of what would be considered evidence of P depletion from other studies (Krauk et al. 2006; White et al. 2006b).

In field-collected Trichodesmium colonies, \%polyP ranged from $8-25 \%$ of the total $\mathrm{P}$ as detected with solid-state ${ }^{31} \mathrm{P}$ NMR spectroscopy (Table 2). The polyP normalized between stations as the polyP:C ratio, was significantly correlated with temperature, latitude, and mixed layer depth (Table 2). There was no significant correlation between Trichodesmium polyP:C and DOP, DIP concentration, Trichodesmium N:P ratio, or Trichodesmium APA. There was also no significant correlation between APA and DIP concentration, $\mathrm{C}: \mathrm{P}$ ratio or $\mathrm{N}: \mathrm{P}$ ratio.

\section{Discussion}

Storage of cellular $\mathrm{P}$ as polyP, is considered an important aspect of microbial $\mathrm{P}$ physiology, and could influence P cycling in aquatic systems. However, there are very few studies that have examined polyP in marine phytoplankton, and none have examined polyP accumulation in low $\mathrm{P}$ oligotrophic systems. Others have hypothesized that phytoplankton polyP could accumulate in phytoplankton from oligotrophic low $\mathrm{P}$ regions as part of an overplus type response (Karl and Björkman 2001). To address this hypothesis we examined polyP in Trichodesmium cultures and in field populations from the Sargasso Sea. 


\section{PolyP dynamics in culture}

All of the Trichodesmium species tested in culture have the genetic machinery to produce and degrade polyP. This is consistent with solid-state ${ }^{31} \mathrm{P}$ NMR data that detected polyP in $\mathrm{P}$ replete cultures of Trichodesmium, with maximal polyP percentages that were similar among species. These data suggest that the polyP dynamics observed in T. erythraeum IMS101 are likely representative of the other species, although this warrants further study. The solid-state ${ }^{31} \mathrm{P}$ NMR method is non-destructive and can provide data on $\mathrm{P}$ allocation patterns that is complimentary to other approaches that have detected polyP accumulated in granules in Trichodesmium populations from the Caribbean Sea using electron microscopy (Romans et al. 1994).

Under P replete conditions T. erythraeum IMS101 had the highest \%polyP of total cellular P during stationary phase. In fact, polyP was often below the detection limit in P replete log phase cultures. This is consistent with the hypothesis that polyP is important for survival in stationary phase or that polyP is accumulating in response to general stress (Rao and Kornberg 1996; Kornberg and Ault-Riche 1999). Luxury uptake may also be occurring in these cultures, but luxury $\mathrm{P}$ is either not being stored as polyP or is below the detection limit for this assay. These results contrast with those from $\mathrm{P}$ deplete cultures, where log phase P deplete samples had significantly higher percentages of polyP relative to $\log$ phase $\mathrm{P}$ replete samples. This could be the result of an overplus-like response. Because DIP was not re-fed to $\mathrm{P}$ deplete cells this is not entirely consistent with traditional definitions of the overplus response. However, upon becoming $\mathrm{P}$ deplete $T$. 
erythraeum up-regulates a suite of genes encoding enzymes to access $\mathrm{P}$ from DOP (Dyhrman et al. 2006a; Orchard et al. 2009). These cultures were grown on Sargasso Sea water containing DOP, and cells would have been able to access a new source of $\mathrm{P}$ upon DIP depletion. This DOP access and utilization might have resulted in an overplus like accumulation of polyP. This could be analogous to what could happen in P deplete oligotrophic systems where cells experience variation in the P supply while switching between growth on low concentration DIP, to growth on comparatively higher concentrations of DOP.

\section{PolyP dynamics in the Sargasso Sea}

PolyP accumulation in phytoplankton has previously been observed in the coastal zone and eutrophic lakes, and in these regions polyP accumulation was generally attributed to luxury uptake of P (Diaz et al. 2008; Schelske and Sicko-Goad 1990). In the oligotrophic Sargasso Sea polyP was between $8-25 \%$ of the total cellular $\mathrm{P}$ in

Trichodesmium despite the low DIP concentrations in this area $\left(<5 \mathrm{nmol} \mathrm{L}^{-1}\right)$. These data are striking in that they demonstrate that even in low $\mathrm{P}$ regions some phytoplankton sequester a significant proportion of their $\mathrm{P}$ as polyP. These field data are consistent with the culture results that highlight the allocation of $\mathrm{P}$ to polyP can be elevated in $\mathrm{P}$ deplete Trichodesmium.

Unlike the other marine systems that have been examined (e.g. Carribean; Romans e al. 1994), the presence of high percentages of polyP in Trichodesmium from the Sargasso Sea is unlikely to be due to luxury uptake. Evidence from culture studies 
suggest Trichodesmium may be capable of luxury uptake (White et al. 2006b), but elevated N:P, C:P, and APA (metrics of P deficiency) in this study and others from the region suggest that Trichodesmium populations are P deficient (Dyhrman et al. 2002; Mulholland et al. 2002; Sohm et al. 2008). Luxury uptake is probably not a driving factor for polyP accumulation in either Trichodesmium or other P deficient phytoplankton from low P oligotrophic regimes.

Trichodesmium is unique relative to some other phytoplankton in that some species can regulate buoyancy. It has been hypothesized that this organism may migrate to the phosphocline, store $\mathrm{P}$ as polyP, and return to the surface in a process termed $\mathrm{P}$ mining (Villareal and Carpenter 2003). Although this could result in elevated polyP, the phosphocline ranged from $160-300 \mathrm{~m}$ on this transect which is deeper than Trichodesmium is likely to be able to migrate (White et al. 2006a), and deeper than Trichodesmium was observed in this region (Davis and McGillicuddy 2006; Orcutt et al. 2001). Additionally, a study from the Caribbean found that polyP granules in Trichodesmium were more abundant in negatively buoyant colonies than in positively buoyant colonies; a trend opposite of that expected if P-mining were occurring (Romans et al. 1994). These factors suggest that P-mining is not driving the high percentages of polyP observed in Trichodesmium from the Sargasso Sea.

In the field, Trichodesmium may increase allocation of $\mathrm{P}$ to polyP due to an overplus-like response upon up-regulating genes involved in DOP acquisition, or experiencing a change in $\mathrm{P}$ supply in an already $\mathrm{P}$ deficient population. There is the additional possibility that in the environment Trichodesmium colonies are encountering 
micro-scale variability in $\mathrm{P}$ availability, and thus constantly experiencing fluxes in $\mathrm{P}$ supply. These micro-scale fluctuations in P at the single cell or colony level are not captured by traditional bulk chemical sampling. The importance of understanding the environment of the microorganism at the nanometer or micrometer scale is increasingly appreciated (Azam and Malfatti 2007), and is likely to be crucial to understanding the nutritional physiology of phytoplankton in situ.

\section{Comparisons between PolyP and other environmental factors}

To examine how physical, chemical and physiological parameters influence polyP formation along the transect, Trichodesmium polyP:C was calculated to account for changes in the absolute quantity of polyP and total P. PolyP:C was not correlated to Trichodesmium physiology as indicated by C:P, N:P or APA activity, although, with the possible exception of Sta. 3, all samples were clearly P deplete based on these indicators. No gradient in P physiology was observed across stations that had such low DIP concentrations. PolyP:C was also not correlated to DOP or DIP concentration, and therefore polyP:C does not seem to be dependant on the standing stock concentration of P. However, the DIP and DOP concentrations were very low across the transect, and it may be that comparisons with other systems with higher DIP concentrations are necessary to resolve differences in $\mathrm{P}$ allocation as a function of $\mathrm{P}$ standing stock. APA is known to be correlated with large changes in DIP concentration in previous studies (Mulholland et al. 2002; Dyhrman and Ruttenberg 2006). However, in this study it was not, further underscoring the fact that there was not a gradient in $\mathrm{P}$ concentrations and 
Trichodesmium physiology because of the consistently low DIP concentrations. The lack of relationship is consistent with the hypothesis that micro-scale flux in $\mathrm{P}$, or shifts between DIP and DOP metabolism, in a $\mathrm{P}$ deplete environment, is driving polyP accumulation, not the overall standing stock.

There was a correlation between polyP:C and latitude and other physical parameters that co-vary with latitude such as temperature and mixed layer depth, where polyP:C was the highest at the northern end of the transect with cooler temperatures, and a deeper mixed layer. Work with other microbes found that polyP concentrations increased with heat stress, or with general stress (Kornberg et al. 1999; Seufferheld et al. 2008). In this study, polyP accumulated with decreasing temperature, which is the opposite of the previously observed pattern, but may indicate increased stress in the more northern stations, given that Trichodesmium's growth is optimum at $24-30^{\circ} \mathrm{C}$ (Breitbarth et al. 2006). Therefore, the northern most stations were at the edge of the optimal growth temperatures for Trichodesmium. Clearly many different factors can influence polyP and it would be useful to examine polyP in Trichodesmium cultures and field populations under a greater suite of conditions to determine the consistency of this trend in the field data.

\section{Impact of polyP to the biogeochemistry of the Sargasso Sea}

It remains to be determined if elevated $\mathrm{P}$ allocation to polyP is a trait common to phytoplankton in regions like the Sargasso Sea, or unique to Trichodesmium, yet this can have profound ramifications for the $\mathrm{P}$ cycle of oligotrophic systems. It is widely 
accepted that microbial phosphoesters (Ammerman et al. 2003; Benitez-Nelson 2000; Benitez-Nelson and Buesseler 1999), and potentially microbial phosphonates (Dyhrman et al. 2009) contribute to upper water column DOP and microbial polyP may also be present and dissolved in the upper water column. While polyP is an inorganic compound, known to be bioavailable to support production (Moore et al. 2005), it is often measured as DOP, and could represent a previously ignored $\mathrm{P}$ source for production in the upper water column. Diaz et al (2008) observed a similar \%polyP in phytoplankton and in DOP in a coastal region ( $7 \%$ and $11 \%$ respectively). Assuming Trichodesmium polyP accumulation is representative of Sargasso Sea phytoplankton in general, then we can extrapolate from Trichodesmium to the water column. On average in the Sargasso Sea there was $15 \%$ polyP in Trichodesmium. If the average of $49 \mathrm{nmol} \mathrm{L}^{-1} \mathrm{DOP}$ for this transect is $15 \%$ polyP, then the standing stock of polyP in the upper water column is on average $5 \mathrm{nmol} \mathrm{L}^{-1}$. This is higher than the average DIP concentration of $1.2 \mathrm{nmol} \mathrm{L}^{-1}$, and would more than double the bioavailable inorganic P supply. Further study is warranted to assay for the presence of polyP in phytoplankton and the water column of this region, given the possible importance of polyP to the $\mathrm{P}$ cycle in this and potentially other oligotrophic systems.

\section{Conclusions}

In this study, we found that Trichodesmium forms polyP in a low $\mathrm{P}$ environment (the Sargasso Sea), and that polyP can be a major component of Trichodesmium P pool. While it is unclear what exact factors induce the formation of polyP in this system, the 
data are consistent with a possible overplus-type response. It may be that Trichodesmium is taking advantage of fluxes in $\mathrm{P}$ supply, and that polyP is a physiological fingerprint of this variability. Additionally, if polyP formation is a common trait in phytoplankton, these data suggest that polyP might be an important additional bio-available component of DOP. Taken together, this study highlights the potential importance of this compound, and suggests the importance of further studies into the dynamics of polyP formation in oligotrophic systems.

\section{Acknowledgements}

We thank S. Haley, A. Heithoff, and L. Wurch for useful discussions, V. Starczak for help with statistics, R. Styles for running C, N, and P analyses, and J. Waterbury for providing stock cultures. The crew of the Atlantic Explorer and members of the Atlantic Time-series Phosphorus Process Program $\left(\mathrm{ATP}^{3}\right)$ project provided valuable assistance at sea. This research was supported by the National Science Foundation Biological Oceanography Program through awards OCE-0453023 (M.W.L.), OCE-0451419 (S.T.D.), and the Center for Microbial Oceanography: Research and Education. 
Table 1. The \%polyP detected in T. erythraeum IMS101 cultures grown on phosphorus (P) replete or $\mathrm{P}$ deplete media in different growth phases.

\begin{tabular}{llll} 
& $\begin{array}{l}\text { Log phase } \\
\text { Preplete } \\
(\mathrm{n}=8)\end{array}$ & $\begin{array}{l}\text { Stationary phase } \\
\text { P replete } \\
(\mathrm{n}=4)\end{array}$ & $\begin{array}{l}\text { Log phase } \\
\text { P deplete } \\
(\mathrm{n}=3)\end{array}$ \\
\hline mean & $0.2^{\mathrm{b}}$ & 16 & 16 \\
standard deviation $^{\mathrm{a}}$ & 0.5 & 9 & 13 \\
$p$ value $^{\mathrm{c}}$ & & $\mathbf{0 . 0 0 0 3}$ & $\mathbf{0 . 0 0 6}$
\end{tabular}

${ }^{a}$ The average C:P ratio for the $\mathrm{P}$ replete cultures was $130 \pm 35$, and was $486 \pm 201$ for the $\mathrm{P}$ deplete samples.

${ }^{\mathrm{b}}$ Each \%polyP value has a $\pm 5 \%$ error.

${ }^{\mathrm{c}}$ All samples were compared to the log phase P replete condition using a two-tailed $\mathrm{t}$ test, bold font denotes significance. 

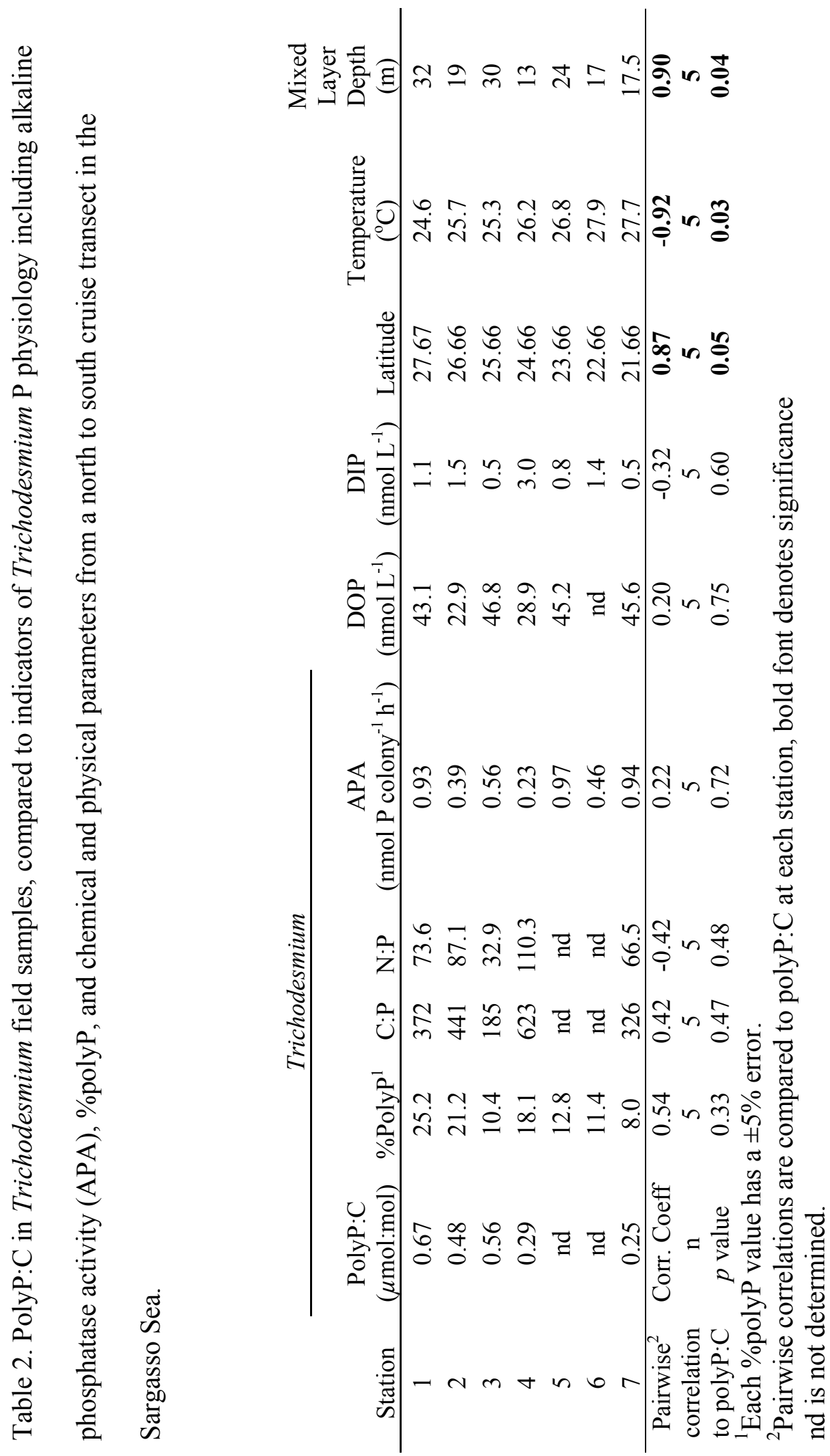


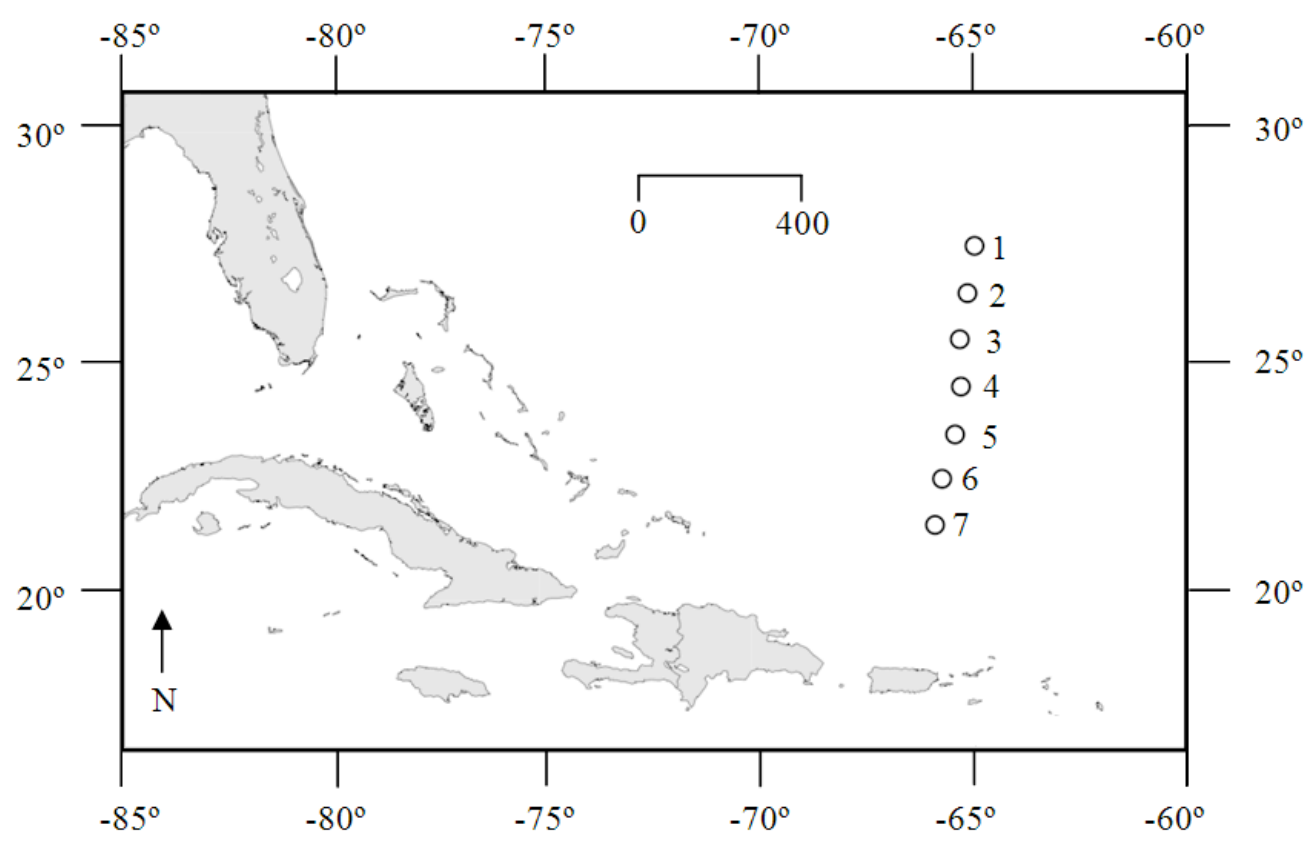

Figure 1. Station locations for a May 2006 transect from north to south in the Sargasso Sea. 


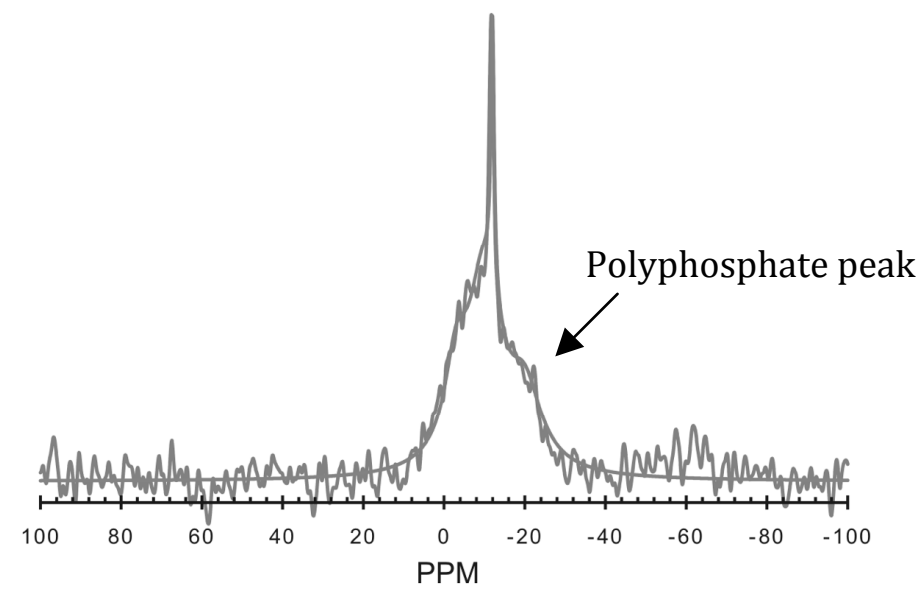

Figure 2. Representative solid-state ${ }^{31} \mathrm{P}$ NMR spectrum from Station 2 during the May 2006 cruise transect in the Sargasso Sea, the polyphosphate peak is noted at $-23 \mathrm{ppm}$. 


\section{References}

AkiYAma, M., E. Crooke, and A. KornBerg. 1993. An exopolyphosphatase of Escherichia coli, the enzyme and its $p p X$ gene in polyphosphate operon. J. Biol. Chem. 268: 633-639.

Ammerman, Hood, CASE, and Cotner. 2003. Phosphorous deficiency in the Atlantic: an emerging paradigm in oceanography. EOS 84: 165.

AzAm, F., and F. MALFATTI. 2007. Microbial structuring of marine ecosystems. Nature Reviews Microbiology 5: 782-791.

BeniteZ-Nelson, C. R. 2000. The biogeochemical cycling of phosphorus in marine systems. Earth-Science Reviews 51: 109-135.

Benitez-Nelson, C. R., and K. O. Buesseler. 1999. Variability of inorganic and organic phosphorus turnover rates in the coastal ocean. Nature 398: 502-505.

Benitez-Nelson, C. R., L. P. O' Neill, L. C. Kolowith, P. Pellechia, and R. C. THUNELL. 2004. Phosphonates and particulate organic phosphorus cycling in an anoxic marine basin. Limnol. Oceanogr. 49: 1593-1604.

Bertilsson, S., O. Berglund, D. Karl, and S. W. Chisholm. 2003. Elemental composition of marine Prochlorococcus and Synechococcus: Implications for the ecological stoichiometry of the sea. Limnol. Oceanogr. 48: 1721-1731.

Bolier, G., C. J. DE Koningh, J. C. Schmale, and M. Donze. 1992. Differential luxury phosphate response of planktonic algae to phosphorus removal. Hydrobiologia 243/244: 113-118.

Breitbarth, E., A. Oschlies, and J. LaRoche. 2006. Physiological constraints on the global distribution of Trichodesmium- effect of temperature on diazotrophy. Biogeosciences 3: 779-801.

Crocetti, G. R., P. Hugenholtz, P. L. Bond, A. Schuler, J. Keller, D. Jenkins, and L. L. BLACKALL. 2000. Identification of polyphosphate-accumulating organsims and design of $16 \mathrm{~S}$ rRNA-directed probes for their detection and quantification. Appl. Environ. Microbiol. 66: 1175-1182.

DAVIS, C., and D. MCGILLICUDDY. 2006. Transatlantic abundance of the $\mathrm{N}_{2}$-fixing colonial cyanobacterium Trichodesmium determined by in situ digital imaging. Science 312: 1517-1520. 
Diaz, J., E. D. Ingall, C. R. Benitez-Nelson, D. PATerson, M. D. DE Jonge, I. MCNULTY, and J. A. BRANDES. 2008. Marine polyphosphate: a key player in geologic phosphorus sequestration. Science 320: 652-655.

Dyhrman, S. T., C. R. Benitez-Nelson, E. D. Orchard, S. T. Haley, P. J. Pellechia. 2009. A microbial source of phosphonates in oligotrophic marine systems. Nature Geosci. 2: 665-732.

Dyhrman, S.T., and K. C. RutTenBerg. 2006. Presence and regulation of alkaline phosphatase activity in eukaryotic phytoplankton from the coastal ocean: implications for dissolved organic phosphorus remineralization. Limnol. Oceanogr. 51: 1381-1390.

Dyhrman, S. T., P. D. Chappell, S. T. Haley, J. W. Moffett, E. D. Orchard, J. B. WATERBURY, and E. A. WeBB. 2006a. Phosphonate utilization by the globally important marine diazotroph Trichodesmium. Nature 439: 68-71.

Dyhrman, S. T., S. T. Haley, S. R. Birkeland, L. L. Wurch, M. J. Cipriano, and A. G. MCARTHER. 2006b. Long serial analysis of gene expression for gene discovery and transcriptome profiling in the widespread marine coccolithophore Emiliania huxleyi. Appl. Environ. Microbiol. 72: 252-260.

Dyhrman, S. T., E. A. WebB, J. W. Moffett, and J. B. Waterbury. 2002. Cell-specific detection of phosphorus stress in Trichodesmium from the western North Atlantic. Limnol. Oceanogr. 47: 1832-1836.

EhrenReich, I. M., J. B. WATERBURY, and E. A. WebB. 2005. Distribution and diversity of natural product genes in marine and freshwater cyanobacterial cultures and genomes. Appl. Environ. Microbiol. 71: 7401-7413.

Gomez-Garcia, M. R., M. LosAdA, and A. SERrano. 2003. Concurrent transcriptional activation of $p p A$ and $p p X$ genes by phosphate deprivation in the cyanobacterium Synechocystis sp. strain PCC 6803. Biochem. Biophys. Res. Commun. 302: 601609.

Hewson, I., R. S. Poretsky, S. T. Dyhrman, B. Zielinski, A. E. White, H. J. TripP, J. P. MONTOYA, J. P. ZEHR. 2009. Microbial community gene expression within colonies of the diazotroph Trichodesmium from the southwest Pacific ocean. ISME J. 11: 1286-1300.

JaCoBson, L., and M. HALMANN. 1982. Polyphosphate metabolism in the blue-green alga Microcystis aeruginosa. J. Plank. Res. 4: 481-488. 
KARL, D., and K. M. BJÖRKMAN. 2002. Dynamics of DOP, p. 249-366. In D. A. Hansell and C. A. Carlson [eds.], Biogeochemistry of Marine Dissolved Organic Matter. Academic Press.

KarL, D. M. J. Dore, D. J. Hebel, and C. WinN. 1991. Procedures for particulate carbon, nitrogen, phosphorus and total mass analysis in the US-JGOFS Hawaii Ocean Time-series program. p 17-71. In D. Hurd and D. W. Spencer [eds.], Marine Pariculates: Analysis and Characterization, Geophysical Monograph 63. American Geophysical Union.

KARL, D. M., and G. TIEN. 1992. MAGIC: A sensitive and precise method for measuring dissolved phosphorus in aquatic environments. Limnol. Oceanogr. 37: 105-116.

KORNBERG, A. 1995. Inorganic polyphosphate: toward making a forgotten polymer unforgettable. J. Bacteriol. 177: 491-496.

KornberG, A., N. RaO, and D. AulT-Riche. 1999. Inorganic polyphosphate: a molecule of many functions. Annual Review of Biochemistry. 68: 89-125.

Krauk, J., T. A. Villareal, J. A. Sohm, J. P. Montoya, and D. G. Capone. 2006. Plasticity of N:P ratios in laboratory and field populations of Trichodesmium Appl. Microb. Ecol. 42: 243-253.

MartinY, A., M. Coleman, and S. W. Chisholm. 2006. Phosphate acquisition genes in Prochlorococcus ecotypes: evidence for genome-wide adaption. Proc. Natl. Acad. Sci. 103: 12552-12557.

Mateo, P., I. Douterelo, E. Berrendero, and E. Perona. 2006. Physiological differences between two species of cyanbacteria in relation to phosphorus limitation. J. Phycol. 42: 61-66.

McGeorge, G., D. W. Alderman, and D. M. Grant. 1999. Resolution enhancement of ${ }^{13} \mathrm{C}$ and ${ }^{15} \mathrm{~N}$ magic angle turning experiments with TPPM decoupling. J. Magn. Reson. 137: 138-143.

Monaghan, E. J. and K. C. Ruttenberg. 1999. Dissolved organic phosphorus in the coastal ocean: reassessment of available methods and seasonal phosphorus profiles from the Eel River Shelf. Limnol. Oceanogr. 44: 1702-1714.

Moore, L. R., M. Ostrowski, D. J. ScAnlan, K. Feren, and T. SweETSiR. 2005. Ecotypic variation in phosphorus-acquisition mechanisms within picocyanobacteria. Aquat. Microb. Ecol. 39: 257-269. 
Mulholland, M. R., S. Floge, E. CARPenter, and D. CAPone. 2002. Phosphorus dynamics in cultures and natural populations of Trichodesmium spp. Mar. Ecol. Prog. Ser. 239: 45-55.

ORChARD, E. D., E. A. WeBB, and S. T. Dyhrman. 2009. Molecular analysis of the phosphorus starvation response in Trichodesmium spp. Environ. Microbiol. 11: 2400-2411.

Orcutt, K. M., F. Lipschultz, K. Gundersen, R. ARimoto, A. Michaels, A. KnaP, and J. R. GALLON. 2001. A seasonal study of the significance of $\mathrm{N}_{2}$ fixation by Trichodesmium spp. at the Bermuda Atlantic Time-series Study (BATS) site. Deep-Sea Res. II 48: 1583-1608.

RAO, N., and A. KORNBERG. 1996. Inorganic polyphosphate supports resistance and survival of stationary-phase Escherichia coli. J. Bacteriol. 178: 1394-1400.

Romans, K. M., E. J. CARPENTER, and B. BERGMAN. 1994. Buoyancy regulation in the colonial diazotrophic cyanobacterium Trichodesmium tenue: ultrastructure and storage of carbohydrate, polyphosphate, and nitrogen. J. Phycol. 30: 935-942.

SCHELSKE, C. L., and L. SiCKO-GOAD. 1990. Effect of chelated trace metals on phosphorus uptake and storage in natural assemblages of Lake Michigan phytoplankton. J. Great Lakes Res. 16: 82-89.

Seufferheld, M. J., H. M. AlvareZ, and M. E. Farias. 2008. Role of polyphosphates in microbial adaptation to extreme environments. Appl. Environ. Microbiol. 74: 5867-5874.

SoHM, J. A., C. MAHAFFEY, and D. G. CAPONE. 2008. Assessment of relative phosphorus limitation of Trichodesmium spp. in the North Pacific, North Atlantic, and the north coast of Australia. Limnol. Oceanogr. 53: 2495-2502.

Su, Z., V. Olman, and Y. Xu. 2007. Computational prediction of Pho Regulons in cyanobacteria. BMC Genomics 8: 156-167.

TzEnG, C. M., and A. KornBerg. 1998. Polyphosphate kinase is highly conserved in many bacterial pathogens. Mol. Microbiol. 29: 381-382.

VALDERRAMA, J. C. 1981. The simultaneous analysis of total nitrogen and total phosphorus in natural waters. Mar. Chem. 10: 109-122.

Villareal, T. A., and E. J. CARPENTER. 2003. Buoyancy regulation and the potential for vertical migration in the oceanic cyanobacterium Trichodesmium. Microb. Ecol. 45: $1-10$. 
WebB, E. A., J. W. MofFetT, and J. B. WATERBURY. 2001. Iron stress in open-ocean cyanobacteria (Synechococcus, Trichodesmium, and Crocosphaera spp.): identification of the IdiA protein. Appl. Environ. Microbiol. 67: 5444-5452.

White, A. E., Y. Spitz, and R. LeTELIER. 2006a. Modeling carbohydrate ballasting by Trichodesmium spp. Mar. Ecol. Prog. Ser. 323: 35-45.

White, A. K., Y. SpItz, D. M. KARL, and R. Letelier. 2006b. Flexible elemental stoichiometry in Trichodesmium spp. and its ecological implications. Limnol. Oceanogr. 51: 1777-1790. 
CHAPTER FOUR

\section{Molecular Analysis of the Phosphorus Starvation Response in Trichodesmium spp.}

Elizabeth D. Orchard ${ }^{1}$

E. A. Webb ${ }^{2, *}$

Sonya T. Dyhrman ${ }^{3}$

${ }^{1}$ MIT-WHOI Joint Program in Oceanography/Applied Ocean Science and Engineering

${ }^{2}$ Biology Department, Woods Hole Oceanographic Institution

*Present address: Department of Biological Sciences, University of Southern California

Reprinted with permission from Environmental Microbiology

(C) 2009 Society for Applied Microbiology and Blackwell Publishing Ltd

Orchard, E. D., E. A. Webb, S. T. Dyhrman. (2009) Molecular analysis of the phosphorus starvation response in Trichodesmium spp. Environmental Microbiology 11(9): 2400-2411. 


\section{Molecular analysis of the phosphorus starvation response in Trichodesmium spp.}

Elizabeth D. Orchard, Eric A. Webb ${ }^{\dagger}$ and

Sonya T. Dyhrman*

Biology Department, Woods Hole Oceanographic

Institution, Woods Hole, MA 02543, USA.

\section{Summary}

The marine diazotroph Trichodesmium is a major contributor to primary production and nitrogen fixation in the tropical and subtropical oceans. These regions are often characterized by low phosphorus (P) concentrations, and $\mathrm{P}$ starvation of Trichodesmium could limit growth, and potentially constrain nitrogen fixation. To better understand how this genus responds to $P$ starvation we examined four genes involved in $\mathrm{P}$ acquisition: two copies of a highaffinity phosphate binding protein (pstS and sphX) and two putative alkaline phosphatases (phoA and phoX). Sequence analysis of these genes among cultured species of Trichodesmium ( $T$. tenue, T. erythraeum, T. thiebautii and $T$. spiralis) showed that they all are present and conserved within the genus. In T. erythraeum IMS101, the expression of sphX, phoA and phoX were sensitive to $P$ supply whereas pstS was not. The induction of alkaline phosphatase activity corresponded with phoA and phoX expression, but enzyme activity persisted after the expression of these genes returned to basal levels. Additionally, nifH (nitrogenase reductase; involved in nitrogen fixation) expression was downregulated under $P$ starvation conditions. These data highlight molecular level responses to low $P$ and lay a foundation for better understanding the dynamics of Trichodesmium $P$ physiology in low-P environments.

\section{Introduction}

Photosynthetic phytoplankton plays a key role in the biogeochemistry of the ocean by fixing $\mathrm{CO}_{2}$ and influencing the flux of carbon to the deep sea. The export of this carbon impacts the atmospheric $\mathrm{CO}_{2}$ concentration, and

Received 7 January, 2009; accepted 8 May, 2009. *For correspondence. E-mail sdyhrman@whoi.edu; Tel. (+1) 508289 3608; Fax (+1) 508457 2134. 'Present address: Department of Biological Sciences, University of Southern California, Los Angeles, CA 90089, USA. therefore climate, over geological time scales (Longhurst, 1991). Photosynthetic diazotrophs, such as the cyanobacterium Trichodesmium, are of particular importance to the biogeochemistry of the ocean because they fix both carbon and nitrogen $(\mathrm{N})$. Thus, they contribute to carbon cycling directly, as primary producers, and indirectly by fixing atmospheric $\mathrm{N}$, which can then promote the growth of other phytoplankton species (Capone, 2001; Coles et al., 2004). For example, the input of 'new N' fixed by Trichodesmium has been estimated to be as much as $1.6 \times 10^{12} \mathrm{~mol} \mathrm{~N}$ into the tropical North Atlantic (Capone et al., 2005).

The factors that constrain Trichodesmium growth and $\mathrm{N}_{2}$ fixation are intensely studied due to the aforementioned importance of this genus to global biogeochemistry. Although iron is often thought to limit $\mathrm{N}_{2}$ fixation by Trichodesmium (Berman-Frank 2001; Webb et al., 2001; Kustka et al., 2002; Mills et al., 2004), recent studies in the Atlantic suggest that phosphorus (P) may also be limiting (Sañudo-Wilhelmy et al., 2001; Dyhrman et al., 2002; Mulholland et al., 2002; Webb et al., 2007). Further supporting these observations, dissolved inorganic phosphate (DIP) concentrations in the Atlantic are significantly lower than those found in a number of other oligotrophic regimes, such as the Pacific (Wu et al., 2000; CavendarBares et al., 2001).

The major forms of $\mathrm{P}$ in the marine environment are DIP and dissolved organic phosphorus (DOP). DIP is considered the preferable $P$ source for bacteria and phytoplankton because it is directly available for growth (Vershinina and Znamenskaia, 2002; Dyhrman et al., 2007), but many microbes are also able to acquire $\mathrm{P}$ from DOP and this ability has been observed in a number of marine cyanobacteria and other phytoplankton (Dyhrman et al., 2002; Dyhrman and Palenik, 2003; Moore et al., 2005). In the upper water column of oligotrophic regimes, DOP often comprises a significant portion of the total $\mathrm{P}$ (Orrett and Karl, 1987; Karl, 1999; Wu et al., 2000), and a recent study by Mather and colleagues (2008) suggests that DOP could fuel up to $30 \%$ of the primary productivity in the North Atlantic (Mather et al., 2008). Within the highmolecular-weight DOP pool that is amenable to characterization (approximately $20-40 \%$ ), roughly $25 \%$ has a phosphonate bond and roughly $75 \%$ has an ester bond (Clark et al., 1998). Therefore, $P$ esters represent a larger potential $\mathrm{P}$ source than phosphonates. It has been shown 
that Trichodesmium is capable of growing on model phosphomonoesters (Stihl et al., 2001), and gene expression analysis has shown that phosphonate compounds are also likely available to this genus (Dyhrman et al., 2006). While the genes for phosphonate acquisition have been examined, the genes encoding the alkaline phosphatase enzyme responsible for the hydrolysis of the larger, $\mathrm{P}$ ester pool have not been studied in Trichodesmium.

In order to survive in low-P environments, microbes typically induce a set of genes involved in high-affinity phosphate uptake and DOP hydrolysis. $P$ uptake in many microbes occurs via the P-specific transport (Pst) system during $\mathrm{P}$-limiting conditions, or via the $\mathrm{P}$-inorganic transport (Pit) system under P-replete conditions (Vershinina and Znamenskaia, 2002). DOP hydrolysis can be mediated by many different enzymes, including alkaline phosphatases, encoded by the phoX and phoA genes (Roy et al., 1982; Moore et al., 2005; Wu et al., 2007). In Escherichia coli and Synechocystis PCC6803 these genes are under the control of a histidine-kinase transcriptional regulator (Vershinina and Znamenskaia, 2002; $\mathrm{Su}$ et al., 2003). This response regulator binds to a sequence referred to as the Pho box in the promoter region of each target gene or gene cluster. Searching for Pho boxes has proved to be a useful approach for identifying genes that may be involved in $\mathrm{P}$ acquisition (Su et al., 2007), although the regulation and function of these genes must be empirically validated.

Trichodesmium spp. are dominant members of the phytoplankton community in tropical and subtropical oceans (Capone et al., 1997), with six described species: T. erythraeum, T. tenue, T. thiebautii, T. hildebrandtii, T. contortum and T. spiralis, formerly known as Katagnymene spiralis (Janson et al., 1995; Lundgren et al., 2005). These species differ both in morphology and distribution, with T. thiebautii and T. erythraeum being the species most frequently associated with blooms in the open ocean (Orcutt et al., 2002). In this study, we examine T. erythraeum, T. tenue, T. thiebautii and T. spiralis for the presence of two genes involved in DIP uptake (the putative $P$ binding proteins: $p s t S$ and $s p h X$ ), and two genes involved in DOP hydrolysis (the putative alkaline phosphatases: phoA and phoX). Using T. erythraeum as a model, we also examine how these genes, and one gene involved in $\mathrm{N}_{2}$ fixation (Nitrogenase reductase: nifH), are regulated in response to changes in $P$ supply.

\section{Results}

\section{Genomic observations}

The genome of T. erythraeum IMS101 contains homologues for genes involved in the acquisition of DIP, and the hydrolysis of DOP (Table 1). Homologues to each of the genes found in the Pst cluster (PstCAB) and two homologues of the high-affinity phosphate binding protein, pstS (YP_723097) and sphX (YP_723095) are present in the T. erythraeum genome (Table 1). These two genes are separated by a small gap, and the sphX gene is preceded by a putative Pho box sequence, whereas the pstS gene is not (Su et al., 2007) (Fig. 1). There are no clear homologues to any genes in the Pit system.

There are three putative alkaline phosphatases in the T. erythraeum genome. One putative alkaline phosphatase, phoA (YP_723031), is related to an atypical alkaline phosphatase in Synechococcus (Ray etal., $1991)$, to which it has a $52 \%$ identity over approximately $50 \%$ of the translated gene. The other two genes, phoX (YP_723360) and phoX2 (YP_723924), which encode putative alkaline phosphatases, share the same conserved protein domain (COG 3911) as the characterized PhoX proteins of Pseudomonas, Pasterella and Vibrio

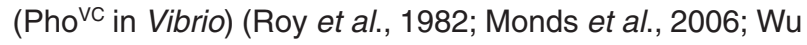
et al., 2007). Both phoX and phoX2 have a $39 \%$ identity over $99 \%$ of the translated gene to $\mathrm{Pho}^{\mathrm{VC}}$ in Vibrio. A Pho box has been identified in front of the putative phoX gene (Su et al., 2007), but not before the putative phoA or phoX2 genes (Table 1). The phoA gene does have a very similar repeat to that of a Pho box in its promoter region, but lacks the three base linker sequence common to the Pho boxes identified in Su and colleagues (2007) (Table 1). Further analyses focused on phoA and phoX.

\section{Sequence analysis}

The genes pstS, sphX, phoX and phoA are present and highly conserved in all Trichodesmium species examined. With the exception of pstS, all genes were 96-100\% identical at the nucleotide level over the gene fragments sequenced (Table 2). For the pstS gene there appear to be two groups: T. tenue and T. erythraeum, which are 99\% identical, and T. spiralis and T. thiebautii, which are $98 \%$ identical, but the two pstS groups are only $87-88 \%$ identical to each other (Table 2).

\section{Culture experiments}

The expression of genes involved in P uptake and DOP hydrolysis were examined in two ways: (i) by transferring exponentially growing cells to replete $(+P)$ and no $P(-P)$ media, in the transfer experiment or (ii) by starving cells for $\mathrm{P}$ and then adding back $\mathrm{P}$, in the re-feed experiment. Each of these experiments was replicated with similar results. Here we present the data from one of each of these experiments.

In the transfer experiment, alkaline phosphatase activity (APA) increased in the $-P$ culture to a final rate of $16.5 \mathrm{nmol} \mathrm{P} \mathrm{h}^{-1} \mu \mathrm{g} \mathrm{Chl} \mathrm{a}^{-1}$, and was statistically greater 


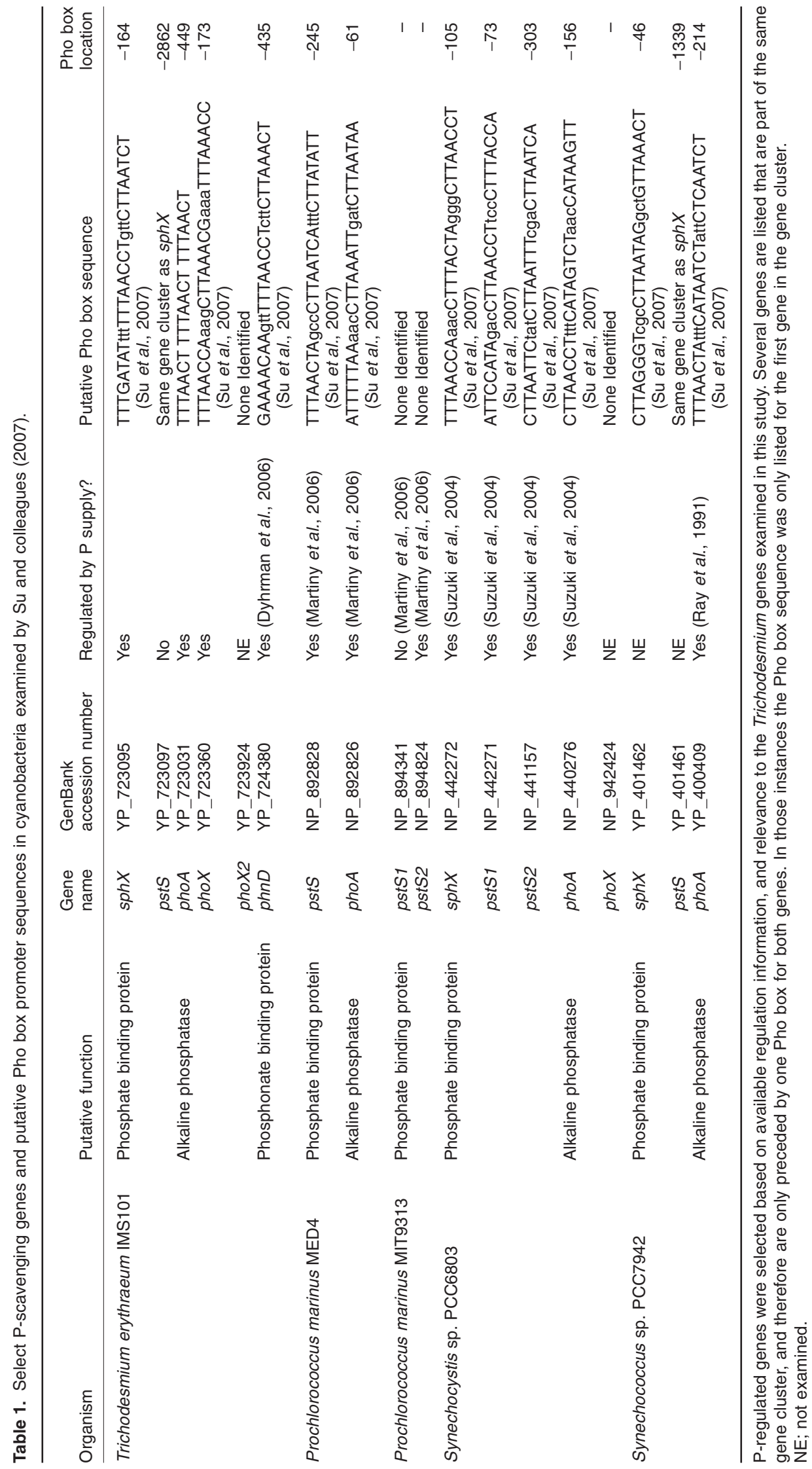




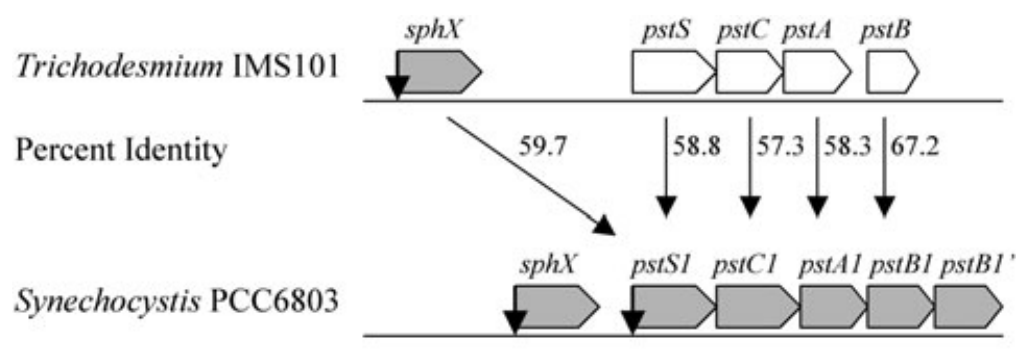

$\underline{1 \mathrm{~kb}}$

Fig. 1. Pst topology of Trichodesmium erythraeum IMS101 and Synechocystis PCC6803 with the percent identity reported for amino acid alignments over $80 \%$ of the translated gene. The $p s t S$ and $s p h X$ genes encode high-affinity binding proteins, pstA, pstB and pstC are components of the phosphate transporter. A vertical arrow next to the gene indicates the location of a Pho box sequence as identified in Su and colleagues (2007). Genes shaded grey have been shown to be upregulated by P starvation in this study or in Suzuki and colleagues (2004).

than the $+\mathrm{P}$ cultures at $168 \mathrm{~h}(P<0.05)($ Fig. 2$)$. In the $+\mathrm{P}$ cultures, APA reached a maximum level of $4.0 \mathrm{nmol}$ $\mathrm{Ph}^{-1} \mu \mathrm{g} \mathrm{Chl} a^{-1}$. The expression of phoA and phoX tracked with the measured APA. The expression of $p h o A$ in the $-\mathrm{P}$ culture was statistically different from the $+\mathrm{P}$ culture by $72 \mathrm{~h}(P=0.031)$, as was the expression of phoX $(P=0.028)$ (Fig. 2). In the re-feed experiment, APA started at $24.9 \mathrm{nmol} \mathrm{P} \mathrm{h}^{-1} \mu \mathrm{g} \mathrm{Chl} a^{-1}$, this rate declined upon $\mathrm{P}$ addition, and was statistically different from the $-\mathrm{P}$ culture by $48 \mathrm{~h}(P<0.05)$ (Fig. 2$)$. The phoA and phoX genes were downregulated compared with the $-P$ culture at each time point (Fig. 2). This difference was statistically significant by $4 \mathrm{~h}$ for phoX $(P<0.001)$ and phoA $(P<0.001)$ (Fig. 2).

The expression of $s p h X$ was upregulated in the $-P$ cultures in the transfer experiment, and was statistically different from the $+\mathrm{P}$ culture at the $216 \mathrm{~h}$ time point $(P=0.021)$. While pstS expression was always detectable, there was no significant change in expression during the time-course of this experiment (Fig. 3). In the re-feed experiment, sph $X$ was downregulated in response to the $P$ addition (Fig. 3). The difference in expression between the $-\mathrm{P}$ and re-fed cultures was statistically significant by $24 \mathrm{~h}(P=0.036)$. There was no clear pattern in expression for pstS, but it was significantly upregulated in the re-fed versus the $-\mathrm{P}$ culture at $48 \mathrm{~h}(P<0.001)$ (Fig. 3$)$.

The expression of nifH was examined in the re-feed experiment. In the -P culture, nifH was significantly downregulated by $24 \mathrm{~h}(P<0.001)$ relative to the culture re-fed with $P$ (Fig. 4). The nifH gene continued to be expressed at the same level in the cultures where $P$ was added (Fig. 4).

\section{Discussion}

Trichodesmium populations are commonly present in lowDIP environments. In these systems, where the DOP concentration typically exceeds that of DIP in the euphotic zone (Orrett and Karl, 1987; Karl, 1999), the ability to utilize DOP would confer a distinct growth advantage to marine microbes. Previous studies have shown that cultures and field populations of Trichodesmium can hydrolyse a model P ester (Stihl et al., 2001; Dyhrman et al., 2002). Additionally, it has been suggested that Trichodesmium is not able to compete with co-occurring plankton for DIP, and that it uses DOP to meet its P demand (Sohm and Capone, 2006). Linking these physiological observations to the genes that control these activities remains a central challenge in microbial oceanography.

Table 2. Nucleotide sequence comparison of key phosphorus-scavenging genes among different species of Trichodesmium.

\begin{tabular}{|c|c|c|c|c|c|c|}
\hline & $\begin{array}{l}\text { T. tenue: } \\
\text { T. erythraeum }\end{array}$ & $\begin{array}{l}\text { T. spiralis: } \\
\text { T. erythraeum }\end{array}$ & $\begin{array}{l}\text { T. thiebautii: } \\
\text { T. erythraeum }\end{array}$ & $\begin{array}{l}\text { T. tenue: } \\
\text { T. spiralis }\end{array}$ & $\begin{array}{l}\text { T. tenue: } \\
\text { T. thiebautii }\end{array}$ & $\begin{array}{l}\text { T. spiralis: } \\
\text { T. thiebautii }\end{array}$ \\
\hline pstS (1077) & $99^{b}$ & 88 & 88 & 87 & 88 & 98 \\
\hline $\operatorname{sph} X(1086)$ & 98 & 98 & 99 & 100 & 99 & 99 \\
\hline phoA (3528) & 98 & 98 & 98 & 97 & 96 & 98 \\
\hline phoX (2358) & 99 & 99 & 97 & 100 & 98 & 98 \\
\hline
\end{tabular}

a. Size of putative gene in T. erythraeum (bp).

b. \% ID to gene fragment sequenced. The $p s t S$ fragment is $\sim 530 \mathrm{bp}$ for all species. The $s p h X$ fragment is $\sim 600 \mathrm{bp}$ in T. tenue and T. spiralis, and is $400 \mathrm{bp}$ in T. thiebautii. The phoA fragment is $\sim 1.8 \mathrm{~kb}$ in T. tenue, $240 \mathrm{bp}$ in T. thiebautii and $202 \mathrm{bp}$ in T. spiralis. The phoX fragment is $136 \mathrm{bp}$ in all species. 
A

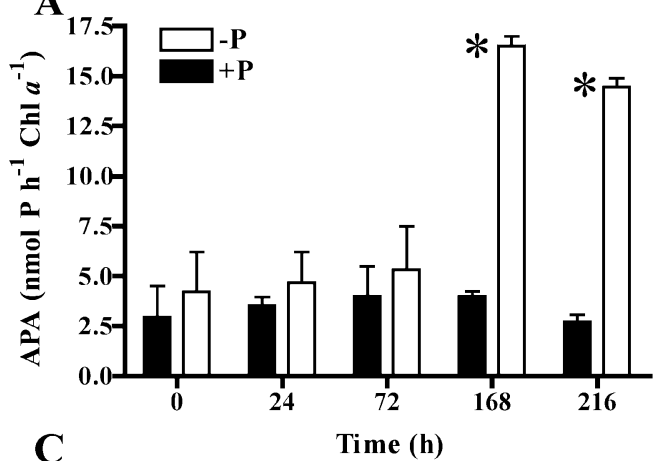

C

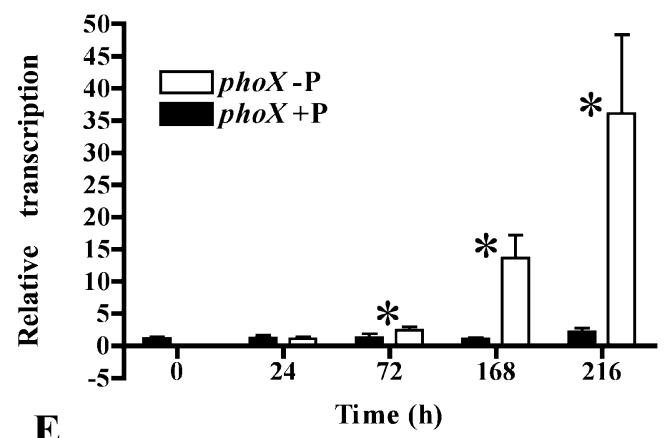

$\mathbf{E}$

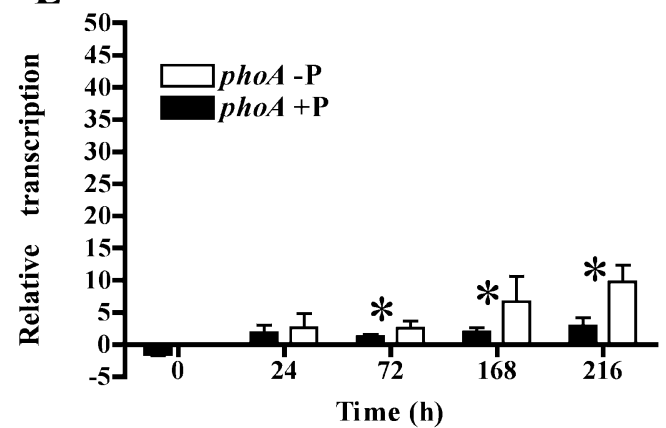

B
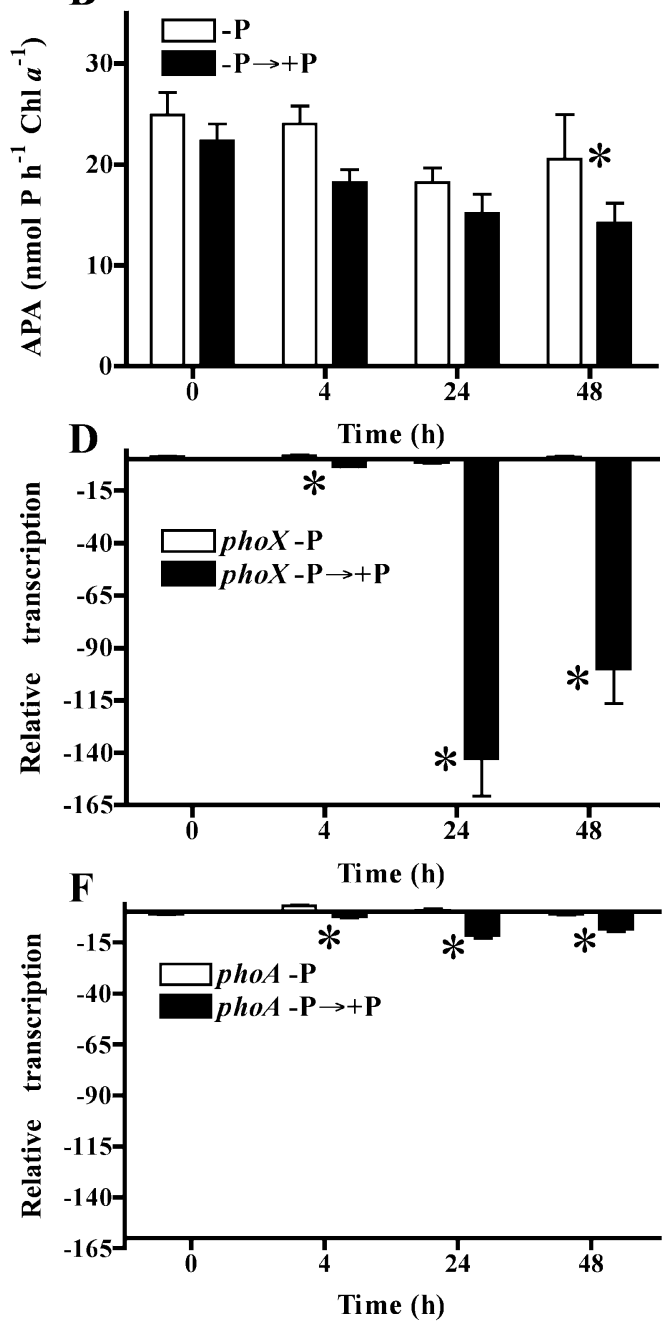

Fig. 2. Plots of APA for both the transfer and the re-feed experiments (A and B), and expression profiles for pho $X$ and phoA for the transfer experiment ( $C$ and $E)$, and the re-feed experiment $(D$ and $F)$. In ( $A$ and $B$ ) error bars indicate standard deviation of triplicate biological replicates. In (C-F) error bars indicate the standard error of the fold change of triplicate measurements between the sample expression and the calibrator expression (i.e. the zero time point). An * indicates a $P$-value of less than 0.05 for the $-\mathrm{P}$ versus the $+\mathrm{P}$ or re-feed culture at a single time point for a paired $t$-test $(\mathrm{A}$ and $\mathrm{B})$ or a pair-wise fixed reallocation randomization analysis $(\mathrm{C}-\mathrm{F})$.

As highlighted previously, $\mathrm{P}$ esters dominate the highmolecular-weight DOP that is amenable to characterization (Clark et al., 1998), and $P$ esters likely represent a significant source of $\mathrm{P}$ to Trichodesmium (Mulholland et al., 2002; Sohm and Capone, 2006). Unfortunately, the alkaline phosphatases that hydrolyse $P$ esters can be difficult to identify by sequence homology alone, as the primary sequence tends to be very heterogeneous (Moore et al., 2005). Only one cyanobacterial alkaline phosphatase has been characterized: the atypical alkaline phosphatase (phoA) of Synechococcus PCC7942 (Ray et al., 1991), and this phoA gene has very little sequence homology to that of other characterized phoA genes. The T. erythraeum genome has a gene similar to this atypical alkaline phosphatase and it is referred to herein as phoA. Another alkaline phosphatase, phoX, has recently been characterized in Pseudomonas and Pasteurella (Monds et al., 2006; Wu et al., 2007), and it consists entirely of one conserved bacterial domain (COG 3211). Trichodesmium has two genes that share this conserved domain ( $p h o X$ and phoX2). Several marine cyanobacteria appear to have this gene, including Cyanothece ATCC 51142, Microcystis aeruginosa, Synechococcus WH8102, Synechococcus WH7803 and Lyngbya PCC 8106, which has two copies like T. erythraeum IMS101 (Sebastian and Ammerman, 2009). Interestingly, there are no apparent phoX genes in the available sequenced genomes for Prochlorococcus.

The putative phoA and phoX gene sequences were compared between all cultured Trichodesmium species, 
A

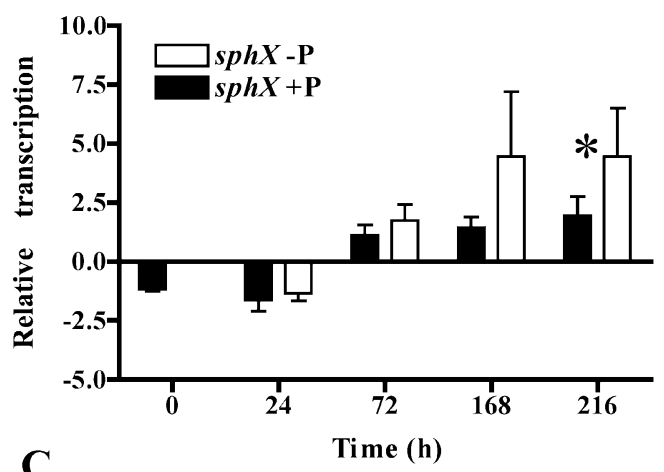

C

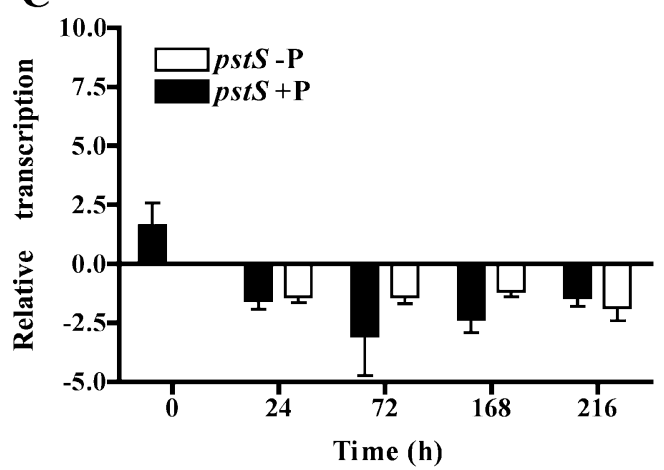

B
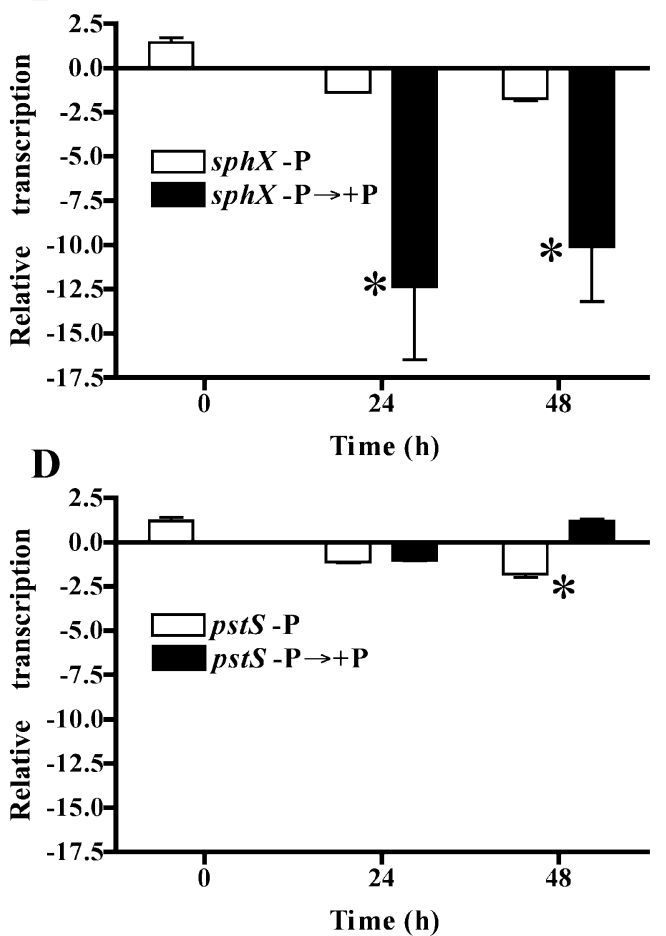

Fig. 3. Expression profiles for $s p h X$ and pstS in the transfer ( $A$ and $C$ ) and re-feed (B and $D)$ experiments. Error bars indicate the standard error of the fold change of triplicate measurements between the sample expression and the calibrator expression (i.e. the zero time point). $A n$ * indicates a $P$-value of less than 0.05 for the $-\mathrm{P}$ versus the $+\mathrm{P}$ or re-feed culture at a single time point using a pair-wise fixed reallocation randomization analysis $(\mathrm{A}-\mathrm{D})$.

and were found to be present in all species tested. Over the fragments sequenced, both of these genes were highly conserved within the genus, suggesting that these genes were both present in the Trichodesmium genome before the radiation of the species.

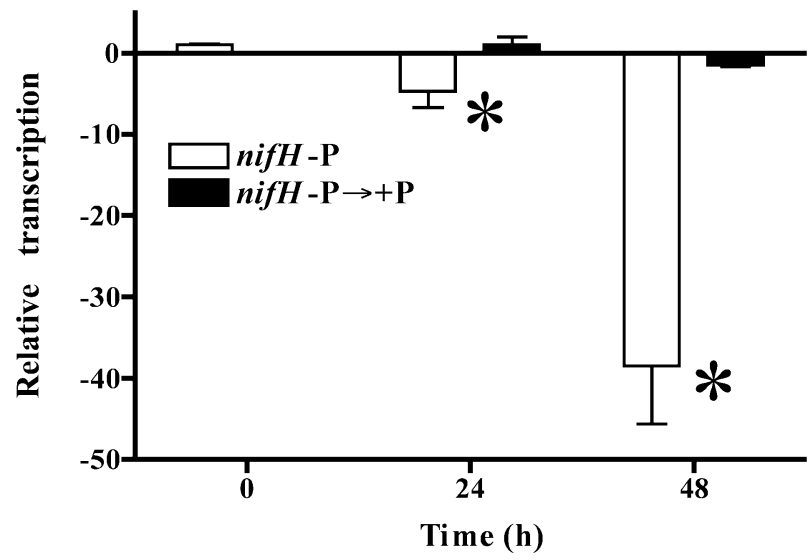

Fig. 4. Expression profiles for nifH in the re-feed experiment. Error bars indicate the standard error of the fold change of triplicate measurements between the sample expression and the calibrator expression (i.e. the zero time point). An * indicates a $P$-value of less than 0.05 for the $-P$ versus re-feed culture at a single time point using a pair-wise fixed reallocation randomization analysis.
The phoA and phoX genes are both upregulated by $\mathrm{P}$ starvation, but phoX showed a much stronger response than phoA. APA also showed a similar pattern of induction to the gene expression pattern. In the re-feed experiment, phoA and phoX expression quickly dropped (by $4 \mathrm{~h}$ ) after $\mathrm{P}$ was added back to a P-starved culture; however, APA decreased more slowly. This is contrary to a previous study of Trichodesmium APA, in which APA decreased by $50 \%$ or more within $48 \mathrm{~h}$ after $\mathrm{P}$ was added back to a P-starved culture (Stihl et al., 2001). Our data suggest that the alkaline phosphatase enzyme may persist somewhat after expression of the gene has decreased, and therefore the enzyme is not actively being degraded in the time-course of our study. Although, under these experimental conditions, we cannot rule out the possibility that additional phosphatases or co-cultured heterotrophs are also contributing to observed activities. In this context, measuring $p h o A$ or phoX gene expression may provide a more instantaneous picture of physiology, whereas APA may reflect a longer window into the history of $P$ starvation. This is an important consideration given the common use of APA as a physiological indicator of $P$ limitation in field populations.

This work represents the first evidence for a P-regulated marine cyanobacterial phoX. The difference 
in the magnitude of expression between phoX and phoA in Trichodemium suggests that phoX may have a more significant contribution to DOP hydrolysis than phoA, although there need not be a linear relationship between expression of the gene and activity of the enzyme. Notably, phoX was also present and more highly expressed than phoA under $\mathrm{P}$ starvation in a recent study of a freshwater thermophilic Synechococcus sp. (Adams et al., 2008). Given the presence and expression of phoX in several cyanobacteria, $P$ regulation studies in other groups would assess the potential importance of this enzyme.

If the phoX and phoA alkaline phosphatases have different substrate specificity and cofactor requirements, it would increase the range of potential DOP compounds Trichodesmium can hydrolyse and the range of trace metal limitation Trichodesmium can withstand. The characterization work done with PhoX to date indicates a broad substrate specificity including some diesters (Monds et al., 2006; Wu et al., 2007). Additionally, the PhoX of Pasteurella does not require Zinc (Zn), whereas proteins of the PhoA family typically require $\mathrm{Zn}$ as a cofactor (Kim and Wyckoff, 1991; Wu et al., 2007). There are several regions of the ocean, such as the Sargasso Sea, where both $\mathrm{P}$ concentrations and $\mathrm{Zn}$ concentrations are extremely low (Jakuba et al., 2008), and it has been hypothesized that the Sargasso Sea is co-limited by $P$ and $\mathrm{Zn}$ because of the $\mathrm{Zn}$ requirement by phosphatases (Shaked et al., 2006; Jakuba et al., 2008). Having an alternative alkaline phosphatase that does not require $\mathrm{Zn}$ as a cofactor could provide a growth advantage in such areas. Further studies into the substrate specificity and metal requirements of the PhoX and PhoA in Trichodesmium are needed to address this observation.

Previous studies of the presence and regulation of highaffinity phosphate binding proteins in cyanobacteria have provided useful insights into how these organisms are adapted to low-P environments and how they respond to P starvation (Scanlan et al., 1997; Moore et al., 2005; Martiny et al., 2006). In the T. erythraeum genome there appear to be two copies of genes encoding a high-affinity $\mathrm{P}$ binding protein, pstS and $s p h X$. Several other cyanobacteria have multiple copies of high-affinity $P$ binding proteins, for example in freshwater Synechocystis, Gloeobacter, Anabaena PCC 7120, and in marine Synechococcus WH8102, Synechococcus WH7803, Prochlorococcus MIT9313 as well as the marine diazotroph Crocosphaera WH8501 (Moore et al., 2005; Dyhrman and Haley, 2006). Although multiple copies are common, the association of pstS and sphX with pstCAB (responsible for $\mathrm{P}$ transport into the cell) and the gene topologies of the pstSCAB cluster can vary substantially between genera (Moore et al., 2005; Martiny et al., 2006). Among the cyanobacterial genomes currently available, the topology of the
Trichodesmium Pst system is most similar to that of Synechocystis, although the sphX and pstS genes of Trichodesmium are both more similar to the pstS gene of Synechocytis than to the sphX gene of Synechocystis.

Given the marked ecotype variation of nutrientscavenging capacities in the marine cyanobacteria Prochlorococcus and Synechococcus (Moore et al., 2005; Martiny et al., 2006), we were interested in comparing the sequence and presence of sphX and pstS among species of Trichodesmium (Moore et al., 2005). All species tested contain both sphX and pstS, but the phylogenetic relationship inferred from their sequences is different. There is more sequence heterogeneity among the species in pstS than sphX. The sequence identity for pstS divides the species into two distinct clusters: T. erythraeum and T. tenue in one cluster and T. thiebautii and T. spiralis in another. This differs from the phylogeny inferred using the internal transcribed spacer sequence, which places T. erythraeum in one clade and T. tenue, T. spiralis, and T. thiebautii in another (Orcutt et al., 2002), and the relationship inferred from the sequence of a functional gene sequence, hetR, which places $T$. spiralis and T. thiebautii in one cluster and $T$. tenue and $T$. erythraeum each in their own clusters (Lundgren et al., 2005). Given the sequence heterogeneity in pstS found here, further analysis of the pstSCAB topology and expression patterns is warranted in the other cluster.

The sphX gene was regulated by $P$ supply in the transfer experiment, while pstS was not. The induction time for sphX was longer than what was observed for phoA and phoX; however, it is difficult to resolve significant expression changes for $s p h X$ relative to these genes because of the lower expression levels. This is a relatively long lag before induction of $s p h X$ in comparison with other studies of cyanobacterial pstS/sphX expression in the unicellular Prochlorococcus and Synechocystis, which tend to respond within $48 \mathrm{~h}$ (Suzuki et al., 2004; Martiny et al., 2006). However, it has been observed that $P$ can be adsorbed to the outside of Trichodesmium cell walls (Sañudo-Wilhelmy et al., 2004), and this $P$ may not be removed by the washing procedure used in this experiment. This could delay the onset of $P$ starvation, as would internal stores of $\mathrm{P}$, such as polyphosphate. Additionally, Trichodesmium is relatively slow-growing and may not sense and respond to its environment as quickly as other cyanobacteria.

In the re-feed experiment, sphX was downregulated in response to the $\mathrm{P}$ addition, but pstS was not. In fact, pstS was upregulated at the $48 \mathrm{~h}$ time point. The global downregulation of genes in response to starvation, and recovery from $\mathrm{P}$ starvation in the re-fed culture may be driving this change in pstS expression. While there was no clear $P$ regulation of pstS in these experiments, it is possible that a slightly different time-course, or more sensitive 
tools, would reveal subtle regulation patterns that we were unable to detect.

Differential regulation of genes encoding phosphate binding proteins has been observed in other cyanobacteria (Moore et al., 1998; Suzuki et al., 2004), but never between two such genes that appear to be in a single operon. For example, Synechocystis has two nonidentical copies of the entire Pst system (Pst1 and Pst2). Both copies are regulated by $\mathrm{P}$, but one, Pst1, acts as a rapid response to $P$ starvation while Pst2 is upregulated later under P-starvation conditions (Suzuki et al., 2004). Prochlorococcus MIT9313 also has two copies of pstS, one regulated by $\mathrm{P}$ and one not, but neither are associated with pstCAB as is the case in T. erythraeum (Martiny et al., 2006). Given the location of the pstS gene relative to the rest of the Pst system, it is possible that pstCAB are co-transcribed with pstS and this suggests that pstCAB are expressed but not regulated by $P$. With the apparent lack of the constitutively expressed Pit system, it is possible that the PstSCAB system is fulfilling that role for $P$ uptake during replete growth conditions, with $s p h X$ upregulated under low $\mathrm{P}$. This is consistent with the position of the Pho box (see below) and with studies on Trichodesmium $\mathrm{P}$ uptake kinetics, where under $\mathrm{P}$ limitation the $\mathrm{V}_{\max }$ for $\mathrm{P}$ uptake increases, but the $K_{\mathrm{m}}$ remains constant relative to replete cultures (Fu et al., 2005).

To evaluate the diagnostic effectiveness of the presence of a Pho box for identifying P-regulated genes, we summarized all the cyanobacteria that have been examined for Pho boxes (Su et al., 2007) and for which there are $P$ regulation data (Table 1 ). In most species, P-regulated genes are preceded by a Pho box, except in Prochlorococcus marinus MIT9313 for which Su and colleagues (2007) did not identify a Pho box preceding the P-regulated pstS or phoA (Martiny et al., 2006; Su et al., 2007). Also, while there was no Pho box preceding phoA in $T$. erythraeum, this gene was still regulated by $P$. The presence of a sequence resembling a Pho box preceding this gene suggests that there is possibly more heterogeneity in this binding sequence in Trichodesmium than predicted. In Synechocystis, sphX and pstSCAB are separated by a small gap, but both $s p h X$ and pstS are preceded by a Pho box (Su et al., 2007). In T. erythraeum, sphX and pstSCAB are also separated by a small gap, and only $s p h X$ is preceded by a putative Pho box (Su et al., 2007). The absence of a second Pho box is consistent with the lack of $\mathrm{P}$ regulation in pstS. Therefore, examining a genome for Pho box sequences is a useful first tool for identifying potential genes involved in $\mathrm{P}$ acquisition, but the regulation and activity of these genes still needs to be confirmed.

To examine the impact of $\mathrm{P}$ starvation on $\mathrm{N}_{2}$ fixation, nifH (nitrogenase reductase) expression was assayed as a proxy for $\mathrm{N}_{2}$ fixation rate (Chen et al., 1998; El-Shahawy et al., 2003). In the re-feed experiment, nifH expression was significantly downregulated in the P-starved cultures, and therefore $\mathrm{P}$ starvation may lead to a decrease in nifH expression and a reduction in $\mathrm{N}_{2}$ fixation rate. This has important implications for the field, and suggests that increased expression of $s p h X$, phoX or phoA, indicates a decrease in $\mathrm{N}_{2}$ fixation due to $\mathrm{P}$ starvation in situ. When re-fed with $\mathrm{P}$, nifH expression remained constant relative to the start of the experiment while the P-regulated genes were repressed, suggesting that the link between decreased $\mathrm{N}_{2}$ fixation rates and $\mathrm{P}$ starvation is not as tight as has been seen with iron starvation (Shi et al., 2007; Kupper et al., 2008). A more detailed time-course study with $\mathrm{N}_{2}$ fixation assays would further resolve molecularlevel linkages between $P$ starvation and changes in $N_{2}$ fixation rate.

Here we studied the interplay among $P$ starvation, APA and gene expression patterns. The pstS, sphX, phoA and phoX genes are present in all examined species of Trichodesmium. Additionally, the expression of phoA, phoX and $\operatorname{sph} X$ were all responsive to $\mathrm{P}$ supply, while pstS was not. These data suggest that the expression of $s p h X$, pho $A$ and phoX could provide a useful marker for $\mathrm{P}$ physiology in natural populations. Combining these measurements with APA would also provide insights into the nutritional history of this organism. Together with measurements of nifH expression or $\mathrm{N}_{2}$ fixation rates, we can identify the importance and prevalence of $\mathrm{P}$ starvation, and decreases in $\mathrm{N}_{2}$ fixation due to $\mathrm{P}$ starvation in the environment. Additionally, we demonstrate for the first time the $P$ regulation of a putative phoX in a marine cyanobacterium. The presence of a $\mathrm{P}$-regulated phoX in Trichodesmium could provide a means to access the $P$ ester pool without an increased $\mathrm{Zn}$ requirement. In oligotrophic regimes, where $P$ esters are the dominate $P$ pool and $\mathrm{Zn}$ concentrations are low (Jakuba et al., 2008), having a PhoX-type alkaline phosphatase could allow Trichodesmium to occupy a unique niche relative to cyanobacteria solely using a PhoA-type alkaline phosphatase.

\section{Experimental procedures}

\section{Culture conditions}

Trichodesmium cultures were grown in RMP medium with Sargasso seawater as previously described (Webb et al., 2001). Species examined include Trichodesmium erythraeum IMS101, T. tenue, T. thiebautii and T. spiralis, obtained from the culture collection of John Waterbury. All cultures were unialgal but not axenic. Cultures were grown at $25^{\circ} \mathrm{C}$ on a shaker table with daily cycles that consisted of $1 \mathrm{~h}$ at $13.5 \mu \mathrm{E} \mathrm{m}^{-2} \mathrm{~s}^{-1}, 10 \mathrm{~h}$ at $33.7 \mu \mathrm{E} \mathrm{m}^{-2} \mathrm{~s}^{-1}, 1 \mathrm{~h}$ at $13.5 \mu \mathrm{E} \mathrm{m}^{-2} \mathrm{~s}^{-1}$ and $12 \mathrm{~h}$ of dark. To examine the regulation of $P$ acquisition genes in the transfer experiment, $1 \mathrm{I}$ of exponentially growing cells was divided in half and gently filtered, 
Table 3. Primer sequences and product sizes for PCR and qPCR reactions.

\begin{tabular}{|c|c|c|c|c|}
\hline Gene & Sequencing primers $5^{\prime}-3^{\prime}$ & $\begin{array}{l}\text { Annealing } \\
\text { Temperature }\left({ }^{\circ} \mathrm{C}\right)\end{array}$ & $\begin{array}{l}\text { Product } \\
\text { size }\end{array}$ & Efficiency \\
\hline phoA & $\begin{array}{l}\text { ATGCGTGGGGACTTAACAGTAA } \\
\text { TCTAATCACAAAATCATCTGTTGTGAGAG }\end{array}$ & 61.2 & $3.5 \mathrm{~kb}$ & N.A. \\
\hline pstS & $\begin{array}{l}\text { ACAAGCACAAACTAAAACCAG } \\
\text { GACGAATCAGCAGTGACAAG }\end{array}$ & 58.5 & $1.5 \mathrm{~kb}$ & N.A. \\
\hline $\operatorname{sphX}$ & $\begin{array}{l}\text { AAATTAGTATCGTTGCCTAAAT } \\
\text { TTTGTGCTTATACATTTATTATC } \\
\text { qPCR primers } 5^{\prime}-3^{\prime}\end{array}$ & 59 & $1.5 \mathrm{~kb}$ & N.A. \\
\hline phoA & $\begin{array}{l}\text { AGATGATGATGGAGAAAATGAAAG } \\
\text { CGTCTTCCCTGGTGAGGAG }\end{array}$ & 60.7 & $131 b p$ & $105 \%$ \\
\hline phoX & $\begin{array}{l}\text { TGGTGAAAAGTATGGCTGGATGG } \\
\text { GCTGCTAACGGTTTACCTGCTTC }\end{array}$ & 60.7 & $135 \mathrm{bp}$ & $99 \%$ \\
\hline pstS & $\begin{array}{l}\text { TGGAGTTTTCACGAAGCATTTGAG } \\
\text { GCAGTTACACCATCATTCTTGGC }\end{array}$ & 60.7 & $120 \mathrm{bp}$ & $98 \%$ \\
\hline $\operatorname{sphX}$ & $\begin{array}{l}\text { TCAGTTGGTAGTGGTGCTGG } \\
\text { CGAGAGACCTTGGCTATTTCAC }\end{array}$ & 60.7 & 104 bp & $103 \%$ \\
\hline nifH & $\begin{array}{l}\text { AGTGTGTTGAGTCTGGTGGTCCTG } \\
\text { TGTTTTCACGGATAGGCATTGC }\end{array}$ & 60.7 & 174 bp & $101 \%$ \\
\hline $\operatorname{rot} A$ & $\begin{array}{l}\text { CCAAGGAGGTTGCCCAAAAGG } \\
\text { GAACGCCATCTAAATGAGGTTGAG }\end{array}$ & 60.7 & 175 bp & $97 \%$ \\
\hline
\end{tabular}

Annealing temperatures for PCR reactions and primer efficiencies are as indicated. If no sequencing primer is listed, then qPCR primers were used for sequencing.

N.A., not applicable.

washed three times in media with or without $8 \mu \mathrm{M} \mathrm{H}_{3} \mathrm{PO}_{4}$ $(+\mathrm{P}$ or $-\mathrm{P})$, then re-suspended in $500 \mathrm{ml}$ of $+\mathrm{P}$ or $-\mathrm{P}$ media respectively. The resulting cell suspensions were split into replicate $500 \mathrm{ml}$ polycarbonate flasks with $100 \mathrm{ml}$ of culture in each. Whole flasks were harvested at 0, 24, 72, 168 and $216 \mathrm{~h}$. For each time point, $+\mathrm{P}$ and $-\mathrm{P}$ flasks were harvested one at a time starting approximately $2 \mathrm{~h}$ after the mid-point of the light cycle. For this experiment, we could not assay nifH expression due to the diel periodicity of the expression of this gene and differences in harvest time between samples. To examine the downregulation of $\mathrm{P}$ acquisition genes in the re-feed experiment, cells were grown without $P$ for 10 days, and $P$ was added back to two of the flasks to a concentration of $8 \mu \mathrm{M}$. Flasks were subsampled at $0,4,24$ and $48 \mathrm{~h}$. For each time point, flasks were harvested in parallel exactly $2 \mathrm{~h}$ after the mid-point of the light cycle, allowing for nifH expression assays.

\section{Genome annotation}

P-scavenging genes were identified using the integrated microbial genomes portal at the Joint Genome Institute-US Department of Energy website (http://img.jgi.doe.gov/) and the National Center for Biotechnology Information GenBank database (http://www.ncbi.nlm.nih.gov/), based on homology.

\section{DNA amplification and sequencing}

Cells were collected by filtration onto a $5 \mu \mathrm{m}$ polycarbonate filter and stored at $-20^{\circ} \mathrm{C}$ until extraction. DNA was extracted using the Instagene Matrix (Bio-Rad, Hercules, CA) according to the manufacturer's instructions or as described elsewhere (Ehrenreich et al., 2005). PCR primers were designed to either amplify fragments or the entire putative $s p h X, p s t S$,
phoX and phoA genes. Annealing temperatures were empirically determined for each primer pair (Table 3). Each PCR reaction consisted of a $5 \mathrm{~min}$ denaturation step at $95^{\circ} \mathrm{C}$, followed by 35 cycles of $1 \mathrm{~min}$ at $95^{\circ} \mathrm{C}, 1 \mathrm{~min}$ at the annealing temperature, $1 \mathrm{~min}$ per $500 \mathrm{bp}$ at $72^{\circ} \mathrm{C}$ and a final extension of $10 \mathrm{~min}$ at $72^{\circ} \mathrm{C}$, in a Bio-Rad iCycler (Hercules, CA). PCR amplification was done using $0.5 \mu \mathrm{l}$ PfuTurbo DNA polymerase (Stratagene, La Jolla, Ca), $2.5 \mu$ l of DNA template, $2.5 \mu \mathrm{l}$ of $2 \mathrm{mM}$ dNTP, $2.5 \mu \mathrm{l}$ of $10 \times$ Pfu buffer, $50 \mathrm{pmol}$ of each primer and sterile water to a final volume of $25 \mu \mathrm{l}$. PCR products were gel-extracted using the QIAquick gel extraction kit (Qiagen, Valencia, CA), and direct-sequenced at the Josephine Bay Paul Center of the Marine Biological Laboratory (Woods Hole, MA), MWG Biotech (Hunstville, AL) or at the University of Maine (Orono, ME) according to the facility's protocols. Using the genome of T. erythraeum IMS101 as a guide, internal sequencing primers were designed for any PCR product sequenced larger than $500 \mathrm{bp}$ in order to cover the entire product at least once on each strand. Sequences were edited using Sequencher (Gene Codes, Ann Arbor, MI) and verified manually. Alignments were done in MacVector (Cary, NC). The sequences have been deposited in General Bank (Accession\# FJ602760-602771).

\section{RNA isolation and cDNA synthesis}

Cells were collected via filtration on $5 \mu \mathrm{m}$ polycarbonate filters and immediately stored in liquid nitrogen until extraction. RNA was extracted using RNeasy kit (Qiagen, Valencia, $\mathrm{CA}$ ) according to the manufacturer's instructions using the bead beating protocol. The RNA was then treated with Turbo DNase (Ambion, Austin, TX) following the rigorous protocol to remove genomic DNA. RNA was quantified spectrophometrically, and a total of $60 \mathrm{ng}$ of RNA was transcribed into cDNA using the iScript cDNA Synthesis kit (Bio-Rad, Hercules, CA). 
A second reaction was performed for each sample containing no reverse transcriptase to serve as controls for genomic contamination in subsequent analyses.

\section{Quantitative PCR}

Primers were designed using MacVector (Cary, NC). For each biological replicate, triplicate reactions were run using the iQ SYBR Green SuperMix (Bio-Rad, Hercules, CA) as follows: $12.5 \mu$ I SYBR Green SuperMix, $200 \mathrm{nM}$ forward and reverse primers, $2 \mu \mathrm{l}$ of diluted cDNA (the rough equivalent of $1.2 \mathrm{ng}$ of total RNA), and sterile water to a final volume of $25 \mu$ l. The Quantitative PCR (qPCR) programme consisted of $95^{\circ} \mathrm{C}$ for $5 \mathrm{~min}$, followed by 45 cycles of $95^{\circ} \mathrm{C}$ for $30 \mathrm{~s}, 60.7^{\circ} \mathrm{C}$ for $30 \mathrm{~s}$, then one cycle of $95^{\circ} \mathrm{C}$ for $1 \mathrm{~min}$ in an iCycler iQ (Bio-Rad, Hercules, CA). Melt curves for each reaction were performed to test the quality of the product. For each sample and primer pair no reverse transcriptase controls and no template controls were run to test for DNA contamination and specificity of amplification. These negative controls did not typical amplify, but in the rare cases where there was any amplification the measured template concentration was at least two orders of magnitude less than the sample template concentration.

The comparative, or $\Delta \Delta \mathrm{C}_{\mathrm{t}}$, method was used to normalize the expression of each gene. The amplification efficiency and validation of the $\Delta \Delta C_{t}$ method were tested for each primer set on cDNA. Amplification efficiency was determined to be acceptable if it fell between $90 \%$ and $110 \%$ with an $r^{2}$ of 0.98 or higher (Table 3 ). Each primer pair was considered acceptable if the $\Delta C_{t}$ of the two slopes was less than 0.1 . Samples were endogenously normalized to the constitutively expressed $\operatorname{rot} A$ (encoding a peptidyl-prolyl cis-trans isomerase) (Hassidim et al., 1992; Thellin et al., 1999). The $C_{t}$ of the reference gene did not vary with treatment, further validating its application as a reference gene. Fold changes were calculated using the Relative Expression Software Tool, which accounts for differences in efficiency in its fold change calculation (http://www.gene-quantification.de/ download.html). For each experiment a single $T_{0}$ time point sample was used as a calibrator for calculating fold changes. The $P$-values were calculated using a pair-wise fixed reallocation randomization analysis comparing the $+P$ to the $-P$ samples at each time point (Pfaffl et al., 2002).

\section{Chlorophyll a}

Between 5 and $25 \mathrm{ml}$ of culture were collected onto GF/F filters and frozen at $-20^{\circ} \mathrm{C}$. Filters were extracted in $90 \%$ acetone and incubated overnight at $-20^{\circ} \mathrm{C}$. Chlorophyll a fluorescence was measured on an aquafluor handheld fluorometer and analysed according to Arar and Collins (1997).

\section{Bulk $A P A$}

For APA assays, triplicate samples at each time point were taken. These consisted of 5-20 ml of culture filtered onto a $5 \mu \mathrm{m}$ polycarbonate filter and frozen at $-20^{\circ} \mathrm{C}$. Samples were processed as described elsewhere (Dyhrman and Ruttenberg, 2006). Briefly, $10 \mu \mathrm{M}$ 6,8-difluoro-4-methylumbelliferyl phosphate was added to each sample in a Petri dish and fluorescence was measured on a Fluostar plate reader every 5-20 min for five time points. Previous kinetics experiments found the $10 \mu \mathrm{M}$ substrate concentration to be saturating (data not shown). Standard curves were generated for each sample run using 6,8-difluoro-7-hydroxy-4-methylcoumarin. The $+\mathrm{P}$ and $-\mathrm{P}$ samples at each time point were determined to be statistically significantly different using a paired $t$-test.

\section{Acknowledgements}

We thank S. Haley for valuable technical assistance, and J. Waterbury for providing cultures. This work was supported by the NSF Biological Oceanography Program and The Center for Microbial Oceanography: Research and Education.

\section{References}

Adams, M.M., Gómez-García, M.R., Grossman, A.R., and Bhaya, D. (2008) Phosphorus deprivation responses and phosphonate utilization in a thermophilic Synechococcus sp. from microbial mats. J Bacteriol 190: 8171-8184.

Arar, E., and Collins, G. (1997) In vitro determination of chlorphyll $a$ and pheophytin $a$ in marine and freshwater algae by fluorescence. USEPA Method 44.5.

Berman-Frank, I., Cullen, J., Shaked, Y., Sherrell, R.M., and Falkowski, P. (2001) Iron availability, cellular iron quotas, and nitrogen fixation in Trichodesmium. Limnol Oceanogr 46: $1249-1260$.

Capone, D.G. (2001) Marine nitrogen fixation; what's the fuss? Curr Opin Microbiol 4: 341-348.

Capone, D.G., Zehr, J.P., Paerl, H.W., Bergman, B., and Carpenter, E. (1997) Trichodesmium, a globally significant marine cyanobacterium. Science 276: 1221-1229.

Capone, D.G., Burns, J., Montoya, J.P., Subramaniam, A., Mahaffey, C., Gunderson, T., et al. (2005) Nitrogen fixation by Trichodesmium spp. An important source of new nitrogen to the tropical and subtropical North Atlantic Ocean. Global Biogeochem Cycles 19: GB2024.

Cavendar-Bares, K.K., Karl, D.M., and Chisholm, S.W. (2001) Nutrient gradients in the western North Atlantic Ocean: relationship to microbial community structure and comparison to patterns in the Pacific Ocean. Deep Sea Res 48: 2373-2395.

Chen, Y.B., Dominic, B., Mellon, M.T., and Zehr, J.P. (1998) Circadian rhythm of nitrogenase gene expression in the diazotrophic filamentous nonheterocystous cyanobacterium Trichodesmium sp. strain IMS101. J Bacteriol 180: 3598-3368.

Clark, L.L., Ingall, E.D., and Benner, R. (1998) Marine phosphorus is selectively remineralized. Nature 393: 426.

Coles, V.J., Wilson, C., and Hood, R.R. (2004) Remote sensing of new production fuelled by nitrogen fixation. Geophys Res Lett 31: L06301. 10.1029/2003GLO19018.

Dyhrman, S.T., and Haley, S.T. (2006) Phosphorus scavenging in the unicellular marine diazotroph Crocosphaera watsonii. Appl Environ Microbiol 72: 1452-1458.

Dyhrman, S.T., and Ruttenberg, K.C. (2006) Presence and regulation of alkaline phosphatase activity in eukaryotic phytoplankton from the coastal ocean: Implications for 
dissolved organic phosphorus remineralization. Limnol Oceanogr 51: 1381-1390.

Dyhrman, S.T., Webb, E.A., Moffett, J.W., and Waterbury, J.B. (2002) Cell-specific detection of phosphorus stress in Trichodesmium from the Western North Atlantic. Limnol Oceanogr 47: 1832-1836.

Dyhrman, S.T., and Palenik, B. (2003) Characterization of ectoenzyme activity and phosphate-regulated proteins in the coccolithophorid Emiliania huxleyi. J Plankton Res 205: 230-231.

Dyhrman, S.T., Chappell, P.D., Haley, S.T., Moffett, J.W., Orchard, E.D., Waterbury, J.B., and Webb, E.A. (2006) Phosphonate utilization by the globally important marine diazotroph Trichodesmium. Nature 439: 68-71.

Dyhrman, S.T., Ammerman, J.W., and Van Mooy, B.A.S. (2007) Microbes and the marine phosphorus cycle. Oceanography 20: 110-116.

Ehrenreich, I.M., Waterbury, J.B., and Webb, E.A. (2005) Distribution and diversity of natural product genes in marine and freshwater cyanobacterial cultures and genomes. Appl Environ Microbiol 71: 7401-7413.

El-Shahawy, R., Lugomela, C., Ernst, A., and Bergman, B. (2003) Diurnal expression of hetR and diazocyte development in the filamentous non-heterocystous cyanobacterium Trichodesmium erythraeum. Microbiology 149: 1139-1146.

Fu, F.-X., Zhang, Y., Bell, P.R.F., and Hutchins, D. (2005) Phosphate uptake and growth kinetics of Trichodesmium (cyanobacteria) isolates from the North Atlantic ocean and the Great Barrier Reef, Australia. J Phycol 41: 62-73.

Hassidim, M., Schwarz, R., Lieman-Hurwitz, J., Marco, E., Ronen-Tarazi, M., and Kaplan, A. (1992) A cyanobacterial gene encoding peptidyl-prolyl cis-trans isomerase. Plant Physiol 100: 1982-1986.

Jakuba, R.W., Moffett, J.W., and Dyhrman, S.T. (2008) Evidence for the linked biogeochemical cycling of zinc, cobalt, and phosphorus in the western North Atlantic Ocean. Global Biogeochem Cycles 22: 6B4012. doi: 10.1029/ 2007GB003119.

Janson, S., Siddiqui, P.J., Walsby, A.E., Romans, K.M., Carpenter, E.J., and Bergman, B. (1995) Cytomorphological characterization of the planktonic diazotrophic cyanobacteria Trichodesmium spp. from the Indian Ocean and Caribbean and Sargasso Seas. J Phycol 31: 463-477.

Karl, D.M. (1999) A sea of change: biogeochemical variability in the North Pacific Subtropical gyre. Ecosystems 2: 181214.

Kim, E.E., and Wyckoff, H.W. (1991) Reaction mechanism of alkaline phosphatase based on crystal structures, twometal ion catalysis. J Mol Biol 218: 449-464.

Kupper, H., Setlik, I., Seibert, S., Prasil, O., Setlikova, E., Strittmatter, M., et al. (2008) Iron limitation in the marine cyanobacterium Trichodesmium reveals new insights into regulation of photosynthesis and nitrogen fixation. New Phytol 179: 784-798.

Kustka, A., Carpenter, E.J., and Sañudo-Wilhelmy, S.A. (2002) Iron and marine nitrogen fixation: progress and future directions. Res Microbiol 153: 255-262.

Longhurst, A. (1991) Role of the marine biosphere in the global carbon cycle. Limnol Oceanogr 36: 1507-1526.

Lundgren, P., Janson, S., Jonasson, S., Singer, A., and
Bergman, B. (2005) Unveiling of novel radiations within Trichodesmium cluster by hetR gene sequence analysis. Appl Environ Microbiol 71: 190-196.

Martiny, A., Coleman, M., and Chisholm, S.W. (2006) Phosphate acquisition genes in Prochlorococcus ecotypes: evidence for genome-wide adaption. Proc Natl Acad Sci USA 103: 12552-12557.

Mather, R.L., Reynolds, S.E., Wolff, G.A., Williams, R.G., Torres-Valdes, S., Woodward, E.M.S., et al. (2008) Phosphorus cycling in the North and South Atlantic Ocean subtropical gyres. Nature Geosci 1: 439-443.

Mills, M., Ridame, C., Davey, M., La Roche, J., and Geider, R.J. (2004) Iron and phosphorus co-limit nitrogen fixation in the eastern tropical North Atlantic. Nature 429: 292-294.

Monds, R., Newell, P., Schwartzman, J., and O'Toole, G. (2006) Conservation of the Pho regulon in Pseudomonas fluorescens Pf0-1. Appl Environ Microbiol 72: 1919011924.

Moore, L.R., Rocap, G., and Chisholm, S.W. (1998) Physiology and molecular phylogeny of coexisting Prochlorococcus ecotypes. Nature 393: 464-467.

Moore, L.R., Ostrowski, M., Scanlan, D.J., Feren, K., and Sweetsir, T. (2005) Ecotypic variation in phosphorusacquisition mechanisms within picocyanobacteria. Aquat Microb Ecol 39: 257-269.

Mulholland, M.R., Floge, S., Carpenter, E., and Capone, D. (2002) Phosphorus dynamics in cultures and natural populations of Trichodesmium spp. Mar Ecol Prog Ser 239: 45-55.

Orcutt, K.M., Rasmussen, U., Webb, E.A., Waterbury, J.B., Gundersen, K., and Bergman, B. (2002) Characterization of Trichodesmium spp. by genetic techniques. Appl Environ Microbiol 68: 2236-2245.

Orrett, K., and Karl, D.M. (1987) Dissolved organic phosphorus production in surface seawaters. Limnol Oceanogr 32: 383-398.

Pfaffl, M.W., Horgan, G., and Leo, D. (2002) Relative Expression Software Tool (REST) for group wise comparison and statistical analysis of relative expression results in real-time PCR. Nucleic Acids Res 30: E36.

Ray, J.M., Bhaya, D., Block, M.A., and Grossman, A.R. (1991) Isolation, transcription, and inactivation of the gene for an atypical alkaline phosphatase of Synechococcus sp. strain PCC 7942. J Bacteriol 173: 4297-4309.

Roy, N.K., Ghosh, R.K., and Das, J. (1982) Monomeric alkaline phosphatase of Vibrio cholerae. J Bacteriol 150: 10331039.

Sañudo-Wilhelmy, S.A., Kustka, A.B., Gobler, C.J., Hutchins, D.A., Yang, M., Lwiza, K., et al. (2001) Phosphorus limitation of nitrogen fixation by Trichodesmium in the Central Atlantic Ocean. Nature 411: 66-69.

Sañudo-Wilhelmy, S.A., Tovar-Sanchez, A., Fu, F.X., Capone, D.G., Carpenter, E.J., and Hutchins, D.A. (2004) The impact of surface-adsorbed phosphorus on phytoplankton Redfield stoichiometry. Nature 432: 897-901.

Scanlan, D.J., Silman, N.J., Donald, K.M., Wilson, W.H., Carr, N.G., Joint, I., and Mann, N.H. (1997) An immunoloigical approach to detect phosphate stress in populations and single cells of photosynthetic picoplankton. Appl Environ Microbiol 63: 2411-2420.

Sebastian, M., and Ammerman, J.W. (2009) The alkaline 
phosphatase PhoX is more widely distributed in marine bacteria than the classical PhoA. ISME J 3: 563-572. doi: 10.1038/ismej.2009.10.

Shaked, Y., Xu, Y., Leblanc, K., and Morel, F.M.M. (2006) Zinc availability and alkaline phosphatase activity in Emiliania huxleyi: Implications for Zn-P co-limitation in the ocean. Limnol Oceanogr 51: 299-309.

Shi, T., Sun, Y., and Falkowski, P.G. (2007) Effects of iron limitation on the expression of metabolic genes in the marine cyanobacterium Trichodesmium erythraeum IMS101. Environ Microbiol 9: 2945-2956.

Sohm, J.A., and Capone, D.G. (2006) Phosphorus dynamics of the tropical and subtropical North Atlantic: Trichodesmium spp. versus bulk plankton. Mar Ecol Prog Ser 317: 21-28.

Stihl, A., Sommer, U., and Post, A. (2001) Alkaline phosphatase activities among populations of the colony-forming diazotrophic cyanobacterium Trichodesmium spp. (Cyanobacteria) in the Red Sea. J Phycol 37: 310-317.

Su, Z., Dam, P., Chen, X., Olman, V., Jiang, T., Palenik, B., and $\mathrm{Xu}, \mathrm{Y}$. (2003) Computational inference of regulatory pathways in microbes: an application to phosphorus assimilation pathways in Synechococcus sp. WH8102. Genome Inform 13: 3-13.

Su, Z., Olman, V., and Xu, Y. (2007) Computational prediction of Pho Regulons in cyanobacteria. BMC Genomics 8: 156-167.

Suzuki, S., Ferjani, A., Suzuki, I., and Murata, N. (2004) The
SphS-SphR two component system is the exclusive sensor for the induction of gene expression in response to phosphate limitation in Synechocystis. J Biol Chem 279: 13234-13240.

Thellin, O., Zorzi, W., Lakaye, B., De Borman, B., Coumans, B., Hennen G., et al. (1999) Housekeeping genes as internal standards: use and limits. J Biotechnol 75: 291295.

Vershinina, O.A., and Znamenskaia, L.V. (2002) The Pho regulons of bacteria. Mikrobiologia 71: 581-595.

Webb, E., Jakuba, R.W., Moffett, J.W., and Dyhrman, S. (2007) Molecular assessment of phosphorus and iron physiology in Trichodesmium populations from the Western Central and Western South Atlantic. Limnol Oceanogr 52: 2221-2232.

Webb, E.A., Moffett, J.W., and Waterbury, J.B. (2001) Iron stress in open-ocean cyanobacteria (Synechococcus, Trichodesmium, and Crocosphaera spp.): identification of the IdiA protein. Appl Environ Microbiol 67: 5444-5452.

Wu, J., Sunda, W., Boyle, E.A., and Karl, D.M. (2000) Phosphate depletion in the western North Atlantic Ocean. Science 289: 759-762.

Wu, J.-R., Shien, J.-H., Shieh, H.K., Hu, C.-C., Gong, S.-R., Chen, L.-Y., and Chang, P.-C. (2007) Cloning of the gene and characterization of the enzymatic properties of the monomeric alkaline phosphatase (PhoX) from Pasteurella multocida strain X-73. FEMS Microbiol Lett 267: 113120. 


\title{
CHAPTER 5
}

\section{Molecular evidence for phosphorus limitation of Trichodesmium growth and nitrogen fixation in the North Atlantic}

\begin{abstract}
The nitrogen $(\mathrm{N})$ fixing cyanobacterium, Trichodesmium has a significant impact on the $\mathrm{N}$ and carbon (C) cycles of the tropical and subtropical oceans. Phosphorus (P) concentrations are very low in these regions, and therefore $\mathrm{P}$ has been suggested to constrain $\mathrm{N}_{2}$ and $\mathrm{CO}_{2}$ fixation by this genus. However, there is little direct evidence of $\mathrm{P}$ limitation of Trichodesmium or its affect on $\mathrm{N}_{2}$ fixation in these tropical oceans. By combining molecular techniques with culture experiments we can probe the interplay between nutrient limitation, gene expression, and physiological responses such as decreased $\mathrm{N}_{2}$ fixation rates in culture and in the field. This study identifies $\mathrm{P}$ limitation levels that are indicative of decreases in $\mathrm{N}_{2}$ fixation rate in Trichodesmium by measuring $\mathrm{N}_{2}$ fixation and several metrics of $\mathrm{P}$ physiology (alkaline phosphatase activity, cellular ratios of $\mathrm{C}: \mathrm{P}$ and phoX gene expression) in culture. Expression of the phoX gene, which encodes an alkaline phosphatase, was calibrated to decreases in $\mathrm{N}_{2}$ fixation in semicontinuous cultures of T. erythraeum IMS101 grown at different P-limited growth rates. The expression of phoX, measured in field populations of Trichodesmium from the North Atlantic and South Pacific, was significantly correlated to inorganic phosphate concentration. Additionally, expression levels of phoX in the North Atlantic were
\end{abstract}


indicative of a $40-70 \%$ reduction in $\mathrm{N}_{2}$ fixation due to $\mathrm{P}$ limitation. These data indicate that $\mathrm{P}$ can limit growth and $\mathrm{N}_{2}$ fixation in Trichodesmium from the North Atlantic.

\section{Introduction}

Understanding the controls on primary production is a critical area of research in oceanography. Marine diazotrophs, such as Trichodesmium, are important contributors to primary production because they fix both atmospheric carbon $(\mathrm{C})$ and nitrogen $(\mathrm{N})$. Trichodesmium often dominates in tropical and subtropical oceans where approximately $50 \%$ of the oceans primary production occurs (Capone et al., 1997; Karl, 2002). In these regions the input of $\mathrm{N}$ from diazotrophs accounts for an estimated 50\% of the "new" nitrogen to these systems (Karl, 2002). Further, it is this "new" nitrogen that supports export production in oligotrophic regions (Capone, 2001). Therefore, understanding the controls on growth and $\mathrm{N}_{2}$ fixation of Trichodesmium is critical to understanding the constraints on primary productivity in oligotrophic oceans.

Iron $(\mathrm{Fe})$ and phosphorus $(\mathrm{P})$ are generally considered the two most important nutrients in limiting $\mathrm{N}_{2}$ fixation. Culture work, field correlations, and qualitative molecular assays have repeatedly suggested that Trichodesmium can be Fe-limited (Berman-Frank et al., 2001; Kustka et al., 2003; Moore et al., 2009) P-limited (Wu et al., 2000; Sañudo-Wilhelmy et al., 2001; Dyhrman et al., 2002; Sohm et al., 2008; Hynes et al., 2009), or Fe and P co-limited (Mills et al., 2004). The bulk of these studies suggest that Trichodesmium or $\mathrm{N}_{2}$ fixation is more often Fe-limited in the Pacific and South Atlantic, and P-limited in the North Atlantic. These conclusions are based on studies using a variety of metrics to determine nutrient physiology, and the results of these 
experiments can vary greatly depending on the time scale considered and the process being measured.

Traditional metrics for determining nutrient limitation, such as incubation experiments, chemical analysis, and mathematical modeling have been extremely useful, but they do not allow for the determination of the nutritional status of a single component in a natural assemblage. Enzyme-labeled fluorescence (ELF) alkaline phosphatase activity (APA) assays do allow for cell-specific identification of P physiology, but is qualitative (Dyhrman et al., 2002). There is a need for new techniques that can probe the physiology of a single group of interest quantitatively. Quantitative gene expression is just such an assay. Previous work has shown that Trichodesmium regulates phoX, which encodes an alkaline phosphatase, in response to P physiology (Orchard et al., 2009). Therefore, the expression of this gene in the field can be a genus-specific method to quantitatively assess $\mathrm{P}$ physiology. Additionally, the abundance of the phoX transcript decreases rapidly upon recovery from P limitation in culture (within hours), unlike the activity of the enzyme it encodes (APA) which can take days to decrease (Orchard et al., 2009). Because of its rapid response and turnover, phoX expression is a more instantaneous metric of P physiology than APA.

This study used a semi-continuous culture technique to link P-limited growth rate to changes in $\mathrm{N}_{2}$ fixation rate, APA, cellular C:P ratios, and phoX expression in laboratory cultures. The expression of $p h o X$ was then measured in the both North Atlantic and South Pacific Trichodesmium populations, providing a direct and quantitative assay 
of $\mathrm{P}$ limitation of Trichodesmium $\mathrm{N}_{2}$ fixation. To our knowledge, this is the first quantitative genus-specific detection of $\mathrm{P}$ limitation in Trichodesmium field populations.

\section{Methods}

\section{Culture experiments}

Trichodesmium erythraeum IMS101 cultures were grown in $250 \mathrm{~mL}$ flasks at $25^{\circ} \mathrm{C}$ on a shaker table with daily cycles that consisted of $1 \mathrm{hr}$ at $13.5 \mu$ Ein m $\mathrm{m}^{-2}, 10 \mathrm{hrs}$

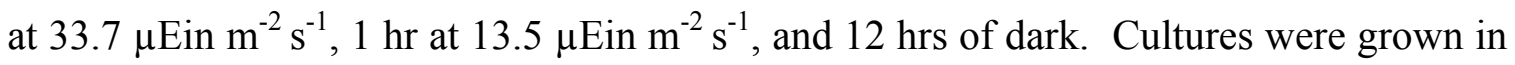
duplicate on RMP media as described in Webb et al. (2001) using a phosphate concentration of $2 \mu \mathrm{M}$. Once cultures reached exponential growth they were diluted daily. Two separate semi-continuous experiments were preformed, one to measure $\mathrm{N}_{2}$ fixation, APA, C:P ratio, which was diluted at $0.1,0.15$ or $0.25 \mathrm{~d}^{-1}$. The second measured phoX and nifH expression, and the cultures were diluted at $0.1,0.2$ or $0.25 \mathrm{~d}^{-1}$. Cultures were considered entrained at a specific growth rate when in-vivo chlorophyll $a$ fluorescence was stable for seven days. These cultures were unialgal, but not axenic. However, biomass was dominated by Trichodesmium.

\section{Field Samples}

Samples were taken during three cruises to the North Atlantic and one in the South Pacific (Figure 1; Table 1). Trichodesmium colonies were collected from the near surface (roughly within the top 20m) using a hand held $130 \mu \mathrm{m}$ net. Colonies were split by morphotype and only colonies with a raft morphology (parallel trichomes) were used 
in further analyses. Single colonies were picked into $0.2 \mu \mathrm{m}$-filtered local surface seawater, and then transferred into fresh $0.2 \mu \mathrm{m}$-filtered water to reduce contamination of closely associated organisms. Colonies were then separated for further analyses as indicated below. To the extent possible, samples were collected at similar times of the day to avoid possible diel variability in gene expression patterns (Table 1). Water samples were collected from a Niskin bottle on a conductivity, temperature and depth (CTD) rosette from a depth of $5 \mathrm{~m}$, and were processed to determine nutrient concentrations as described below.

\section{Enzyme activity assays}

For APA assays, 3-5 field colonies or 5-20 $\mathrm{ml}$ of culture were filtered onto a $5 \mu \mathrm{m}$ polycarbonate filter. Samples were processed as described elsewhere (Dyhrman and Ruttenberg, 2006). Briefly, $10 \mu \mathrm{mol} \mathrm{L}^{-1}$ 6,8-difluoro-4-methylumbelliferyl phosphate (di-MUF-P) (Invitrogen) was added to each sample in a petri dish with artificial seawater containing no added $\mathrm{P}$, and fluorescence was measured on a Fluostar Optima plate reader (BMG Labtech) every 5-20 minutes for 5 time points, within the linear range of the assay. Previous kinetics experiments found the $10 \mu \mathrm{mol} \mathrm{L}^{-1}$ substrate concentration to be saturating (data not shown). Standard curves were generated for each assay using 6,8difluoro-7-hydroxy-4-methylcoumarin (di-MUF).

$\mathrm{N}_{2}$ fixation was measured using the acetylene reduction assay as described in Capone and Montoya (2001). Incubations were conducted with $30 \mathrm{ml}$ of culture in $75 \mathrm{ml}$ (total volume) Nalgene bottles with septa lids. To each sample, $6 \mathrm{ml}$ of acetylene was 
added to the headspace at the mid-point of the light cycle (when Trichodesmium $\mathrm{N}_{2}$ fixation should be highest). The ethylene concentration in the headspace was measured in duplicate every hour using a GC-8A gas chromatograph (Shimadzu Norwell, MA). A ratio of 4:1 $\mathrm{C}_{2} \mathrm{H}_{2}: \mathrm{N}_{2}$ was used to convert to $\mathrm{N}_{2}$ fixation rates. A two-tailed $t$ test was used to determine if rates were statistically different.

\section{Chlorophyll a}

Between 5-25 $\mathrm{ml}$ of culture was collected onto $\mathrm{GF} / \mathrm{F}$ filters and frozen at $-20^{\circ} \mathrm{C}$. Filters were extracted in $90 \%$ acetone and incubated overnight at $-20^{\circ} \mathrm{C}$. Chlorophyll $a$ fluorescence ( $\operatorname{chl} a$ ) was measured on an aquafluor handheld fluorometer and analyzed according to Arar and Collins (1997).

\section{Nutrients}

Approximately $15 \mathrm{ml}$ of culture from the semi-continuous experiment was collected on pre-combusted $\left(500^{\circ} \mathrm{C}\right.$ for 5 hours $) 25 \mathrm{~mm}$ Whatman $\mathrm{GF} / \mathrm{F}$ and dried at $60^{\circ} \mathrm{C}$ for particulate $\mathrm{C}$ and $\mathrm{P}$ measurements. Particulate $\mathrm{C}$ was measured on Flash EA1112 CHN Analyzer using a Dynamic Flash Combustion technique. Intracellular P $\left(\mathrm{P}_{\mathrm{IC}}\right)$ and total cellular $\mathrm{P}\left(\mathrm{P}_{\mathrm{TC}}\right)$ were compared by washing or not washing with oxalate reagent as in (Sañudo-Wilhelmy et al., 2004). Samples were then combusted for 1 hour at $500^{\circ} \mathrm{C}$. They were then incubated at $104^{\circ} \mathrm{C}$ for 2 hours with $0.4 \mathrm{ml}$ of $1 \mathrm{~N} \mathrm{HCl}$ and $2 \mathrm{ml}$ of DI water, and measured according the method of Murphy et al. (1962). Samples were read on a UV-1700 Spectrophometer (Shimadzu, Norwell MA) at $885 \mathrm{~nm}$. A two-tailed $t$ test 
was used to determine if ratios were statistically different.

Soluble reactive phosphorus (SRP) from a depth of $5 \mathrm{~m}$ was measured according to the MAGIC-SRP method (Karl and Tien, 1992), for samples from the Atlantic or using the molybdenum blue procedure (Bernhardt and Wilhelms, 1967) for samples from the Pacific. For station 11 on the SPAC cruise, there was no SRP sample taken, but it is estimated as $54 \mathrm{nM}$ as the average of the SRP concentration from the two closest stations (Table 1). SRP concentrations measured here are referred to as the dissolved inorganic phosphorus (DIP) concentration.

\section{RNA Isolation and cDNA Synthesis}

Field colonies or cultures were collected via filtration on $5 \mu \mathrm{m}$ polycarbonate filters, frozen in liquid nitrogen as quickly as possible (typically around 2 minutes for cultures and 15-30 minutes for field samples), and stored in liquid nitrogen until they were extracted. RNA was extracted using an RNeasy kit (Qiagen, Valencia, CA) according to the manufacturer's instructions using the bead beating protocol. The RNA was then treated with Turbo DNase (Ambion, Austin, TX) following the rigorous protocol to remove genomic DNA. RNA from field samples were precipitated with $100 \%$ ethanol and stored at $-80^{\circ} \mathrm{C}$ overnight. Field RNA samples were then spun for 30 minutes at $14000 \mathrm{rpm}$ and the ethanol was removed form the RNA pelleted, and the pellet was re-suspended in RNase free water. All RNA was quantified spectrophometrically, and a total of $60 \mathrm{ng}$ of RNA for culture samples and $120 \mathrm{ng}$ for field samples was transcribed into cDNA using the iScript cDNA Synthesis kit (Bio-Rad, Hercules, CA). A 
second reaction was performed for each sample containing no reverse transcriptase to serve as controls for genomic contamination in subsequent analyses.

\section{Quantitative PCR (qPCR)}

Quantitative PCR was performed following the protocol and using the primers (phoX and rotA) from Orchard et al. (2009). These primers were designed to conserved regions of these genes and have been used to amplify a broad spectrum of Trichodesmium species. Further, the expression of phoX has been examined in a representative species from a second Trichodesmium clade (Trichodesmium spp. H9-4) (Chappell and Webb, 2009) and was found to have the same expression pattern for phoX (data not shown). Melt curves for each reaction were performed to test the quality of the product. For each sample and primer pair no reverse transcriptase controls and no template controls were run to test for DNA contamination and specificity of amplification. These negative controls did not typical amplify, but in the rare cases where there was any amplification the measured template concentration was at least two orders of magnitude less than the sample template concentration. For field samples, multiple template dilutions were tested for each sample to confirm that the primers had the same efficiencies as they did in culture (Orchard et al., 2009), and therefore confirm that the reactions were not inhibited. It was empirically determined that when the template was diluted at least 1:5 for all the field samples tested here, the reaction was not inhibited.

The comparative, or $\Delta \Delta \mathrm{C}_{\mathrm{t}}$, method was used to normalize the expression of each gene. The amplification efficiency and validation of the $\Delta \Delta \mathrm{C}_{\mathrm{t}}$ method were tested for 
each primer set on cDNA. Samples were endogenously normalized to the constitutively expressed rotA (encoding a peptidyl-prolyl cis-trans isomerase) (Orchard et al., 2009). Fold changes were calculated using the Relative Expression Software Tool (REST), which accounts for differences in efficiency in its fold change calculation (http://www.gene-quantification.de/download.html). In both field and culture expression data a replicate of the $0.25 \mathrm{~d}^{-1}$ diluted culture (the most P replete) was used as a calibrator for calculating fold changes. The $p$-values were calculated using a pair-wise fixed reallocation randomization test (Pfaffl et al., 2002).

\section{Results}

\section{Semi-continuous experiment}

Three different metrics were used to examine $\mathrm{P}$ physiology in the semicontinuous culture experiment: APA, C:P ratios (using both total cellular $\mathrm{P}, \mathrm{P}_{\mathrm{TC}}$; and intracellular $\left.\mathrm{P}, \mathrm{P}_{\mathrm{IC}}\right)$, and the expression of phoX. APA normalized to chl $a$ tracked inversely with dilution rate (Figure 2C). APA from cultures growing at $0.1 \mathrm{~d}^{-1}$ was significantly higher than cultures growing at $0.25 \mathrm{~d}^{-1}(p<0.001)$. The ratio of $\mathrm{C}: \mathrm{P}_{\mathrm{TC}}$ ranged from 96-156, and also tracked inversely with dilution rate (Figure 2E). This range spans from slightly below the Redfield ratio $(106: 1)$ to well above. Although the $0.1 \mathrm{~d}^{-1}$ and $0.15 \mathrm{~d}^{-1}$ diluted cultures had similar $\mathrm{C}: \mathrm{P}_{\mathrm{TC}}$ ratios of $149.7+/-0.524$ and $156.1+/-12.45$, the $\mathrm{C}: \mathrm{P}_{\mathrm{IC}}$ for the $0.10 \mathrm{~d}^{-1}$ cultures was much higher than the $0.15 \mathrm{~d}^{-1}$ cultures. The 
cultures diluted at $0.1 \mathrm{~d}^{-1}$ had a significantly higher $\mathrm{C}: \mathrm{P}_{\mathrm{TC}}$ and $\mathrm{C}: \mathrm{P}_{\mathrm{IC}}$ than the cultures diluted at $0.25 \mathrm{~d}^{-1}(p=0.04$ and $p=0.004$ respectively).

Like C:P ratio and APA, phoX expression tracked inversely with dilution rate. The expression of phoX was significantly higher (56 fold; $p>0.001$ ) in the $0.1 \mathrm{~d}^{-1}$ diluted culture compared to the $0.25 \mathrm{~d}^{-1}$ diluted culture (Figure 2D). The expression of phoX in the $0.2 \mathrm{~d}^{-1}$ diluted cultures was intermediate with a fold change of 17 higher than the 0.25 $\mathrm{d}^{-1}$ diluted cultures. Therefore, the expression of phoX has a similar relationship as the gene it encodes and tracks with traditional metrics of $\mathrm{P}$ physiology.

$\mathrm{N}_{2}$ fixation rates were measured for each culture. The cultures diluted at $0.25 \mathrm{~d}^{-1}$ had the highest $\mathrm{N}_{2}$ fixation rates per unit chl $a$, with $\mathrm{N}_{2}$ fixation decreasing with increasing P limitation. The $0.1 \mathrm{~d}^{-1}$ dilution rate cultures had a significantly lower $\mathrm{N}_{2}$ fixation rate than the cultures diluted at $0.25 \mathrm{~d}^{-1}(p<0.05)$ (Figure 2A). The highest expression for nifH in the $0.25 \mathrm{~d}^{-1}$ diluted sample at 1.2 the replicate $0.25 \mathrm{~d}^{-1}$ culture (Figure 2B). The nifH gene was down regulated in the $0.2 \mathrm{~d}^{-1}$ and the $0.1 \mathrm{~d}^{-1}$ diluted culture by 2.3 and 5.8 fold respectively. The expression of nifH was significantly lower $(p<0.001)$ for the $0.1 \mathrm{~d}^{-1}$ diluted culture relative to the $0.25 \mathrm{~d}^{-1}$ diluted culture. Therefore, nifH expression showed the same relative pattern between the cultures as $\mathrm{N}_{2}$ fixation.

By plotting the expression of $p h o X$ versus the percent reduction in $\mathrm{N}_{2}$ fixation (relative to the maximal $\mathrm{N}_{2}$ fixation measured) $p h o X$ expression can be calibrated to $\mathrm{P}$ driven reductions in $\mathrm{N}_{2}$ fixation (Figure $2 \mathrm{~F}$ ). This calibration can then be used to predict reductions in $\mathrm{N}_{2}$ fixation in the field based on the degree of $p h o X$ expression. The data 
was divided into three bins indicating the level of $p h o X$ expression where there was a 0 $40 \%, 40-70 \%$ or above $70 \% \mathrm{P}$ driven reduction in $\mathrm{N}_{2}$ fixation.

\section{Basin-wide comparisons of DIP, APA and phoX expression.}

Inorganic phosphate (DIP) concentration varied with region. The South Pacific had the highest DIP concentration ranging from 43-114 nM, and the North Atlantic samples had significantly lower DIP concentrations ranging from 0.5-17.6 nM (Table 1; Figure 3) $(p<0.001)$. Trichodesmium APA was significantly higher in the North Atlantic (0.23-0.56 nmol $\mathrm{P} \mathrm{h}^{-1}$ colony $\left.^{-1}\right)$ than the South Pacific, $\left(0.009-0.03 \mathrm{nmol} \mathrm{P} \mathrm{h}{ }^{-1}\right.$ colony $\left.{ }^{-1}\right)$ (Table 1; Figure 3) $(p<0.001)$. Trichodesmium APA also trended with DIP concentration, where the highest APA values occurred in the locations with the lowest DIP

concentrations. These data had a log-linear relationship with $\left(\mathrm{r}^{2}=0.83 ; p>0.001\right)$. While the data was significant correlated, most of the values clustered together in the North Atlantic with low DIP and high APA, or in the South Pacific with low APA and higher DIP (Figure 3C).

The expression of phoX in the field was variable depending on location. The South Pacific samples expression ranged from 5-17.5 fold higher than the $0.25 \mathrm{~d}^{-1}$ diluted culture. The samples from the North Atlantic were higher with expression ranging from 51-453 fold higher than the $0.25 \mathrm{~d}^{-1}$ diluted culture. The data from X0804 station 8 is included in the graphs, but not in the regression, because the DIP concentration at this station is anomalously high. The expression of $p h o X$ was significantly correlated to DIP 
concentration with a $\log$-log relationship that had a $\left(\mathrm{r}^{2}=0.75 ; p>0.001\right)$ (Figure $3 \mathrm{~A}$ and B).

\section{Discussion}

Understanding what constrains $\mathrm{N}_{2}$ fixation is critical to understanding ocean biogeochemistry and the limits on primary productivity. There have been a number of studies in the North Atlantic that have suggested that $\mathrm{P}$ could be limiting to $\mathrm{N}_{2}$ fixation (Sañudo-Wilhelmy et al., 2001; Mills et al., 2004; Webb et al., 2007) and to Trichodesmium (Dyhrman et al., 2002; Mulholland et al., 2002). But without a quantitative, genus-specific metric for $\mathrm{P}$ physiology, it is difficult to assess the extent of $\mathrm{P}$ limitation in natural populations of Trichodesmium and the extent to which $\mathrm{P}$ could be limiting $\mathrm{N}_{2}$ fixation. By examining the expression of P-regulated genes in Trichodesmium and linking those expression patterns to known affects on $\mathrm{N}_{2}$ fixation rates it was possible to identify the level of $\mathrm{P}$ limitation in situ, and predict reductions in $\mathrm{N}_{2}$ fixation due to $\mathrm{P}$ limitation in Trichodesmium.

\section{Culture experiments}

Trichodesmium erythraeum IMS101 was entrained at different P-limited growth rates (by varying the dilution rate) to calibrate the expression of $p h o X$ to decreases in $\mathrm{N}_{2}$ fixation rate due to $\mathrm{P}$ limitation. APA, C:P and $p h o X$ expression tracked inversely with growth rate, $\mathrm{N}_{2}$ fixation, and nifH expression. The cultures with the highest growth rate, and the largest input of new P per day had the lowest APA and the highest $\mathrm{N}_{2}$ fixation 
rate when normalized to chl $a$. Therefore, $\mathrm{N}_{2}$ fixation in Trichodesmium was constrained by $\mathrm{P}$ supply. In fact, the $\mathrm{N}_{2}$ fixation rate in the cultures with the lowest growth rate $(0.1$ $\mathrm{d}^{-1}$ ) was reduced by $70 \%$ compared to that of the cultures diluted at the highest growth rate $\left(0.25 \mathrm{~d}^{-1}\right)$, and all metrics of $\mathrm{P}$ physiology indicated that Trichodesmium was $\mathrm{P}$ limited in those cultures. A similar $\mathrm{P}$ driven reduction in $\mathrm{N}_{2}$ fixation rate of $66 \%$ in Trichodesmium semi-continuous culture was observed in Hutchins et al (2007). This experiment allows for the calibration of $p h o X$ expression to reductions in $\mathrm{N}_{2}$ fixation due to $\mathrm{P}$ limitation (Figure 2F), which can then be used to predict the degree to which $\mathrm{N}_{2}$ fixation is limited by $\mathrm{P}$ in field samples by measuring phoX expression.

It is important to note that these cultures were not axenic, and both $\mathrm{C}: \mathrm{P}$ ratios and APA were influenced by heterotrophs in the culture. Additionally, Trichodesmium colonies in the field are rich microbial consortia, and APA and C:P would likewise be affected by heterotrophs associated with Trichodesmium in natural populations. Furthermore, APA in Trichodesmium does not appear to be actively degraded (Orchard et al., 2009), and therefore the APA more accurately reflects the nutritional history of the population not the current physiology. So while APA does track with Trichodesmium physiology this not the ideal metric to use in field populations to identify genus-specific $\mathrm{P}$ limitation.

The C:P ratio is frequently used as a measure of $\mathrm{P}$ physiology in both culture and field populations (Falkowski, 1997; Tyrrell, 1999). However, there is considerable plasticity in this ratio in cyanobacteria in general, and in Trichodesmium in particular, which confounds the interpretation (Bertilsson et al., 2003; Krauk et al., 2006; White et 
al., 2006). A further complication is that a portion of the $\mathrm{P}$ associated with the cell appears to be adsorbed to the surface (Sañudo-Wilhelmy et al., 2004). C:P $\mathrm{P}_{\mathrm{IC}}$ ratios followed the same general pattern as APA and the inverse of $\mathrm{N}_{2}$ fixation rates. C: $\mathrm{P}_{\mathrm{TC}}$ ratios were very similar for cultures grown at either $0.1 \mathrm{~d}^{-1}$ or $0.15 \mathrm{~d}^{-1}$. This was unexpected considering the APA data, which suggests that the cultures diluted at $0.10 \mathrm{~d}^{-1}$ were much more limited than those diluted at $0.15 \mathrm{~d}^{-1}$. However, based on C:P $\mathrm{P}$ concentration cultures diluted at $0.1 \mathrm{~d}^{-1}$ had much higher C:P ratios. It may also be that oxalate washing removes more $\mathrm{P}$ than is simply adsorbed to the surface, or that with increased APA proportionally more $\mathrm{P}$ was adsorbed to the outside of these cells as a natural step before being assimilated into the cell. Taken together, C:P $\mathrm{P}_{\text {IC }}$ tracks best with other metrics of P physiology, but given the variability of this metric observed in this study and elsewhere, C:P ratios may not be the most practical method for inferring $\mathrm{P}$ limitation of $\mathrm{N}_{2}$ fixation rates in the field.

These culture results demonstrate that the expression of $p h o X$ can be used to identify P physiology of Trichodesmium and infer affects on $\mathrm{N}_{2}$ fixation by this genus. Utilizing the expression of $p h o X$ has the added benefit of being genus-specific, so unlike APA or C:P, examining phoX expression will not be affected by epibionts. Therefore, using phoX expression is a useful metric for identifying Trichodesmium physiology and identifying areas where $\mathrm{P}$ limits $\mathrm{N}_{2}$ fixation.

\section{Basin-wide comparisons of DIP, APA and phoX expression}


The expression of phoX was detectable in all field populations of Trichodesmium in the North Atlantic and South Pacific. To our knowledge nifH is the only other Trichodesmium functional gene whose expression has been measured quantitatively in a marine system (Church et al., 2005; Foster et al., 2009). The expression of phoX in the field shows a log-log relationship with DIP concentration. It is important to note that phoX expression is regulated by $\mathrm{P}$ physiology not DIP supply. Therefore, whether Trichodesmium is utilizing DIP, or DOP, as a P source, phoX is down-regulated. This has been demonstrated in Synechococcus where phoX was not highly expressed when growing on phosphonate (a DOP compound) as compared to cultures that were P-starved (Adams et al., 2008). Additionally spiking either P ester or phosphonate to a P-starved culture of Trichodesmium results in the down-regulation of phoX within 4 hours (data not shown). Therefore, this tight correlation between $p h o X$ and DIP implies that the bioavailable P pool is probably correlated to the DIP concentration.

There was also a significant relationship between APA and DIP. Although the majority of the samples clustered together at very high rates for the North Atlantic samples and low rates for the South Pacific samples. Given that APA is not a Trichodesmium specific signal and that previous culture results suggest that APA may not be actively degraded, we would expect to see generally higher values in the North Atlantic.

Within the North Atlantic there were detectable differences in the expression of pho $X$ and therefore gradations in the degree of $\mathrm{P}$ limitation in Trichodesmium within this ocean gyre. Further demonstrating that $p h o X$ is a very sensitive metric of $\mathrm{P}$ physiology. 
It is striking that even in the very low $\mathrm{P}$ North Atlantic small changes in DIP concentration can led to large changes in phoX expression, suggesting even more variation in the degree of $\mathrm{P}$ limitation in this area than previously considered.

The high level of expression of phoX in the North Atlantic Trichodesmium samples implies that Trichodesmium growth rate and $\mathrm{N}_{2}$ fixation by were depressed, and C:P ratios was elevated. This is consistent with previous studies from the North Atlantic that have shown elevated C:P ratios for Trichodesmium (Krauk et al., 2006; White et al., 2006). Based on the level of phoX expression, Trichodesmium $\mathrm{N}_{2}$ fixation is P-limited in the North Atlantic by over $40 \%$ and in many cases over $70 \%$ relative to maximal potential rates in culture. These data suggest that if Trichodesmium were re-fed $\mathrm{P}$ in the North Atlantic, then $\mathrm{N}_{2}$ fixation rate would increase in this region by as much as $70 \%$ (assuming no co-limitation is occurring).

\section{P limitation in other gyres}

There was little change in phoX expression above $7 \mathrm{nM}$, but below $7 \mathrm{nM}$ phoX expression increased rapidly (Figure 3A). This implies that there could be a threshold concentration of DIP (representing bio-available P) where P becomes limiting. Moutin et al (2005) calculated a similar threshold DIP concentration of $9 \mathrm{nM}$ for Trichodesmium in the South Pacific based on DIP uptake kinetics. Assuming that this threshold DIP concentration is applicable for other regions of the ocean (in addition to the South Pacific and North Atlantic), it can be used to predict where $\mathrm{P}$ is limiting to Trichodesmium in the ocean. The western North Atlantic has chronically low DIP concentration in the 
subnamolar to $10 \mathrm{nM}$ range (Wu et al., 2000; Lomas et al., 2009), therefore we would predict that $\mathrm{P}$ general limits Trichodesmium growth and $\mathrm{N}_{2}$ fixation in this region. DIP concentrations in the North Pacific are much more variable ranging from 6-100 nM (Bjorkman et al., 2000; Grabowski et al., 2008), therefore Trichodesmium could at times be experiencing P limitation in the North Pacific but this would be transient compared to the North Atlantic. While DIP concentrations in the South Atlantic and the South Pacific tend to be higher than the $7 \mathrm{nM}$ threshold, there are locations, at least for the South Pacific where the DIP concentration has dropped below this threshold (Moutin et al., 2005). This suggests that while $P$ is probably not limiting for most of the year, there are times where DIP could reach limiting concentrations. In the Mediterranean P concentrations can be sub-nanomolar (Thingstad et al., 2005), and if the Trichodesmium in this region have a similar P threshold then P would be limiting. As this study would predict based on threshold $\mathrm{P}$ concentrations, during a large-scale $\mathrm{P}$ addition experiment that was conducted in the Mediterranean, there was an increase in $\mathrm{N}_{2}$ fixation rate relative to outside of the P addition area (Rees et al., 2006).

It has been suggested that diazotrophy is enhanced under higher $\mathrm{CO}_{2}$ conditions (Hutchins et al., 2007). Increases in $\mathrm{N}_{2}$ fixation could drive regimes towards $\mathrm{P}$ limitation (Hutchins et al., 2007). It has further been suggested that increased $\mathrm{N}_{2}$ fixation is driving the North Pacific, a traditionally N-limited system, towards P limitation (Karl, 1999), and increased $\mathrm{N}_{2}$ fixation would only further drive the system towards $\mathrm{P}$ limitation. Therefore, while currently there are few places in the ocean where $\mathrm{N}_{2}$ fixation is 
predicted to be limited by P (Moore et al., 2004), P limitation could become much more wide spread in the future.

\section{Conclusion}

The expression of phoX is a useful quantitative species-specific metric for $\mathrm{P}$ physiology in Trichodesmium. Using a semi-continuous culture approach we determined levels of phoX indicative decreased $\mathrm{N}_{2}$ fixation due to P limitation. In field populations there is a tight relationship between DIP concentration and $p h o X$ expression. Further, these data suggest that the North Atlantic is chronically P-limited, but that there are detectable differences in the degree of limitation using $p h o X$ expression. All the samples measured in the North Atlantic had a level of phoX expression greater or very near the level at which there was a 70\% reduction in $\mathrm{N}_{2}$ fixation rate in culture, but South Pacific samples were not P-limited based on these metrics. The relationship between phoX expression and DIP concentration suggests that there is a threshold concentration of bioavailable $\mathrm{P}$ that is proportional to $7 \mathrm{nM}$ DIP, and at this threshold $\mathrm{P}$ starts to become limiting for $\mathrm{N}_{2}$ fixation in Trichodesmium. While there are few areas of the ocean that have DIP concentrations consistently below this threshold, seasonal variability can lead to periods of $\mathrm{P}$ limitation. Additionally, if $\mathrm{CO}_{2}$ concentrations continue to rise, and oligotrophic systems are driven towards lower DIP concentration, then P limitation of $\mathrm{N}_{2}$ fixation may become more common. This work utilized molecular indicators of physiology and link molecular biology to biogeochemical processes. These data 
underscore the potential for combining these techniques to probe genus or speciesspecific responses to environmental stimuli.

\section{Acknowledgement}

I would like to thank the chief scientists, M. Lomas, D. Hutchins, J. Zehr and J. Montoya from the BVAL39, X0804, X0705 and SPAC cruises as well as the crew of the R/V Atlantic Explorer and the R/V Kilo-Moana. I would also like to thank A. White and M. Lomas for providing dissolved inorganic phosphate concentrations, J. Waterbury for providing cultures, P. Moisander, V. Michelou, A. Hynes, L. Wurch and S. Haley for help sampling and for useful discussions of the data. This work was funded by the National Science Foundation Biological Oceanography Program through awards OCE0451419 (S.T.D.) and the Center for Microbial Oceanography: Research and Education. 


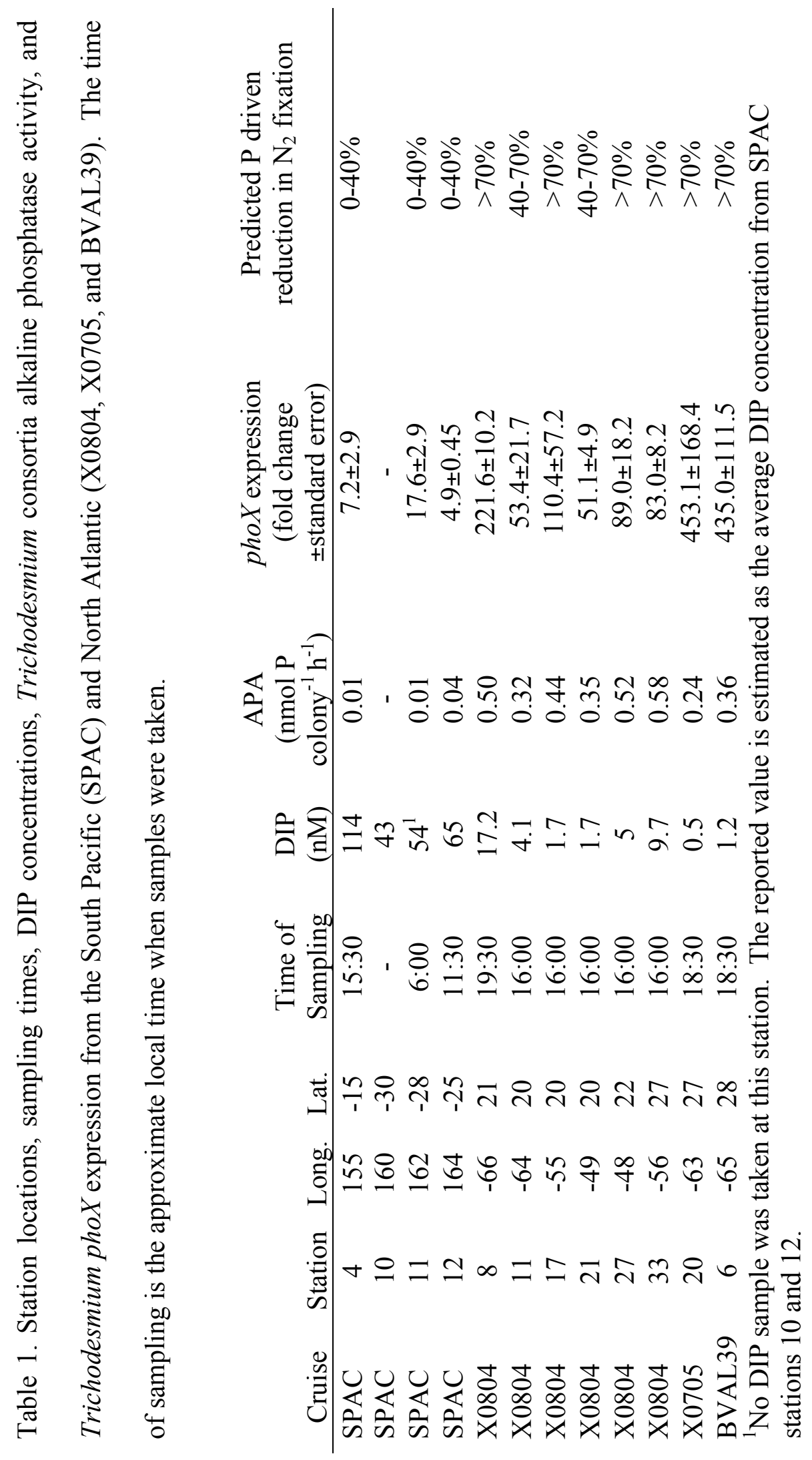



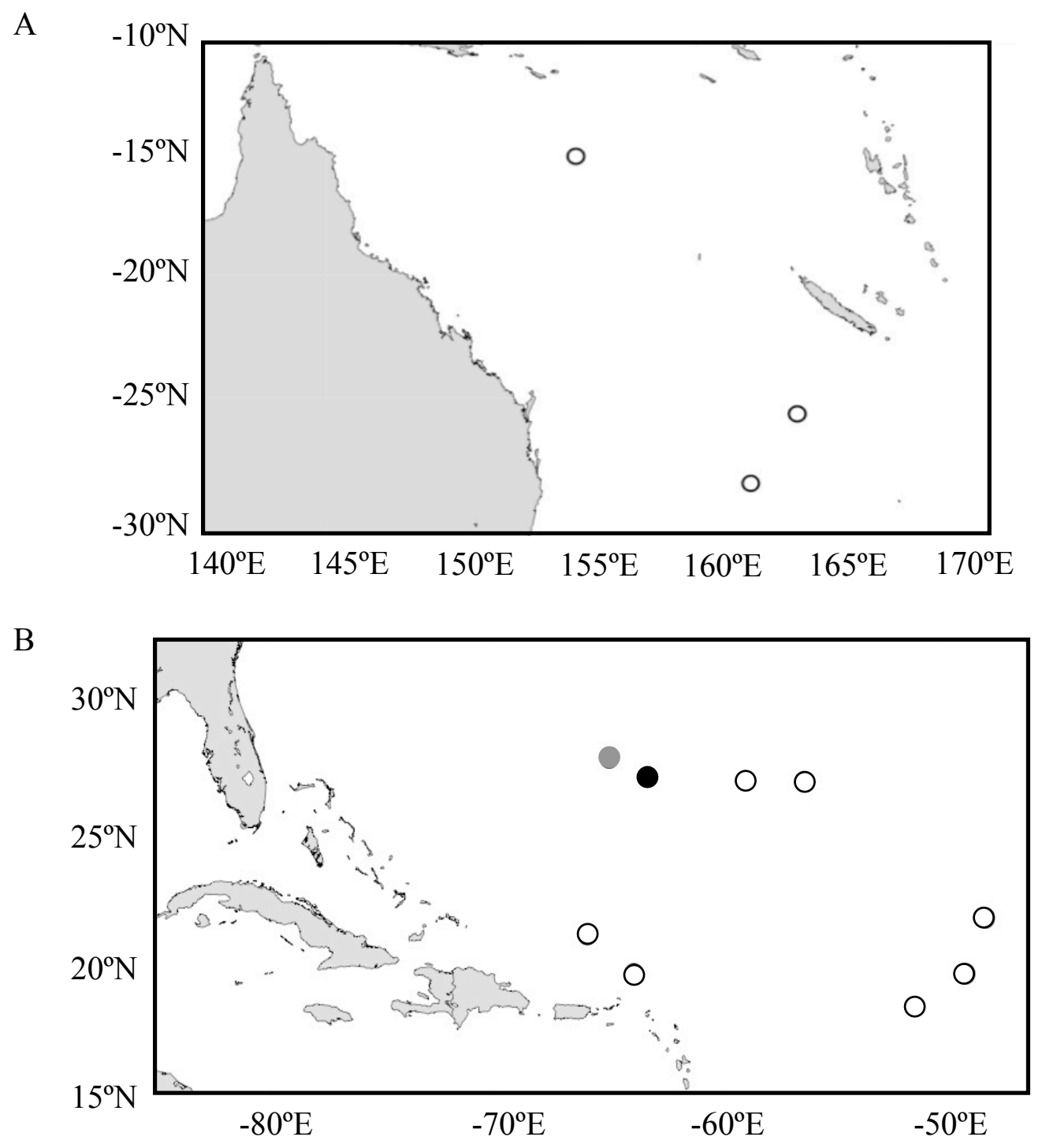

Figure 1. Station locations from (A) the South Pacific and (B) the North Atlantic. In (B) open circles indicate stations from May 2008 (X0804), the black circle indicates a station from June 2007 (X0705) and the grey circle indicates a station from October 2007 (BVAL39). 
A

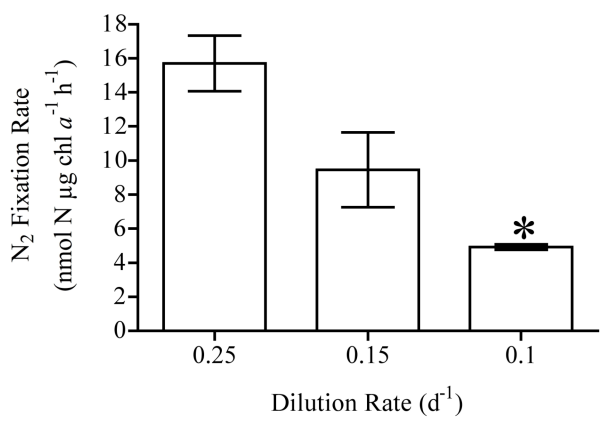

$\mathrm{C}$

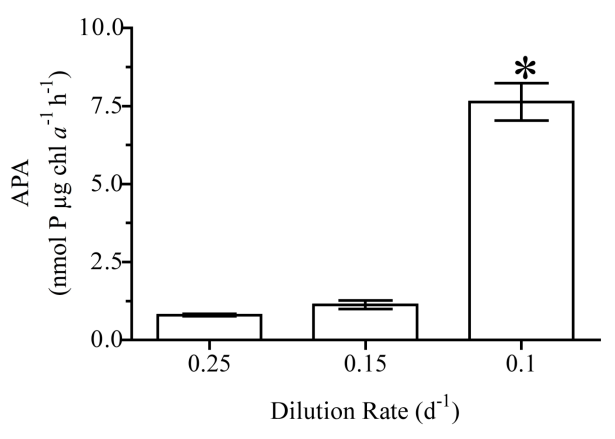

$\mathrm{E}$

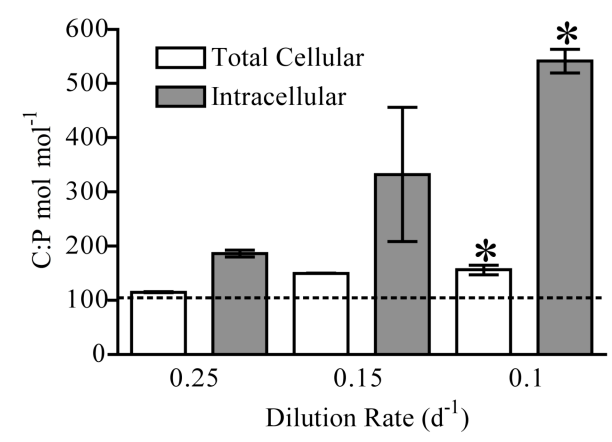

$\mathrm{B}$

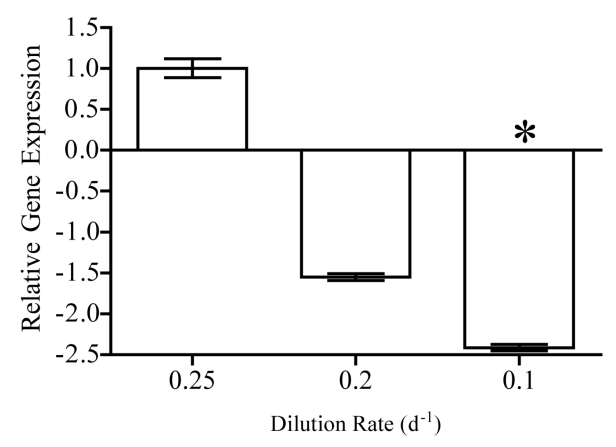

$\mathrm{D}$

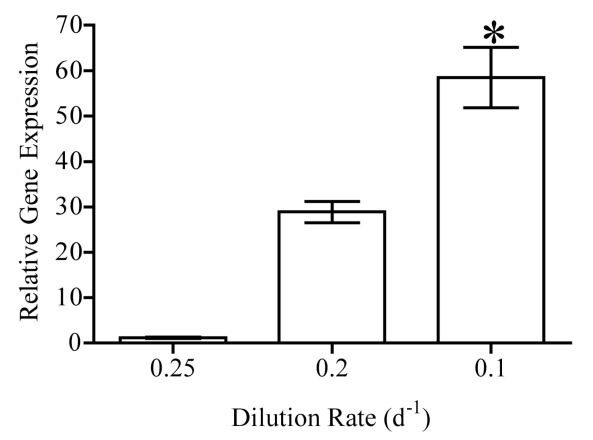

$\mathrm{F}$

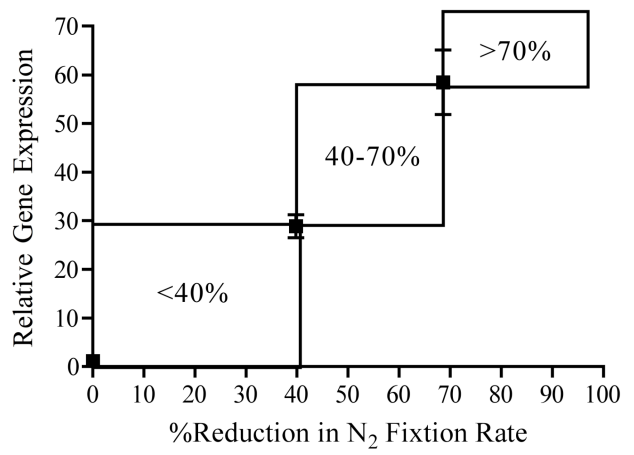

Figure 2. Trichodesmium $\mathrm{N}_{2}$ fixation rate (A), nifH expression (B), alkaline phosphatase activity (APA) (C), phoX expression (D), C:P ratio (E) and the relationship of phoX expression and \% reduction in $\mathrm{N}_{2}$ fixation relative to maximal measured rates (F) from semi-continuous culture experiments. In plot $\mathrm{F}$ data is binned to show the predicted reduction in $\mathrm{N}_{2}$ fixation rate at different levels of phoX expression. Plots $\mathrm{A}, \mathrm{C}$ and $\mathrm{E}$ represent the average value of duplicate bottles, and error bars indicate standard deviations. For plots B, D and F error bars indicate the standard error of the fold change of triplicate measurements on a single biological replicate between the sample expression and the calibrator expression (a replicate of the $0.25 \mathrm{~d}^{-1}$ diluted culture). The $(*)$ indicates a $p$-value of less than 0.05 for the sample relative to the $0.25 \mathrm{~d}^{-1}$ diluted culture using a $t$-test (A, C and $\mathrm{E}$ ), or a pair-wise fixed reallocation randomization analysis (B and D). In plot E, molar C:P ratios from cultures are shown for both total cellular 

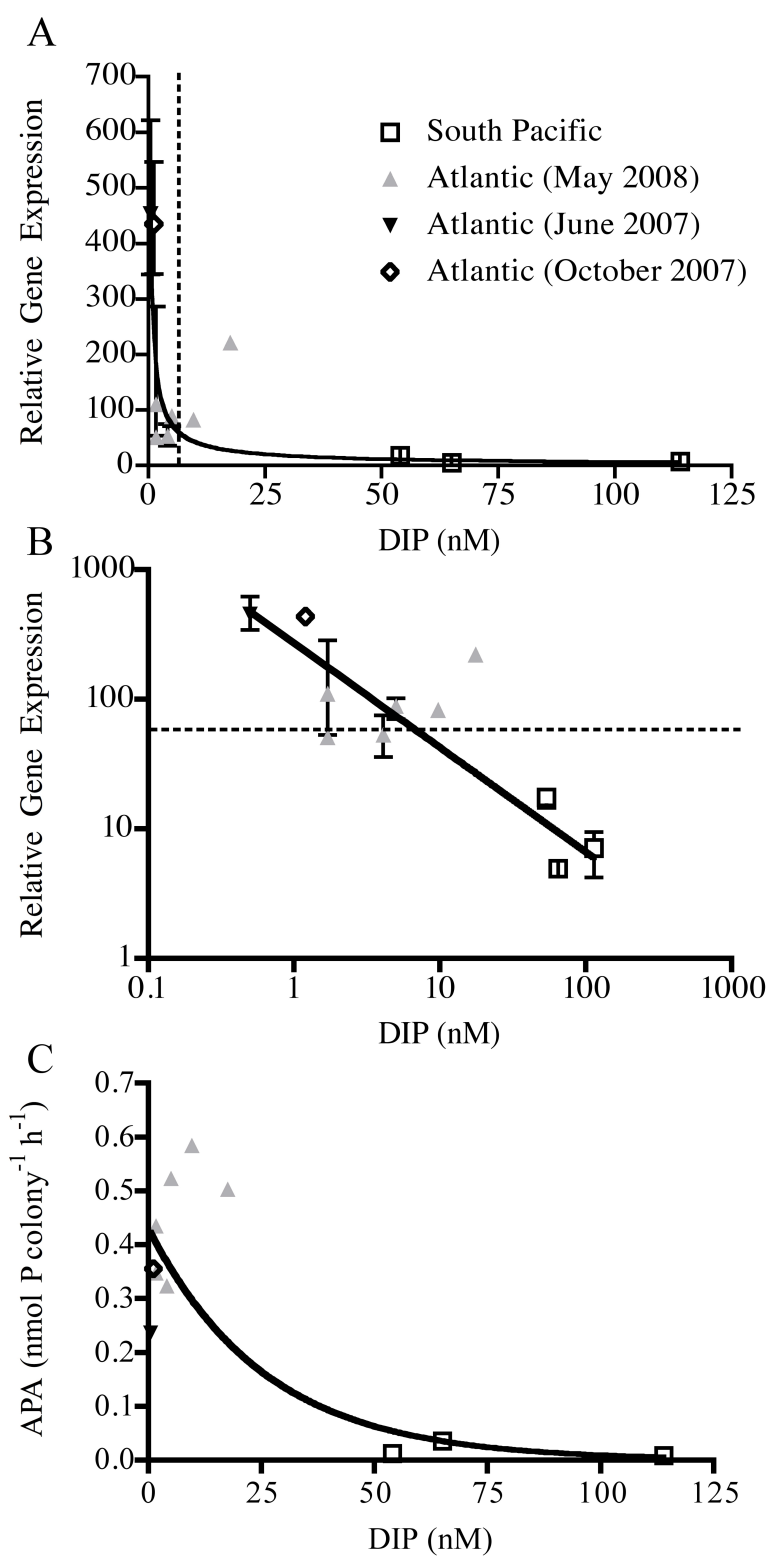

Figure 3. Plots of phoX expression versus DIP concentration on a linear (A) and log-log scale (B), alkaline phosphatase activity (APA) versus DIP concentration (C). The dashed line in $\mathrm{A}$ indicates the $7 \mathrm{nM}$ DIP threshold line. The dashed line in $\mathrm{B}$ indicates the fold change for phoX in the semi-continuous experiment where $\mathrm{N}_{2}$ fixation was reduced by $70 \%$ relative to the maximum for the semi-continuous cultures. Error bars in plots A and $\mathrm{B}$ represent the standard error of the fold change. The solid lines indicate the regression lines. A power regression for plots $\mathrm{A}$ and $\mathrm{B}\left(\mathrm{r}^{2}=0.75\right)$ and an exponential regression was used to fit plot $\mathrm{C}\left(\mathrm{r}^{2}=0.83\right)$. 


\section{References}

Adams, M.M., Gomez-Garcia, M.R., Grossman, A.R., and Bhaya, D. (2008) Phosphorus deprivation responses and phosphonate utilization in a thermophilic Synechococcus sp. from microbial mats. J. Bacteriol 190: 8171-8184.

Arar, E., and Collins, G. (1997) In vitro determination of chlorophyll $a$ and pheophytin $a$ in marine and freshwater algae by fluorescence. USEPA Method 44.5.

Berman-Frank, I., Cullen, J., Shaked, Y., Sherrell, R.M., and Falkowski, P. (2001) Iron availability, cellular iron quotas, and nitrogen fixation in Trichodesmium. Limnol. Oceanogr. 46: 1249-1260.

Bernhardt, H., and Wilhelms, A. (1967) The continuous determination of low level iron, soluble phosphorus and total phosphate with the AutoAnalyzer. Technicon Symposium 1: 385-389.

Bertilsson, S., Berglund, O., Karl, D., and Chisholm, S.W. (2003) Elemental composition of marine Prochlorococcus and Synechococcus: Implications for the ecological stoichiometry of the sea. Limnol. Oceanogr. 48: 1721-1731.

Bjorkman, K.M., Thomson-Bulldis, A.L., and Karl, D.M. (2000) Phosphorus dynamics in the North Pacific subtropical gyre. Aquatic Microbial Ecology 22: 185-198.

Capone, D.G. (2001) Marine nitrogen fixation: what's the fuss. Current Opinion in Microbiology 4: 341-348.

Capone, D.G., Zehr, J.P., Paerl, H.W., Bergman, B., and Carpenter, E. (1997) Trichodesmium, a globally significant marine cyanobacterium. Science 276: 1221-1229.

Chappell, P.D., and Webb, E.A. (2009) A molecular assessment of the iron stress response in the two phylogenetic clades of Trichodesmium. Environ. Microbiol:: doi:10.1111/j.1462-2920.2009.02026.x.

Church, M., Short, C., Jenkins, B.D., Karl, D.M., and Zehr, J.P. (2005) Temporal Patterns of Nitrogenase Gene (nifH) Expression in the Oligotrophic North Pacific Ocean. Appl Environ Microbiol 71: 5362-5370.

Dyhrman, S.T., and Ruttenberg, K.C. (2006) Presence and regulation of alkaline phosphatase activity in eukaryotic phytoplankton from the coastal ocean: Implications for dissolved organic phosphorus remineralization. Limnol. Oceanogr. 51: 1381-1390.

Dyhrman, S.T., Webb, E.A., Moffett, J.W., and Waterbury, J.B. (2002) Cell-specific detection of phosphorus stress in Trichodesmium from the western North Atlantic. Limnol. Oceanogr. 47: 1832-1836. 
Falkowski, P.G. (1997) Evolution of the nitrogen cycle and its influence on the biological sequestration of $\mathrm{CO}_{2}$ in the ocean. Nature 387: 272-275.

Foster, R.A., Paytan, A., and Zehr, J.P. (2009) Seasonality of N2 fixation and nifH gene diversity in the Gulf of Aqaba (Red Sea). Limnol. Oceanogr. 54: 219-233.

Grabowski, M.N.W., Church, G.M., and Karl, D.M. (2008) Nitrogen fixation rates and controls at Stn ALOHA. Aquatic Microb Ecol 52: 175-183.

Hutchins, D.A., Fu, F.-X., Zhang, Y., Warner, M.E., Feng, Y., Portune, K. et al. (2007) $\mathrm{CO}_{2}$ controls of Trichodesmium $\mathrm{N}_{2}$ fixation, photosynethesis, growth rates, and elemental ratios: implications for past, present, and future ocean biogeochemistry. Limnol. Oceanogr. 52: 1293-1304.

Hynes, A.M., Chappell, P.D., Dyhrman, S.T., Doney, S.C., and Webb, E.A. (2009) Cross-basin comparisons of phosphorus stress and nitrogen fixation in Trichodesmium. Limnol. Oceanogr. 54: 1438-1448.

Karl, D. (1999) A sea of change: biogeochemical variability in the North Pacific subtropical gyre. Ecosystems 2.

Karl, D.M. (2002) Nutrient dynamics in the deep blue sea. Trends Microbiol. 10: 410418.

Karl, D.M., and Tien, G. (1992) MAGIC: A sensitive and precise method for measuring dissolved phosphorus in aquatic environments. Limnol. Oceanogr. 37: 105-116.

Krauk, J., Villareal, T.A., Sohm, J.A., Montoya, J.P., and Capone, D.G. (2006) Plasticity of N:P ratios in laboratory and field populations of Trichodesmium spp. Aquat. Microb. Ecol. 42: 243-253.

Kustka, A., Sanudo-Wilhelmy, S.A., Carpenter, E.J., Capone, D.G., Burns, J., and Sunda, W. (2003) Iron requirements for dinitrogen- and ammonium-supported growth in cultures of Trichodesmium (IMS101): Comparison with nitrogen fixation rates and iron: carbon ratios of field populations. Limnol. Oceanogr. 48: 1869-1884.

Lomas, M.W., Burke, A.L., Lomas, D.A., Bell, D.W., Shen, C., Dyhrman, S.T., and Ammerman, J.W. (2009) Sargasso Sea phosphorus biogeochemistry: an important role for dissolved organic phosphorus (DOP). Biogeosciences Discussions 6: 10137-10175.

Mills, M., Ridame, C., Davey, M., La Roche, J., and Geider, R.J. (2004) Iron and phosphorus co-limit nitrogen fixation in the eastern tropical North Atlantic. Nature 429: 292-294. 
Moore, C.M., Mills, M.M., Achterberg, E.P., Geiber, R.J., LaRoche, J., Lucas, M.I. et al. (2009) Large-scale distribution of Atlantic nitrogen fixation controlled by iron availability. Nature Geosciences 2: 867-871.

Moore, J.K., Doney, S.C., and Lindsay, K. (2004) Upper ocean ecosystem dynamics and iron cycling in a global three dimensional model. Global Biogeochem Cy 18: GB4028.

Moutin, T., Van Den Broeck, N., Beker, B., Dupouy, C., Rimmelin, P., and Bouteiller, A. (2005) Phosphate availability controls Trichodesmium spp. biomass in the SW Pacific Ocean. Mar. Ecol. Prog. Ser. 297: 15-21.

Mulholland, M.R., Floge, S., Carpenter, E., and Capone, D. (2002) Phosphorus dynamics in cultures and natural populations of Trichodesmium spp. Mar. Ecol. Prog. Ser. 239: 4555.

Murphy, J., and Riley, J.P. (1962) A modified single solution method for the determination of phosphate in natural waters. Anal Chim 45: 207-216.

Orchard, E.D., Webb, E.A., and Dyhrman, S.T. (2009) Molecular analysis of the phosphorus starvation response in Trichodesmium spp. Environ. Microbiol. 11: 24002411.

Pfaffl, M.W., Horgan, G., and Leo, D. (2002) Relative Expression Software Tool (REST) for group wise comparison and statistical analysis of relative epxpression results in realtime PCR. Nucleic Acids Res. 30: E36.

Rees, A.P., Law, C.S., and Woodward, E.M.S. (2006) High rates of nitrogen fixation during an in-situ phosphate release experiment in the Eastern Mediterranean Sea. Geophysical Research Letters 33: L10607.

Sañudo-Wilhelmy, S.A., Tovar-Sanchez, A., Fu, F.X., Capone, D.G., Carpenter, E.J., and Hutchins, D.A. (2004) The impact of surface-adsorbed phosphorus on phytoplankton Redfield stoichiometry. Nature 432: 897-901.

Sañudo-Wilhelmy, S.A., Kustka, A.B., Gobler, C.J., Hutchins, D.A., Yang, M., Lwiza, K. et al. (2001) Phosphorus limitation of nitrogen fixation by Trichodesmium in the Central Atlantic Ocean. Nature 411: 66-69.

Sohm, J.A., Mahaffey, C., and Capone, D.G. (2008) Assessment of relative phosphorus limitation of Trichodesmium spp. in the North Pacific, North Atlantic, and the north coast of Australia. Limnol. Oceanogr. 53: 2495-2502.

Thingstad, T.F., Krom, M.D., Mantoura, R.F.C., Flaten, G.A.F., Groom, S., Herut, B. et al. (2005) Nature of phosphorus limitation in the ultraoligotrophic Eastern Mediterranean. Science 309: 1068-1071. 
Tyrrell, T. (1999) The relative influences of nitrogen and phosphorus on oceanic primary production. Nature 400: 525-531.

Webb, E., Jakuba, R.W., Moffett, J.W., and Dyhrman, S. (2007) Molecular assessment of phosphorus and iron physiology in Trichodesmium populations from the Western Central and Wesern South Atlantic. Limnol. Oceanogr. 52: 2221-2232.

Webb, E.A., Moffett, J.W., and Waterbury, J.B. (2001) Iron stress in open-ocean cyanobacteria (Synechococcus, Trichodesmium, and Crocosphaera spp.): identification of the IdiA protein. Appl. Environ. Microbiol. 67: 5444-5452.

White, A.E., Spitz, Y., Karl, D.M., and Letelier, R. (2006) Flexible elemental stoichiometry in Trichodesmium spp. and its ecological implications. Limnol Oceanogr 51: $1777-1790$.

Wu, J., Sunda, W., Boyle, E.A., and Karl, D.M. (2000) Phosphate depletion in the western North Atlantic Ocean. Science 289: 759-762. 


\section{CHAPTER SIX}

\section{Summary and Future Directions}

\section{Summary}

The marine cyanobacterium Trichodesmium is a major contributor to dinitrogen $\left(\mathrm{N}_{2}\right)$ fixation and primary production in tropical and subtropical oceans. These regions are often characterized by low phosphorus $(\mathrm{P})$ concentrations, and $\mathrm{P}$ starvation may limit growth and $\mathrm{N}_{2}$ fixation in Trichdoesmium. This thesis focused on examining three major components of $\mathrm{P}$ metabolism: dissolved inorganic $\mathrm{P}\left(\mathrm{P}_{i}\right)$ uptake (chapter two and four), dissolved organic P (DOP) hydrolysis (chapter two and four) and polyphosphate (polyP) formation and degradation (chapter three). Additionally, this thesis examines the extent of $\mathrm{P}$ limitation and its possible affect on $\mathrm{N}_{2}$ fixation in Trichodesmium from the North Atlantic and South Pacific (chapter five).

Recent studies have hypothesized that between $12-60 \%$ of the primary productivity in the Sargasso Sea is supported by $\mathrm{P}$ ester not $\mathrm{P} i$ (Mather et al., 2008; Lomas et al., 2009). Chapter two addresses the relative importance of $\mathrm{P}_{i}$ and $\mathrm{P}$ ester in supporting the growth of Trichodesmium, the microbial community, and other taxonomically significant groups from the literature (Casey et al., 2009). The in situ uptake rates suggest that the contribution of $\mathrm{P}$ ester to total $\mathrm{P}$ uptake can be greater than $25 \%$ for Trichodesmium, the microbial community, and key phytoplankton groups, depending on the station. The $\mathrm{P}$ ester contribution to Trichodesmium is over $25 \%$ at half 
of the stations examined. Further work in other systems with variable P chemistry will indicate whether this frequency is similar in higher $\mathrm{P}$ systems, or to what extent the $\mathrm{P}$ ester uptake rate changes with ambient DOP over a larger dataset. A comparison of the $\mathrm{K}_{\mathrm{m}}$ values for both ${ }^{33} \mathrm{P}_{i}$ and ${ }^{33} \mathrm{P}$ ester uptake suggests that Trichodesmium is a better competitor for $\mathrm{P}$ ester than for $\mathrm{P}_{i}$ relative to the microbial community. This is consistent with previous work (Sohm and Capone, 2006), which focused solely on $\mathrm{P}_{i}$ uptake kinetics. Additionally, this chapter focused on enzyme activity and uptake assays, and it highlights the importance of pairing tracer level experiments (which measure in situ uptake rates) to experiments where saturating concentrations of substrate are added (which measure the $\mathrm{V}_{\max }$ of enzyme hydrolysis). Trichodesmium growth rates calculated from the ${ }^{33} \mathrm{P}_{i}$ and ${ }^{33} \mathrm{P}$ ester uptake parameters indicate that only a small fraction of the $\mathrm{P}$ ester pool needs to be bio-available to meet $\mathrm{P}$ demand, which further supports the importance of $\mathrm{P}$ ester to this group in the Sargasso Sea. Taken together, these data underscore the importance of $\mathrm{P}$ esters to supporting production by Trichodesmium, picocyanobacteria, and small eukaryotes in the Sargasso Sea.

$\mathrm{P}$ in the form of polyP has recently been detected in coastal systems (Diaz et al., 2008) and has previously been observed in Trichodesmium (Romans et al., 1994), but polyP has never been examined in a very low $\mathrm{P}$ environment such as the Sargasso Sea. Chapter three shows that polyP can be a major component of Trichodesmium cellular P in the Sargasso Sea, despite other metrics of $\mathrm{P}$ physiology indicating that these populations were P-limited. While it is unclear what exact factors induce the formation of polyP in this system, the data are consistent with a possible overplus-type response. The over-plus 
response occurs when P-limited cells accumulate polyP after being refed $\mathrm{P}$ as opposed to luxury uptake where P replete cells take up P above their nutritional demand for P and accumulate that $\mathrm{P}$ as polyP. It may be that Trichodesmium is taking advantage of fluxes in P supply, and that polyP is a physiological fingerprint of this variability in the Sargasso Sea. Additionally, if polyP formation is a common trait in phytoplankton, these data suggest that polyP might be an important additional bio-available component of DOP. This study highlights the potential importance of polyP, and suggests the further studies into the dynamics of polyP formation in oligotrophic systems are a critical area of future research.

Chapter four studies the affect of P physiology on alkaline phosphatase activity (APA) and gene expression patterns in Trichodesmium. Two copies of the high affinity phosphate binding protein (pstS and $s p h X)$ and two putative alkaline phosphatase (phoA, and $p h o X)$ genes are present in all examined species of Trichodesmium. Additionally, the expression of $p h o A, p h o X$, and $\operatorname{sph} X$ are all responsive to variations in $\mathrm{P}$ supply, while $p s t S$ is not. These data suggest that the expression of $\operatorname{sph} X, p h o A$ and $p h o X$ could provide a useful marker for P limitation in natural populations. Combining these measurements with APA would also provide insights into the nutritional history of this organism. This is the first demonstration of phoX P-regulation in a marine cyanobacterium. The presence of a P-regulated phoX in Trichodesmium could provide a means to access the $\mathrm{P}$ ester pool without an increased zinc ( $\mathrm{Zn})$ requirement (Wu et al., 2007). In oligotrophic regimes, where $\mathrm{P}$ esters are the dominant $\mathrm{P}$ pool and $\mathrm{Zn}$ concentrations are low (Jakuba et al., 2008), having a PhoX type alkaline phosphatase could allow Trichodesmium to 
occupy a unique niche relative to cyanobacteria solely using a PhoA type alkaline phosphatase, which typically requires $\mathrm{Zn}$ (Shaked et al., 2006). Molecular characterization of responses to $\mathrm{P}$ limitation lay a foundation for better understanding the dynamics of Trichodesmium P limitation in the sea.

Chapter five calibrates the expression of phoX to decreases in growth and $\mathrm{N}_{2}$ fixation due to $\mathrm{P}$ limitation in Trichodesmium. The expression of $p h o X$ is then used to examine the extent of P limitation in situ. Trichodesmium was P-limited in the North Atlantic, and the expression of $p h o X$ is indicative of as much as a $70 \%$ reduction in $\mathrm{N}_{2}$ fixation by this genus, but $\mathrm{P}$ was no limiting Trichodesmium in the South Pacific from the transect examined here. These data also suggest that $\mathrm{P}$ becomes limiting to Trichodesmium at approximately $7 \mathrm{nM} \mathrm{Pi}$, which agrees with previous estimates of a threshold concentration for Trichodesmium of $9 \mathrm{nM}$ (Moutin et al., 2005). At this concentration P would not be limiting to Trichodesmium in the South Atlantic, but could be limiting, at times, in the North Pacific. These results support models predicting $\mathrm{P}$ limitation of $\mathrm{N}_{2}$ fixation the North Atlantic but not South Pacific or South Atlantic (Moore et al., 2004). While $\mathrm{N}_{2}$ fixation by Trichodesmium is higher in the North Atlantic than many other oligotrophic gyres, probably due to iron (Fe) stress (Kustka et al., 2002; Moore et al., 2004) in other regions, our results suggest that $\mathrm{N}_{2}$ fixation by this genus could be significantly higher with an increased P supply to the North Atlantic.

\section{Future directions}


As is typical, this thesis introduces just as many questions and future avenues of research as it addresses. For example, chapter two highlights the importance of $\mathrm{P}$ ester to support primary production in Trichodesmium, the microbial community, and a few other taxonomically important genera. Future work examining the importance of phosphonate will allow us to understand the relative importance of different DOP bond classes. Extending this work to include more taxonomic groups and more ocean gyres with differing P chemistry will help to determine the global significance of DOP as a P source.

The dynamics of polyP formation and degradation remains somewhat enigmatic. While polyP is clearly important to Trichodesmium its prevalence in other oligotrophic microbes is unknown. This compound has the potential to be very important to the $\mathrm{P}$ cycle in the ocean gyres, and its synthesis and degradation rates should be assayed and compared to standing stock concentrations to better constrain the flux of polyP. Future culture work studying the conditions that promote polyP formation are also needed to determine the role this compound plays in cells.

Chapter four examines key components of the Pho regulon in Trichodesmium, but there are many more genes to examine. For example, Trichodesmium has genes encoding enzymes involved in phosphonate scavenging whose regulation have only been examined qualitatively (Dyhrman et al., 2006). Future work characterizing the regulation phosphonate scavenging genes will broaden our understanding of DOP hydrolysis in Trichodesmium. Furthermore, the regulation of the genes examined in this study suggest that they are correctly annotated, but to confirm these annotations the proteins need to be characterized. This is particularly important for the two alkaline phosphatases: PhoA and 
PhoX. Determining the substrate specificity, cellular localization and metal requirements of PhoX and PhoA, will allow for us to understand which P esters are bio-available, and constrain trace metal requirements. Considering that $\mathrm{Zn}$ may also often be limiting to growth (Shaked et al., 2006; Jakuba et al., 2008), the presence of the PhoX enzyme suggests an interesting adaptation to avoid Zn-P co-limitation. Therefore, additional studies to determine growth rates and gene expression patterns over ranges in $\mathrm{Zn}$ and $\mathrm{P}$ concentrations are warranted.

Utilizing gene expression as a marker of P limitation in Trichodesmium allowed for a unique and powerful view into the physiological ecology of this biogeochemically significant organism in the North Atlantic and South Pacific. The screening for more Trichodesmium populations across a broader range of $\mathrm{P} i$ concentrations and oligotrophic systems will further elucidate the relationship between $\mathrm{P} i$ concentration and Trichodesmium physiology. For example, will the $7 \mathrm{nM}$ threshold for $\mathrm{P}$ limitation be the same for Trichodesmium from the South Atlantic, or will these populations have a higher P $i$ threshold? Also, future studies can utilize additional genes to examine the importance of multiple stressor simultaneously. Utilizing the expression of genes that are diagnostic of cellular physiology allows for the simultaneous analysis of multiple metabolism pathways. For example, idiA, is regulated by Fe availability (Chappell and Webb, 2009). Examining the regulation of both $p h o X$ and $i d i A$ from the same population would allow a clearer understanding of the relationship between $\mathrm{P}$ and $\mathrm{Fe}$, and to explore the possibility of co-limitation. Furthermore, developing this type of assay for other taxa will provide new insights into what limits primary production in the ocean. 
These areas of research will expand our knowledge of Trichodesmium $\mathrm{P}$ physiology, the importance of DOP in driving primary production, and the role nutrients play in controlling $\mathrm{N}_{2}$ fixation.

\section{References}

Casey, J.R., Lomas, M.W., Michelou, V.K., Dyhrman, S.T., Orchard, E.D., Ammerman, J.W., and Sylvan, J.B. (2009) Phytoplankton taxon-specific orthophosphate (Pi) and ATP uptilization in the western subtropical North Atlantic. Aquat. Micro. Ecol. 58: 31-44.

Chappell, P.D., and Webb, E.A. (2009) A molecular assessment of the iron stress response in the two phylogenetic clades of Trichodesmium. Environ. Microbiol.: doi:10.1111/j.1462-2920.2009.02026.x.

Diaz, J., Ingall, E.D., Benitez-Nelson, C.R., Paterson, D., de Jonge, M.D., McNulty, I., and Brandes, J.A. (2008) Marine Polyphosphate: A key player in geologic phosphorus sequestration. Science 320: 652-655.

Dyhrman, S.T., Chappell, P.D., Haley, S.T., Moffett, J.W., Orchard, E.D., Waterbury, J.B., and Webb, E.A. (2006) Phosphonate utilization by the globally important marine diazotroph Trichodesmium. Nature 439: 68-71.

Jakuba, R.W., Moffett, J.W., and Dyhrman, S. (2008) Evidence for the linked biogeochemical cycling of zinc, cobalt, and phosphorus in the western North Atlantic Ocean. Global. Biogeochem. Cy. 22: doi:10.1029/2007GB003119.

Kustka, A., Carpenter, E.J., and Sañudo-Wilhelmy, S.A. (2002) Iron and marine nitrogen fixation: progress and future directions. Res. Microbiol. 153: 255-262.

Lomas, M.W., Burke, A.L., Lomas, D.A., Bell, D.W., Shen, C., Dyhrman, S.T., and Ammerman, J.W. (2009) Sargasso Sea phosphorus biogeochemistry: an important role for dissolved organic phosphorus (DOP). Biogeosciences Discussions 6: 10137-10175.

Mather, R.L., Reynolds, S.E., Wolff, G.A., Williams, R.G., Torres-Valdes, S., Woodward, E.M.S. et al. (2008) Phosphorus cycling in the North and South Atlantic Ocean subtropical gyres. Nature Geosci. 1: 439-443.

Moore, J.K., Doney, S.C., and Lindsay, K. (2004) Upper ocean ecosystem dynamics and iron cycling in a global three dimensional model. Global Biogeochem Cy 18: GB4028. 
Moutin, T., Van Den Broeck, N., Beker, B., Dupouy, C., Rimmelin, P., and Bouteiller, A. (2005) Phosphate availability controls Trichodesmium spp. biomass in the SW Pacific Ocean. Mar. Ecol. Prog. Ser. 297: 15-21.

Romans, K.M., Carpenter, E.J., and Bergman, B. (1994) Buoyancy Regulation in the Colonial Diazotrophic Cyanobacterium Trichodesmium tenue: Ultrastructure and storage of carbohydrate, polyphosphate, and nitrogen. J Phyc 30: 935-942.

Shaked, Y., Xu, Y., Leblanc, K., and Morel, F.M.M. (2006) Zinc availability and alkaline phosphatase activity in Emiliania huxleyi: Implications for $\mathrm{Zn}-\mathrm{P}$ co-limitation in the ocean. Limnol. Oceanogr. 51: 299-309.

Sohm, J.A., and Capone, D.G. (2006) Phosphorus dynamics of the tropical and subtropical north Atlantic: Trichodesmium spp. versus bulk plankton. Mar. Ecol. Prog. Ser. 317: 21-28.

Wu, J.-R., Shien, J.-H., Shieh, H.K., Hu, C.-C., Gong, S.-R., Chen, L.-Y., and Chang, P.C. (2007) Cloning of the gene and characterization fo the enzymatic properties of the monomeric alkaline phosphatase (PhoX) from Pasteurella multocida strain X-73. FEMS Microbiol. Lett. 267: 113-120. 